NBER WORKING PAPER SERIES

\title{
THE ECONOMIC EFFECT OF IMMIGRATION POLICIES: ANALYZING AND SIMULATING THE U.S. CASE
}

\author{
Andri Chassamboulli \\ Giovanni Peri \\ Working Paper 25074 \\ http://www.nber.org/papers/w25074 \\ NATIONAL BUREAU OF ECONOMIC RESEARCH \\ 1050 Massachusetts Avenue \\ Cambridge, MA 02138 \\ September 2018, Revised October 2019
}

We are grateful to Annie Hines and Andrew Padovani for their competent assistance with the data. We also thank participants at the Search and Matching Annual Conference, the ZEW Workshop on the Economics of Immigration, ASSET conference, the Sheffield Workshop on the Macroeconomics of Migration, the University of Glasgow Workshop on Migration and Mobility and seminar participants at the University of Cyprus for useful comments and discussion. The views expressed herein are those of the authors and do not necessarily reflect the views of the National Bureau of Economic Research.

NBER working papers are circulated for discussion and comment purposes. They have not been peer-reviewed or been subject to the review by the NBER Board of Directors that accompanies official NBER publications.

(C) 2018 by Andri Chassamboulli and Giovanni Peri. All rights reserved. Short sections of text, not to exceed two paragraphs, may be quoted without explicit permission provided that full credit, including $\odot$ notice, is given to the source. 
The Economic Effect of Immigration Policies: Analyzing and Simulating the U.S. Case Andri Chassamboulli and Giovanni Peri

NBER Working Paper No. 25074

September 2018, Revised October 2019

JEL No. E24,F22,J64

\begin{abstract}
$\underline{\text { ABSTRACT }}$
In this paper we analyze the economic effects of different immigration policies using a model that incorporates economic and policy features crucial to understanding the migrant flows into the US. We differentiate among the most relevant channels of immigration to the US: family-based, employment-based and undocumented. Moreover we explicitly account for earning incentives to migrate and for the role of immigrant networks in generating immigration opportunities. Hence, we can analyze the effect of policy changes through those channels. In our simulations highly skilled employment and unskilled immigrants generate larger surplus to US firms than natives do. Hence policies restricting their entry either directly or indirectly have a depressing effect on job creation and, in turn, on native labor markets. Our analysis gives new insights into the effect of policies as it accounts for the endogenous immigration response which is overlooked by most existing models.
\end{abstract}

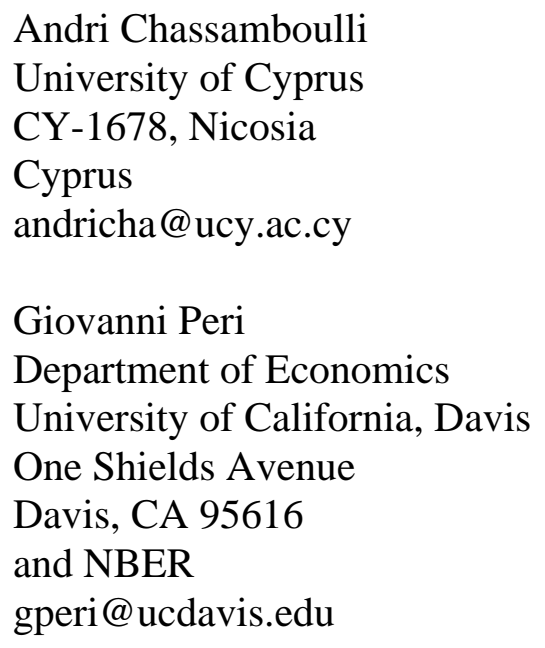




\section{Introduction}

How would different immigration policies impact the US economy? This is an important and debated question. Economists have adopted, so far, rather simplified models to evaluate the consequences of changing immigration policies on the national economy and labor markets. Usually they have analyzed the consequences of a change in the number and in the composition of foreign-born as shiftS in supply within a neoclassical model (e.g. Ottaviano and Peri 2012, or Llull 2017). Actual policies, however, are provisions changing the conditions of entry through specific immigration channels or the degree of enforcement of those conditions. The number of immigrants and their composition are themselves equilibrium outcomes of these policies. To evaluate the effect of a policy change on immigration flows, and in turn of these flows on the economy, one has to account for the impact of policies on current and future incentives for immigration. Models that produce quantitative assessments of the impact of immigration on labor markets and other economic outcomes, have usually neglected the analysis of specific policies and their general equilibrium effects accounting for networks and incentives. To do this one has to model networks of job referrals and family unification opportunities, which may create the conditions for the so called "chain migration effects". Analyzing and simulating how specific policies, affect each channel of entry in the US and, in turn, the long-run immigration flow and labor market outcomes is the goal of this paper.

Sometimes changes in immigration laws have unintended long-run equilibrium effects. Through networks and family linkage effects they may increase substantially the immigration opportunities in the future. For instance, the Immigration and Naturalization act of 1965 , supposed to be a change that could preserve immigrant composition while abolishing quotas, ushered a family-based immigration system in the US, and over time allowed the largest increase in immigrants in the US. Similarly the high tolerance for undocumented immigrants in the 1990's allowed in the US a large number of undocumented foreign workers also affecting labor markets and subsequent immigration opportunities.

The U.S. federal Government does not control directly the number of immigrants entering or staying in the country. Instead, it sets rules about their entry and their opportunities to remain and it decides the intensity of enforcement of these rules. Immigration policies are not usually quotas, but rather they specify different tracks of entry and different conditions for staying in the country. These rules, together with the incentives of immigrants and the effectiveness of their enforcement, generate the observed number of 
immigrants and shape their composition in terms of skills/productivity, bargaining power and expected duration of stay. These elements are key to our understanding of their labor market effects. While it will be impossible to mirror the complexities of the US immigration system, our model aims at capturing the main avenues of entry and stay in the US. No study, to the best of our knowledge, has so far incorporated the important interplay between immigration policies, immigrants' economic incentives and the role of immigrant networks when analyzing the inflow of immigrants and their labor market effects.

We develop a two-country economy that represents the US and the rest of the World, and we model in detail each of three main ways of entry: Family, Employment and Undocumented immigration. The opportunities for legal entry through each specific channel, are affected by policies and by the existing networks (of family or potential co-workers). Similarly illegal entry is affected by the degree of enforcement. A change in one policy will change entry through that channel but also the size of the immigrant network with consequences on the opportunities for entry through other channels. It will also affect incentives of foreigners to migrate through labor market tightness and wages. In order to capture key features of the US labor market, we separate high (college-educated) and low (non college educated) skilled immigrants and we consider their different labor markets and opportunities for entry.

To reflect the current immigration system in the US we assume that the employment route for legal entry is only available to highly skilled, the family route is available to skilled and unskilled, in proportion of the existing family ties, and the illegal route is pursued only by less skilled. We represent the labor market using a search and matching model, which implies that firms post vacancies for skilled and unskilled workers and workers search for jobs. Native and immigrants fill those vacancies and, as they have different outside options, this reflects on their bargaining power and wages. Finally, we model the incentives to migrate so that changes in the wage and unemployment conditions in the US will affect the incentives to move: higher wages and lower unemployment conditions would attract more immigrants. To mirror the US experience in 1990-2015 we choose parameters that reflect the fact that during that period Mexico was the most relevant origin of low skilled immigrants and Asia (especially China and India) was the most relevant source region for high skilled immigrants. We solve the model and then we calibrate it to match aggregate labor market- and immigration statistics for the US, for the average of 2010-2015. We use such an equilibrium as starting point to simulate alternative policy scenarios. 
By capturing these important aspects of the labor market and of immigrant entry, this model allows us three insights into the effect of different policies that would not be present in models based on the canonical labor demand and exogenous supply of immigrants. First, the job creation effects of immigrants from any entry route (family, employment and illegal) are beneficial to natives, but for different reasons. Unskilled family and undocumented immigrants produce large surplus to firms because their wages per unit of productivity are lower than those of natives due to their worse outside options. Highskilled employment immigrants, instead, are selected on ability and increase the expected firm surplus from a match due to their higher productivity. Both effects generate more job creation and tighter labor markets. These job creation channels may attenuate or reverse the prediction on native employment and wages from a pure supply/demand model.

Second, while the family route allows unskilled workers it also generates family opportunities for high-skilled immigrants who come to the US to be employed. High-skilled individuals have larger incentives to migrate and generate "network" opportunities for other high-skilled individuals through job referrals. Symmetrically, the employment route allows only highly skilled workers but it also generates family opportunities for unskilled immigrants. Hence, in the long run, family reunification policies in the US have only a marginally smaller effect in increasing the skilled/unskilled ratio vis-a-vis employmentbased policies. Restricting either of the two routes turns out to have similar negative job creation effects.

Third, given that the job creation effects of immigrants from any entry route are beneficial to natives, if the overall immigration policies are balanced between skilled and unskilled, then both groups of natives will be better off not only in terms of unemployment but also in terms of wages.

An innovation of this paper is that we can illustrate the impact on native wages and unemployment from changing one channel of entry at the time. For instance we can modify the approval rate of family admissions, so as to increase the number of family immigrants by a certain percent, leaving the other policies (relative to other channels of entry ) unchanged. We can then analyze what would happen in equilibrium to the inflow of other groups of immigrants (also indirectly affected by incentives and networks) and to wages and unemployment of natives. We will use the model to evaluate the potential labor market effects of some recent policy proposals. One is the plan to reduce by $50 \%$ the family reunification immigrants (which captures the main provision of the RAISE act 
proposed in 2017 in the U.S. Senate). Another is the substantial increase in deportation rates to reduce (by 10 or 50\%) the population of undocumented immigrants (this reflects the explicit goal of the Trump administration to increased intensity of deportations of undocumented). We can also analyze the plan to reduce the most prominent temporary visa program, the H1B, (which is under scrutiny and several bills proposed in the House in 2017, aimed at making it more restrictive). This would imply a smaller number of temporary high skilled employment immigrants. Our model will provide estimates of the potential effects of these measures on US labor markets, specifically on wage and unemployment rates of natives and immigrants. At the same time we will use the model to analyze the impact on migration flows of some important structural changes in the US, such as the increase in productivity of high skilled workers (skill biased technological change) and the increase in supply of highly educated workers.

The rest of the paper proceeds as follows. Section 2 reviews the relevant papers in the literature and the innovative content of this paper relative to those. Section 3 describes the main components of the model, its equilibrium conditions and provides an intuition of its key mechanisms, with a focus on incentive to immigration, network effects, and the working of the labor market. Section 4 describes the calibration and parameterization of the Model, targeting the US as home country and Mexico/Asia as foreign country, using as steady state the years 2010-2015. Section 5 describes the effects of immigration policies and indirect policies that change the tightness of each entry mechanisms and allow us to discuss the channels at work. It also describes the impact of some specific structural changes in the US, on migration flows, and in turn, on the labor market. Then in Section 6 we present some robustness checks to values of some crucial parameter values. Section 7 provides some concluding remarks.

\section{Literature Review}

This paper contributes to the literature that analyzes the effects of changes in immigration policies on Labor Market outcomes of natives in the US. The novelty of the paper is that we develop a labor market model that allows for the analysis of different channels of entry of immigrants and that we account for the incentive and network effects on immigrants. The basic structure of the model builds on Chassamboulli and Peri (2017), and Chassamboulli and Palivos (2015), but it enriches those models, significantly, by featuring a fully developed 2-country equilibrium model and a much richer set of channels 
of immigration. We also add jobs that can be filled directly with referrals from existing workers, on top of jobs that are filled through the usual search process after opening a vacancy.

There are several papers analyzing the economic effect of immigrants in the US (see Lewis and Peri 2015 and Peri 2016 for overview of the literature). These papers are, however, mostly empirically focused and they identify a portion of the total inflow of immigrants to the US as exogenous and track its effects on the US labor markets. Recently, some papers have analyzed in a general equilibrium framework the impact of high skilled immigrants, admitted through the H1B program, on growth and labor markets in the US. Notably Bound et al. 2017 and Jaimovich and Siu 2017 focus on the fact that highly skilled immigrants have a high propensity to specialize in science and technology and this has a strong impact on innovation and economic growth in the long run. Basso et al. (2017) develop an equilibrium model that analyzes the interaction of technological change and immigration, incorporating the endogeneity of immigrants inflows to technological growth. Battisti et al. (2017) use a search model to examine the effect of changes in high skilled and low skilled immigrants on labor market and fiscal transfers in European countries.

Relative to those papers this study is the first to account for several important aspects of the immigration process. First we consider the response of immigrants to earning incentives. Second we account for the role of networks in facilitating future immigration. Third we allow for the existence of several types of entry avenues. Empirical papers on the determinants of international migrations have studied the impact of wage and unemployment differentials on migration flows across countries (e.g. Grogger and Hanson 2011). However, papers focusing on the impact of immigration on the receiving country economy have usually neglected this "feedback channel" as less relevant. In our analysis we account for the indirect effect of migration policies on immigration incentives, through labor market variables. Similarly, several studies have emphasized the importance of networks in producing persistence in immigration flows (e.g. Munshi 2003; Hanson et al. 2017). None of them, however, has separately analyzed the role of family reunification and jobs referrals as channels contributing to such persistence. Recently, the labor literature has recognized the role of referrals in hiring and its implication for labor markets (e.g. Calvo-Armengol and Zenou, 2005, Fontaine, 2008, Galenianos, 2013, 2014, Horvath, 2014). We are the first to explicitly incorporate the "referral" channel of hiring in the immigration literature. 
One of the contributions of this paper is to explicitly consider the differences in immigrant skills, associated to each channel of entry. Due to legal restrictions immigrants entering through different channels are quite different in skills. This affects their impact on labor markets. We are only aware of few studies (e.g. Hunt 2011) relating the economic performance of immigrants to their channel of entry. However, from a policy perspective this is a very relevant question: changing the costs and opportunities of entry for each channel affects immigrants' composition and hence their labor markets effects. While there is an extensive literature on selection and sorting of migrants across skills (e.g. Grogger and Hanson 2013; Ortega and Peri 2012) and some papers specifically analyze the sorting of immigrants to the US (e.g., Huertas-Moraga 2011; Kastner and Malamoud 2017) those studies do not relate selection to the type of entry channels and hence they do not relate sorting directly to policy.

Finally, recently there have been empirical studies looking at the effect of specific immigration policies on US economic outcomes. Examples are Kerr and Lincoln (2010) and Mayda et al (2018) who look at the change in quota for the H1B visa policy, Pope (2017) who analyzes the effect of DACA (Deferred Action for Childhood Arrival) and Clemens et al (2018) analyzing the effects of the end of a temporary visa program (the Bracero program). Those papers, while careful on identification, have a very specific goal of evaluating the immediate effect of one policy and their results are therefore hard to generalize. Our contribution is to provide a flexible model that can be used to gain insight and simulate a relatively large set of immigration policies.

\section{Model}

We describe here the main features of the model. We consider two countries: country 1 (the US) and country 2 (the rest of the world). Country 1 has higher wages and better employment opportunities relative to country 2. Hence, some workers have incentives to migrate from country 2 to country 1 to increase their income. No worker has incentives to migrate from country 1 to country 2 . The size of the native labor force of country 1 (indicated as $N$ ) is normalized to 1 and it is divided into two types of workers: skilled in measure of $S$ and unskilled in measure of $1-S$. Individuals born in country 2 are, instead, of measure $X$ and are also divided into skilled and unskilled workers in measure of $X_{s}$ and $X_{u}$, respectively. Individuals from either country enter and exit the labor force at rate $\tau$, so that the overall size of the labor force (native of country 1 and 2) 
remains constant. New individuals enter the labor force as unemployed. All agents are risk neutral and discount the future at a common rate $r>0$, equal to the interest rate. Time is continuous.

The natives of country 2 can find opportunities to enter, reside and work legally in country 1 through two channels. First, through family reunification laws that allow lawful permanent residents of country 1 to sponsor their immediate relatives for immigration. In particular, a native of country 2 can enter into country 1 on a family visa, if one of his/her immediate family members is a legal immigrant of country 1 . Second, it is possible to enter on an employment visa. To be qualified for an employment visa an individual must have a job offer in country 1 . Such job offers are made available to the natives of country 2 through referrals from their network of contacts who are lawful permanent residents of country 1. Employment visas, as opposed to family visas, are targeted towards aliens with certain skills, because they are meant to fill specific skill gaps. We account for the fact that in country 1 , which we take to be the US, employment visas are mainly targeted towards foreigners with high abilities and professional skills. We therefore assume that entry through employment is only available to the skilled natives of country 2, whereas, entry through family ties is available to both skilled and unskilled.

Migration to country 1 can also be illegal/unauthorized. Opportunities for illegal migration arise as "random events" occurring at rate $x_{I}$, for the unskilled natives of country 2. Skilled individuals typically face fewer restrictions on legal entry channels and presumably relatively larger payoff, compared to unskilled individuals. It is therefore reasonable to assume that those actively looking for opportunities to migrate illegally are the unskilled individuals only ${ }^{1}$.

In any given period, some of the natives of country 2 will choose to take advantage of opportunities to migrate to country 1 either illegally or legally. Immigrants, together with natives, search for jobs, match with firms, bargain for wages and produce. Individuals admitted on family visas can stay and work in country 1 indefinitely (i.e. family visas are permanent). Employment immigrants, on the other hand, are initially admitted on temporary work permits, and may transition to permanent residence status subsequently. ${ }^{2}$

\footnotetext{
${ }^{1}$ According to estimates reported by the Migration Policy Institute in 2012, more than $80 \%$ of undocumented immigrants in the US had at most a high school degree. See https://www.migrationpolicy.org/programs/us-immigration-policy-program-data-hub/unauthorizedimmigrant-population-profiles.

${ }^{2}$ We assume that the employment entry is constituted by a temporary-permanent visa track as most of the immigrants in the US follow such a path. The Department of State reports that in the years 2010-2017
} 
They may obtain a permanent visa at rate $x_{E}$, or return home at rate $d_{T}$, reflecting the end of their employment contract, the expiration of their visa or other personal reasons. For workers on temporary permits, stay in country 1 is conditional on having a job in country 1 . If they switch to permanent residency they can stay and work in country 1 indefinitely. Legal immigrants with either family or permanent-employment visas face zero deportation risk. They have a positive probability of returning home, however, for personal idiosyncratic reasons. Illegal immigrants face the additional risk of being repatriated by deportation. Hence the return probability of illegal immigrants is higher than that of legal immigrants. Let $d_{L}$ and $d_{I}$ denote the instant return rate of legal and illegal immigrants, respectively. We set $d_{I} \geq d_{L}>0$ due to deportation and the more precarious state of the undocumented.

The total labor force of country 1 thus consists of natives $(N)$ and immigrants, legal and illegal (denoted as $L$ and $I$, respectively) and its size is $1+I+L$, while the size of total labor force in country 2 is $X-I-L$. All illegal immigrants are unskilled and all employment immigrants, temporary or permanent (denoted as $L_{T}$ and $L_{E}$, respectively), are skilled, while family immigrants can be skilled $\left(L_{s F}\right)$ or unskilled $\left(L_{u F}\right)$. The total number of legal immigrants in country 1 is given by $L=L_{u F}+L_{s}$, where $L_{s}=L_{s F}+$ $L_{E}+L_{T}$ gives the number of legal immigrants who are skilled.

\subsection{Workers and firms}

Firms in country 1 operate in one of two intermediate sectors, or in the final sector. ${ }^{3}$ The two intermediate sectors produce intermediate goods $Y_{u}$ and $Y_{s}$, using "unskilled" and "skilled" labor, respectively and they operate a linear technology, which implies that immigrants and natives of the same skill type are perfect substitutes in the production of intermediates. These two intermediate inputs are non-storable and are sold in competitive markets and assembled for the production of country 1's final good $(Y)$, the numeraire. The production technology for the final good of country 1 is as follows:

$$
Y=\left[\alpha Y_{s}^{\sigma}+(1-\alpha) Y_{u}^{\sigma}\right]^{\frac{1}{\sigma}}, \sigma \leq 1
$$

only $10 \%$ of permanent employment permits (green cards) was given each year to people who came directly from abroad. $90 \%$ of them was given as "adjustment of status," to people already in the US with another visa. See https://travel.state.gov/content/travel/en/legal/visa-law0/visa-statistics/nonimmigrant-visastatistics.html.

${ }^{3}$ Our production side borrows from Acemoglu (2001). 
where $\alpha$ is a positive parameter that governs income shares and $\sigma$ determines the elasticity of substitution between the unskilled and skilled inputs. The production technology in (1) implies diminishing marginal products and Edgeworth complementarity between the two inputs $Y_{s}$ and $Y_{u}$.

One important difference between skilled immigrants admitted on employment visas and skilled family immigrants or natives is that the former are screened for their occupational qualifications. Employment visas are targeted towards skilled foreigners with specific abilities and they require that immigrants have a job offer in the US. No such screening applies to skilled family immigrants who are, therefore, less selected on the productivity dimension. There is therefore reason to expect that employment immigrants are more productive than family immigrants and even than natives. We capture this by assuming that each skilled native or family immigrant produces one unit of the intermediate input, while each employment immigrant (either permanent or temporary) produces $\lambda \geq 1$ units. In the numerical experiments that follows we calibrate the value of $\lambda$ by matching the wage difference between skilled employment-immigrants and skilled familyimmigrants and this parameter turns out to be larger than one. Unskilled workers, on the other hand, are all equally productive. They all produce one unit of the intermediate input. Given a linear production technology for the two intermediate inputs, we can write, $Y_{s}=e_{s N}+e_{s F}+\lambda\left(e_{s E}+e_{s T}\right)$ and $Y_{u}=e_{u N}+e_{u F}+e_{u I}$, where $e_{i \kappa}$ denotes the number of employed workers of skill type $i$ and immigration/nativity status $\kappa=[N, I, F, T, E]$ $(N=$ native, $I=$ illegal, $F=$ family-based, $T=$ temporary employment-based and $E=$ permanent employment-based).

Since the two intermediate inputs are sold in competitive markets, their prices, $p_{s}$ and $p_{u}$ will be equal to their marginal products, that is:

$$
\begin{aligned}
& p_{s}=\alpha\left(\frac{Y}{Y_{s}}\right)^{1-\sigma} \\
& p_{u}=(1-\alpha)\left(\frac{Y}{Y_{u}}\right)^{1-\sigma}
\end{aligned}
$$

\subsection{Search and Matching}

There are two labor markets in country 1, one for skilled and one for unskilled labor. In each of the two labor markets unemployed workers and job vacancies are matched via a stochastic technology represented by the matching function $M\left(U_{i}, V_{i}\right)$, where $U_{i}$ 
and $V_{i}$ denote, respectively, the number of unemployed workers and vacancies of skill $i=[u, s]$. We assume that the function $M\left(U_{i}, V_{i}\right)$, exhibits standard properties.It is at least twice continuously differentiable, increasing in its arguments, it exhibits constant returns to scale and satisfies the Inada conditions. Using the property of constant returns to scale, we can write the flow rate of match per unemployed worker of skill type $i$ as $M\left(U_{i}, V_{i}\right) / U_{i}=m\left(\theta_{i}\right)$. The flow rate of match per vacancy is $M\left(U_{i}, V_{i}\right) / V_{i}=q\left(\theta_{i}\right)$, where $\theta_{i}=V_{i} / U_{i}$ is the measure of tightness in market $i$ and $m^{\prime}\left(\theta_{i}\right)>0$ while $q^{\prime}\left(\theta_{i}\right)<0$. Firms post either high-skill vacancies or low-skill vacancies. Each firm posts at most one vacancy and hires one worker. The number of firms of each type is determined endogenously by free entry. While vacancies are skill-specific, they cannot be specifically "targeted" to natives or immigrants. They are open to both native and immigrant workers with those skills. Hence, natives and immigrants of skill type $i$, both find jobs at rate $m\left(\theta_{i}\right)$.

Firms bear a recruitment $\operatorname{cost} c_{i}$ for each vacancy, which is specific to the skill type and related to the expenses of looking for a worker. An unemployed worker of type $i$ receives a flow of income $b_{i}$, which can be considered as the opportunity cost of employment. In addition, unemployed workers pay a search cost $\pi_{i j}$ per unit of time where the subscript $j=[N, I, L]$ denotes the worker's origin and legal status: native $(N)$, illegal-immigrant $(I)$ and legal-immigrant $(L)$. We account for the fact that a legal immigrant worker faces a higher search cost compared to a native worker and an illegal immigrant faces even higher costs. The reason is that legal immigrants, whether on temporary visas or permanent residency, have access to significantly fewer benefits than US citizens, especially when unemployed. ${ }^{4}$ Undocumented immigrants cannot access any unemployment insurance at all and hence their cost of searching is even larger. We standardize the search cost of a native worker to 0 and set $\pi_{i N}=0$, and we presume $\pi_{I}>\pi_{u L}>0, \pi_{s L}>0$ which will be confirmed by the calibration.

When a vacancy and a worker are matched, they bargain over the division of the produced surplus. The status of the worker as well as the output that results from a match are known to both parties. Matches of unskilled firms with unskilled workers (natives or immigrants) produce output $p_{u}$ (given in 3). Matches of skilled firms with skilled natives or family immigrants produce output $p_{s}$ (given in 2), while matches with skilled

\footnotetext{
${ }^{4}$ Since the Personal Responsibility and Work Opportunity Reconciliation Act (PRWORA) of 1996 many federal government benefits (Food stamps, TANF, AFDC and others) were restricted to US citizens only. Hence non-naturalized legal immigrants had a significant larger cost of being without a job. In the 2000's some but not all, states re-instated some of them.
} 
employment immigrants on temporary or permanent visas produce output $p_{E}=\lambda p_{s}$. Wages, denoted as $w_{i \kappa}$, differ by skill type $(i)$ and migration status $\kappa=[N, I, F, T, E]$. They are determined by Nash bargaining of the produced surplus between the firm and the worker. After an agreement has been reached, production commences immediately. Matches dissolve at the rate $s_{i}$. Following a job destruction, the worker and the vacancy enter the corresponding market and search for new match.

\subsection{Optimality Conditions and Free entry}

At each point in time a worker is either employed $(E)$ or unemployed $(U)$, while a vacancy may be either filled $(J)$ or empty $(V)$. We use the notation $E_{i \kappa}, U_{i \kappa}, J_{i \kappa}$ and $V_{i \kappa}$ to denote the present discounted value associated with the state where a worker is employed, a worker is unemployed, a job is filled and a job is vacant, where $i=[s, u]$ indicates the worker's skill type and $\kappa=[N, I, F, T, E]$ the worker's immigration/nativity status. Note that we drop the subscript $\kappa$ from $V_{i \kappa}$, since a vacancy of skill type $i$ is open to any worker of skill type $i$ irrespective of his/her immigration status and is therefore described by the same Bellman equation. We also drop the subscript $i$ whenever $\kappa=[I, T, E]$, since all illegal immigrants are unskilled and all employment immigrants (on either temporary or permanent visas) are skilled. The full set of Bellman equations that describe the optimal behavior of workers and firms in country 1 is in Appendix A.

A second set of equilibrium conditions is that of free-entry (vacancy posting) on the firm side in each of the two labor markets (skilled and unskilled). Firms open vacancies up to the point that an additional one has zero expected value. In equilibrium this implies the following two conditions:

$$
V_{i}=0, \quad i=[s, u]
$$

Wages are then determined by Nash bargain between the matched firm and the worker. The outside options of the firm and the worker are the value of a vacancy (i.e. of searching for a worker) and the value of being unemployed (i.e. of searching for job), respectively. Let $S_{i \kappa}$ denote the surplus of a match between a vacancy of skill type $i$ and a worker of immigration status $\kappa$. With Nash-bargaining the wage is set to a level such that the worker gets a share $\beta$ of the surplus, where $\beta$ represents the relative bargaining power of workers, and the share $(1-\beta)$ goes to the firm. This implies seven equilibrium conditions of the following form: 


$$
\begin{aligned}
\beta S_{i \kappa} & =E_{i \kappa}-U_{i \kappa}, \quad(1-\beta) S_{i \kappa}=J_{i \kappa}-V_{i}, \quad i=[s, u] \quad \text { and } \quad \kappa=[N, F] \\
\beta S_{E} & =E_{E}-U_{E}, \quad(1-\beta) S_{E}=J_{E}-V_{s} \\
\beta S_{I} & =E_{I}-U_{I}, \quad(1-\beta) S_{I}=J_{I}-V_{u} \\
\beta S_{T} & =E_{T}-U_{s}^{2}, \quad(1-\beta) S_{T}=J_{T}-V_{s}
\end{aligned}
$$

Conditions 5 to 7 are relative to workers in Country 1. Only condition 8 is relative to residents of country 2. $U_{i}^{2}$ denotes the value of searching for a job in country 2 for an individual of skill type $i=[s, u]$ who was born in country 2. It gives the outside option of natives of country 2 who are currently employed (or seeking entry) in country 1 on temporary visas, because these workers' stay (or entry) in country 1 is conditional upon having a job in country 1 . If an agreement is not reached and they are not offered a job in country 1, they will have to search for a job in country 2 .

\subsection{Legal Migration}

The two main channels through which the natives of country 2 migrate legally to country 1 are the family unification system and the employment system.

\subsubsection{Family unification}

To be eligible for a family visa, a native of country 2 must have an immediate relative who is a lawful permanent resident of country 1 . Let $L_{P} \equiv L-L_{T}$ denote the number of legal immigrants of country 1 that hold permanent (employment or family) visas. An individual from country 2 is more likely to be eligible to apply for a family visa when a larger share of country-2 natives are legal (permanent) immigrants of country 1. More formally, if we assume that all families have exactly the same probability/share of legal immigrants on permanent visas in country 1 , then the probability that a member of a family network is a permanent-legal immigrant of country 1 is $\frac{L_{P}}{X}$. Suppose that petitions for obtaining family visas are filed and approved at rate $x_{F}$. The rate at which natives of country 2 obtain visas for legal entry into country 1 through family unification, therefore, is given by $x_{F} \frac{L_{P}}{X}$. As the network of incumbent legal-permanent immigrants expands (i.e. as $L_{P}$ increases), entry of new immigrants through family ties becomes more likely. This self-reinforcing channel provided by family ties is sometimes referred to as "chain migration". 


\subsubsection{Employment-based Admissions}

A country-2 native can apply for a permit to enter and work in country 1 only if he has already been offered a job in country 1 . Such job offers are made available to potential skilled migrants from country 2 through referrals from their network of co-ethnics who are legally employed in country 1 . We assume that an employer who is currently employing a skilled legal-immigrant worker may be willing to support a new skilled worker's migration by opening a new position and asking his current legal-immigrant employee to recommend an alien worker for the new position. If the referred worker is unemployed and willing to migrate for the job, then a petition for an employment visa is filed, and if approved, the worker gets the job and migrates to country 1. One way of interpreting this channel of hiring is that incumbent immigrants use their employer contacts in order to assist the migration of other members of their network. In other words, support from incumbent immigrants encourages country 1 employers to create new positions for bringing workers from country 2 lawfully into country 1. Another interpretation is that employers try to take advantage of the information provided by their current skilled immigrant employees in order to identify good quality candidates from abroad that can fill skilled positions, without having to engage in time-consuming search.

Let $e_{s L}$ denote the number of skilled natives of country 2 who are legally employed in country 1 . The employer of each of them is willing to offer a job to another skilled migrant at rate $\rho$. In this event, the immigrant employee will recommend one from his network. ${ }^{5}$ Suppose that $n$ is the size of the network of co-ethnics of each individual from country 2. Each of the skilled natives of country 2 is therefore linked to $\rho n\left(\frac{e_{s L}}{X}\right)$ immigrants who can refer her to a job. Each of these immigrants is in turn linked to $n\left(\frac{X_{s}-L_{s}}{X}\right)$ natives of country 2 who are skilled, thus suited for the job, and are currently residing in country 2. The "referring" immigrant will recommend one among them at random. ${ }^{6}$ Hence, the rate at which a skilled worker who is currently residing in country 2 is referred to an employer in country 1 who is willing to support her migration to country 1 is given by $\rho n\left(\frac{e_{s L}}{X}\right)$ divided by $n\left(\frac{X_{s}-L_{s}}{X}\right)$ which gives $\rho\left(\frac{e_{s L}}{X_{s}-L_{s}}\right)$. We assume for simplicity that being referred to the employer is the same as being offered the job and petitioned for entry. If workpermit petitions are approved at rate $\gamma_{T}$, the skilled natives of country 2 obtain permits

\footnotetext{
${ }^{5}$ Our modeling of referrals borrows from Galenianos (2014).

${ }^{6} \mathrm{We}$ assume that referrals are targeted towards non-migrants, in line with the idea that incumbent immigrants use their employer contacts to bring new immigrants into the country.
} 
to work in country 1 at rate $x_{T}\left(\frac{e_{s L}}{X_{s}-L_{s}}\right)$, where $x_{T} \equiv \rho \gamma_{T}$.

\subsection{The Immigration Decision and Inflows}

A worker will take an opportunity to migrate to country 1 if its benefit exceeds its cost. The migration cost, $z$, is heterogeneous across individuals and is distributed according to the $\operatorname{CDF} \Phi(z)$ with support $[\underline{z}, \bar{z}]$. We assume that only the unemployed natives of country 2 are actively searching for opportunities to migrate illegally, so such opportunities arise only for the unskilled natives of country 2 who are unemployed. We also assume that only unemployed workers are willing to act upon opportunities to legally migrate through either the employment or the family route. ${ }^{7}$ All workers deciding whether to migrate or not, through any of the three possible routes, are therefore unemployed and their benefit from migrating is the difference between their value of being immigrants of country 1 and their value of being unemployed (searching for a job) in their home country.

The value of being an immigrant of country 1 depends on the entry route and on the worker's skill level. New illegal immigrants and new immigrants admitted on family visas arrive in country 1 without a job and must search for a job in the market. For these types of immigrants the benefit from migrating to country 1 is the difference in value between searching for a job in country 1 and searching for a job in country 2. New immigrants on employment visas, by contrast, arrive through referrals, with jobs. Their migration benefit therefore is the difference between the value of being employed in country 1 (on a temporary work permit) and the value of being unemployed in country 2 .

An unskilled individual whose migration cost is $z$, will choose to take advantage of an opportunity to enter illegally into country 1 only if $U_{I}-U_{u}^{2} \geq z$ while she will enter on a family visa (if such an opportunity arises) if $U_{u F}-U_{u}^{2} \geq z$. Likewise a skilled native of country 2 will migrate on a family visa only if $U_{s F}-U_{s}^{2} \geq z$ and on a temporary employment visa only if $E_{T}-U_{s}^{2} \geq z$. The threshold costs, denoted as $\tilde{z}_{I}, \tilde{z}_{i F}$, and $\tilde{z}_{T}$ and representing the highest cost a worker is willing to pay in order to obtain illegal, family-

\footnotetext{
${ }^{7}$ In order to migrate illegally, workers need to actively look for such opportunities, and often, they need to move closer to the border. It is therefore reasonable to assume that those actively looking for opportunities to enter illegally into country 1 are not only unskilled but also unemployed. Although we cannot rule out the possibility of workers quitting their jobs in order to migrate, especially when migrations are legal, we choose not to allow for this possibility in our analysis. Allowing for this possibility would complicate the model considerably, without adding anything fundamental.
} 
based or employment-based entry into country 1, are defined by the following conditions:

$$
\begin{aligned}
\tilde{z}_{I} & =U_{I}-U_{u}^{2} \\
\tilde{z}_{i F} & =U_{i F}-U_{i}^{2} \\
\tilde{z}_{T} & =E_{T}-U_{s}^{2}
\end{aligned}
$$

These threshold immigration costs can then be used to determine the four rates $\Phi\left(\tilde{z}_{I}\right)$, $\Phi\left(\tilde{z}_{T}\right)$ and $\Phi\left(\tilde{z}_{i F}\right)$, at which natives of country 2 take up opportunities to migrate, illegally, on a temporary work permit and on a family visa, respectively. Changes in wage and unemployment conditions, as well as changes in immigration policies in country 1 will affect migration incentives by altering these threshold costs and therefore the inflows of legal and illegal immigrants. Let $u_{i}^{2}$ denote the number of unemployed workers of skill type $i=[s, u]$ in country 2 . Inflows of illegal immigrants are given by $x_{I} \Phi\left(\tilde{z}_{I}\right) u_{i}^{2}$, that of skilled immigrants on temporary work permits by $x_{T}\left(\frac{e_{s L}}{X_{s}-L_{s}}\right) \Phi\left(\tilde{z}_{T}\right) u_{i}^{2}$, and that of skilled and unskilled immigrants on family visas by $x_{F}\left(\frac{L_{P}}{X}\right) \Phi\left(\tilde{z}_{s F}\right) u_{s}^{2}$ and $x_{F}\left(\frac{L_{P}}{X}\right) \Phi\left(\tilde{z}_{u F}\right) u_{u}^{2}$, respectively.

Notice that all the conditions of country 2 that can influence the decision to migrate and the flow of migrants from country 2 to country 1 are summarized in only two values: the value of searching for a job $U_{i}^{2}$ and the number of unemployed individuals $u_{i}^{2}$. The value of searching for a job reflects all home-country labor market conditions that may influence the benefit of migrating, such as wages, employment opportunities etc, while the number of unemployed gives the pool of potential migrants to country 1 . Since our focus is on the receiving country, we will skip a detailed representation of the labor market in country 2 and simply focus on only these two values. Further, we take these two values as given. In other words, we assume for simplicity that labor market conditions in country 2 are independent of immigration and labor market conditions in country 1.

\subsection{The Steady-State Conditions}

The last set of equilibrium conditions are the steady-state conditions. Six of them determine the constant number of unemployed workers of each type in country 1 by equating the flows into and out of unemployment status for each type of worker: $u_{s N}$ and $u_{u N}$ are skilled and unskilled natives in country $1, u_{s F}$ and $u_{u F}$ are skilled and unskilled family immigrants, $u_{E}$ are employment immigrants and $u_{I}$ are illegal immigrants. Five more conditions guarantee the stationarity of the number of family immigrants $\left(L_{s F}\right.$ and $\left.L_{u F}\right)$, 
illegal immigrants $(I)$, and employment immigrants $\left(L_{E}\right.$ and $\left.L_{T}\right)$, by equating the flows into and out of the group. The eleven formal conditions defining these steady state variables are given by equations (41) to (49) in Appendix A. Writing the steady state conditions for unemployed and migrants as a function of parameters, labor market tightness in the respective markets $\left(\theta_{s}, \theta_{u}\right)$ and threshold costs $\tilde{z}_{s F}, \tilde{z}_{u F}, \tilde{z}_{T}, \tilde{z}_{I}$ we obtain the following expressions:

$$
\begin{aligned}
& \tilde{u}_{s N}=\frac{u_{s N}}{S}=\frac{s_{s}+\tau}{s_{s}+m\left(\theta_{s}\right)+\tau} \\
& \tilde{u}_{u N}=\frac{u_{u N}}{1-S}=\frac{s_{u}+\tau}{s_{u}+m\left(\theta_{u}\right)+\tau} \\
& \tilde{u}_{i F}=\frac{u_{i F}}{L_{i F}}=\frac{s_{i}+d_{L}+\tau}{s_{i}+d_{L}+m\left(\theta_{i}\right)+\tau} \\
& \tilde{u}_{E}=\frac{u_{E}}{L_{E}}=\frac{s_{s}}{s_{s}+d_{L}+m\left(\theta_{s}\right)+\tau} \\
& \tilde{u}_{I}=\frac{u_{I}}{I}=\frac{s_{u}+d_{I}+\tau}{s_{u}+d_{I}+m\left(\theta_{u}\right)+\tau} \\
& L_{s F}=\left(\frac{x_{F} \tilde{u}_{s}^{2} \Phi\left(\tilde{z}_{s F}\right) \frac{L_{P}}{X}}{d_{L}+\tau+B x_{F} \tilde{u}_{s}^{2} \Phi\left(\tilde{z}_{s F}\right) \frac{L_{P}}{X}}\right) X_{s} \\
& L_{u F}=\left[\frac{x_{F} \tilde{u}_{u}^{2} \Phi\left(\tilde{z}_{u F}\right) \frac{L_{P}}{X}}{\left(d_{L}+\tau\right)\left(1+\frac{x_{I} \tilde{u}_{u}^{2} \Phi\left(\tilde{z}_{I}\right)}{d_{I}+\tau}\right)+x_{F} \tilde{u}_{u}^{2} \Phi\left(\tilde{z}_{u F}\right) \frac{L_{P}}{X}}\right] X_{u} \\
& L_{E}=\left[\frac{\left(\frac{x_{E}}{x_{E}+d_{T}+\tau}\right) x_{T} \tilde{u}_{s}^{2} \Phi\left(\tilde{z}_{T}\right)\left(1-\tilde{u}_{s F}\right)}{d_{L}+\tau-\left(\frac{x_{E}}{x_{E}+d_{T}+\tau}\right) x_{T} \tilde{u}_{s}^{2} \Phi\left(\tilde{z}_{T}\right)\left(1-\tilde{u}_{E}\right)}\right] L_{s F} \\
& L_{T}=\left[\frac{d_{L}+\tau}{x_{E}}\right] L_{E} \\
& I=\left[\frac{x_{I} \tilde{u}_{u}^{2} \Phi\left(\tilde{z}_{I}\right)}{\left(d_{I}+\tau\right)\left(1+\frac{x_{F} \tilde{u}_{u}^{2} \Phi\left(\tilde{z}_{u F}\right) \frac{L_{P}}{X}}{d_{L}+\tau}\right)+x_{I} \tilde{u}_{u}^{2} \Phi\left(\tilde{z}_{I}\right)}\right] X_{u}
\end{aligned}
$$

where $B=1+\left[\frac{\left(\frac{x_{E}+d_{L}+\tau}{x_{E}+d_{T}+\tau}\right) x_{T} \tilde{u}_{s}^{2} \Phi\left(\tilde{z}_{T}\right)\left(1-\tilde{u}_{s F}\right)}{d_{L}+\tau-\left(\frac{x_{E}}{x_{E}+d_{T}+\tau}\right) x_{T} \tilde{u}_{s}^{2} \Phi\left(\tilde{z}_{T}\right)\left(1-\tilde{u}_{E}\right)}\right]$.

Let us also define the variables $\phi_{u} \equiv \frac{u_{u F}+u_{I}}{u_{u F}+u_{I}+u_{u N}}$ and $\phi_{s} \equiv \frac{u_{s F}+u_{E}}{u_{s F}+u_{E}+u_{s N}}$ to be the share of immigrants in the pool of unemployed unskilled and skilled workers, respectively, $\eta_{I} \equiv \frac{u_{I}}{u_{I}+u_{u F}}$ to be the share of illegal immigrants among unemployed unskilled immigrants and $\eta_{E} \equiv \frac{u_{E}}{u_{E}+u_{s F}}$ to be the share of employment immigrants among unemployed skilled immigrants. In equilibrium these shares are constant.

Expressions (12)-(21) reveal some important mechanisms at work in our model. First, 
as customary in these models, unemployment rates decrease with the matching probability $m\left(\theta_{i}\right)$. The main channel through which immigration policies can influence the unemployment rate of natives that participate in the market is their impact on the labor market tightness, $\theta_{i}$, and in turn, on the matching probability $m\left(\theta_{i}\right)$. Second, expressions (17)-(21) show that the equilibrium numbers of migrants of each type depend negatively on the return probabilities $\left(d_{I}\right.$ and $\left.d_{L}\right)$, positively on the approval rates of visa opportunities $\left(x_{F}, x_{T}, x_{E}\right)$ or illegal immigration opportunities $\left(x_{I}\right)$ and positively on the threshold migration costs $\left(\tilde{z}_{s F}, \tilde{z}_{u F}, \tilde{z}_{T}\right.$ and $\left.\tilde{z}_{I}\right)$. The latter implies any economic and policy factor that increases the value of searching for a job in country 1 relative to country 2 or the value of being employed in country 1 on a temporary visa encourages immigration and translates to larger equilibrium numbers of legal and illegal immigrants in country 1. Third, we see from expressions (17)-(19), the importance of immigrant networks in determining the size of immigrant stocks. The share of legal (permanent) immigrants in total foreign population $\left(\frac{L_{P}}{X}\right)$ affects the probability of entry through family unification positively, thus has a positive impact on legal immigration, while it affects the number of illegal immigrants negatively. Similarly, the number of employment immigrants increases as the employment rate of legal (employment or family) skilled immigrants increases. A change in an immigration policy (affecting either entry or exit of immigrants) will therefore affect the number of immigrants through three different paths: first, it will have a direct impact on the immigrant inflow or outflow (e.g. visa quotas or deportations), second, it will affect immigrant entry thought its impact on immigration incentives (changes in threshold immigration costs $\tilde{z}_{I}, \tilde{z}_{i F}$, and $\tilde{z}_{T}$ ) and third, it will also affect the size of immigrant networks with consequences on opportunity for entry of other immigrants.

Let us notice that once the constant equilibrium values of $L_{i F}, L_{E}, L_{T}, I, u_{i F}, u_{i N}, u_{E}$ and $u_{I}, i=[s, u]$, are determined, a linear technology determines production of intermediates so that $Y_{s}=S+L_{s F}-u_{s N}-u_{s F}+\lambda\left(L_{E}+L_{T}-u_{E}\right)$ and $Y_{u}=S+L_{u F}+I-u_{u N}-u_{u F}-u_{I}$.

\subsection{Equilibrium}

A steady state equilibrium consists of a set of threshold immigration costs, $\tilde{z}_{s F}, \tilde{z}_{u F}, \tilde{z}_{T}, \tilde{z}_{I}$, tightnesses $\theta_{s}, \theta_{u}$, number of unemployed $u_{s N}, u_{u N}, u_{s F}, u_{u F}, u_{E}, u_{I}$, and number of immigrants $L_{s F}, L_{u F}, L_{E}, L_{T}$ and $I$ such that the following apply:

1. Natives of country 2 decide optimally whether to migrate or not (equations 9-11 are satisfied) 
2. The two free-entry conditions in (4) are satisfied

3. Flows into and out of each group of unemployed workers are equal (equations 45-49 in Appendix $\mathrm{A})^{8}$

4. The outflows of immigrants of each type equal their inflows (equations 41-43 in Appendix A)

The two linear production functions described above can determine the steady-state production of intermediates, $Y_{s}, Y_{u}$, and in turn, aggregate production of country 1 (using equation 1$)$. The two marginal productivity conditions $(2,3)$, can be used to determine the set of marginal productivities $p_{u}, p_{s}$ and $p_{E}=\lambda p_{s}$. Finally, equations (50)-(55) in Appendix A determine the seven wages $w_{s N}, w_{u N}, w_{s F}, w_{u F}, w_{E}, w_{T}, w_{I}$, given that wages are the outcome of Nash bargaining. As mentioned above, we take the values of searching for jobs in country 2 por skilled and unskilled workers, $U_{s}^{2}$ and $U_{u}^{2}$, and the unemployment rates in country $2, \tilde{u}_{s}^{2}$ and $\tilde{u}_{u}^{2}$, as given. In Appendix A we show how to derive some intermediate results and provide a description for how to solve the model in blocks. Given the fact, however, that some of the expressions are cumbersome we omit those from the text. We will explain, instead, before calibrating and simulating the full model, the intuition behind some key mechanisms.

Given that free entry drives the value of a vacancy to zero, using (24)-(25) we get:

$$
\begin{aligned}
\frac{c_{u}}{q\left(\theta_{u}\right)} & =\phi_{u}\left[\eta_{I} J_{I}+\left(1-\eta_{I}\right) J_{u F}\right]+\left(1-\phi_{u}\right) J_{u N} \\
\frac{c_{s}}{q\left(\theta_{s}\right)} & =\phi_{s}\left[\eta_{E} J_{E}+\left(1-\eta_{E}\right) J_{s F}\right]+\left(1-\phi_{s}\right) J_{s N}
\end{aligned}
$$

where $\phi_{i}$ is the share of of immigrants in the pool of unemployed individuals of skill type $i, \eta_{I}$ is the share of illegal immigrants among unemployed unskilled immigrants and $\eta_{E}$ the share of employment immigrants among unemployed skilled immigrants. These expressions give the job creation conditions in unskilled and skilled markets, respectively. They set the expected costs of creating a vacancy (left-hand-side) equal to the expected value of a new job (right-hand-side) and can be used to determine the equilibrium market tightness $\theta_{u}$ and $\theta_{s}$, and in turn, the rates at which workers find jobs, $m\left(\theta_{u}\right)$ and $m\left(\theta_{s}\right)$.

\footnotetext{
${ }^{8}$ Apparently, due to the network dependence of legal immigration pathways, the steady-state numbers of legal immigrants, given in equations (17)-(19) depend on the share of permanent immigrants $\frac{L_{P}}{X}$. By adding up (17)-(19) we can get the steady-state condition that determines $\frac{L_{P}}{X}$. That condition is quadratic with two roots. One of the two roots is negative and thus can be ruled out. Hence, we get a unique solution for $\frac{L_{P}}{X}$ in terms of tightness $\theta_{s}, \theta_{u}$ and immigration thresholds $\tilde{z}_{s F}, \tilde{z}_{u F}, \tilde{z}_{T}, \tilde{z}_{I}$, which can be used to determine the steady-state solutions of $L_{s F}, L_{u F}, L_{E}$ and $L_{T}$.
} 
We see, from these expressions, that if the value to the firm from creating a new job differs depending on the type of worker hired (i.e. if $J_{I} \neq J_{u F} \neq J_{u N}$ and $J_{E} \neq J_{s F} \neq J_{s N}$ ) then changes in the size and composition of immigrant stock (i.e. changes in $\phi_{s}, \phi_{u}$, $\eta_{E}$ and $\eta_{I}$ ) can change the expected gains from creating new jobs and in turn affect market tightness and job finding rates. A proportional increase in all types of immigrants that leaves their composition unchanged, but increases their share in the unemployment pool (increases $\phi_{s}$ and $\phi_{u}$ ) will increase the expected value of a new job, and induce firms to open more vacancies per unemployed worker (increase $\theta_{u}$ and $\theta_{s}$ ) if immigrants generate, on average, larger value for firms than natives: $\eta_{I} J_{I}+\left(1-\eta_{I}\right) J_{u F}>J_{u N}$ or $\eta_{E} J_{E}+\left(1-\eta_{E}\right) J_{s F}>J_{s N}$. The reasons why these inequalities are likely to hold are discussed below. Changes in the composition of unemployed immigrants will also alter job creation incentives if different types of immigrants generate different surplus to firms. For instance, an increase in $\eta_{I}$ or $\eta_{E}$ will encourage job creation if $J_{I}>J_{u F}$ or $J_{E}>J_{s F}$. Any positive impact that immigrants may have on job creation and job finding rates will translate into higher wages and lower unemployment rates for native workers, as can be verified from equations (12)-(13) and (50) in Appendix A.

The value to the firm from hiring an immigrant worker may be higher than that from hiring a native worker mainly for two reasons. The first is productivity and is relevant for skilled immigrants. Since employment-based immigrants are selected for their abilities (through referral and visa requirements) they are likely more productive than other skilled immigrants and natives. In our notation this means that $\lambda>1$ so that $p_{E}>p_{s}$, which in turn means $J_{E}>J_{s F}$ (see equation 69 in Appendix A). ${ }^{9}$

The second reason is search costs, and applies mainly to low skilled immigrants. As discussed above, search costs differ between natives and immigrants and may also differ across different types of immigrants. Immigrants, especially illegal ones, are willing to accept lower wages, because they face higher search costs relative to natives as they have limited access to unemployment insurance and welfare programs. As can be verified from the equilibrium wage expressions in (50)-(55) the higher a worker's search costs the lower his wage, since search costs worsen a worker's outside option and thus position in

\footnotetext{
${ }^{9}$ The use of referrals from skilled immigrants can also increase the firm's surplus from employing them. In our baseline model, however, we choose to keep the surplus from hiring skilled immigrants as small as possible, and assume that employers do not internalize the surplus that the use of referrals generates. Since the use of referrals does not generate any rents to the firm, it does not also affect job creation incentives. We discuss the case in which employers internalize this surplus in Appendix A and show results for this case in Appendix B.4 (Table 25).
} 
wage setting. This implies that immigrants generate larger profits to firms because they accept lower wages. By comparing $J_{i F}$ to $J_{i N}$ and $J_{I}$ to $J_{u F}$ we can see more clearly how immigrants' search costs affect the firm's value from hiring them (see Appendix A.5). If family immigrants have higher search cost than natives, that is, if $\pi_{i L}>0$, then $J_{i F}-J_{i N}>0$ as long as $d_{L}$ is small. Hence, the value of a legal immigrant to the firm is higher than that of a native, even given equal productivity, as long as the immigrant's search cost is high enough to compensate for the larger probability of separation. Likewise, if illegal immigrants have worse outside options than legal ones $\left(\pi_{I}-\pi_{u L}>0\right)$, then $J_{I}-J_{u F}>0$ as long as the difference between the return probabilities, $d_{I}-d_{L}-$ representing the deportation rate - is not too large. Hence, low deportation rates and high search cost for illegal immigrants make them particularly valuable to the firm.

An additional channel through which changes in the size and composition of the immigrant population can affect the labor market outcomes of natives, operates through the marginal product of each of the two skill types, $p_{s}$ and $p_{u}$. This is the standard complementarity channel: immigrants of a certain skill type substitute for natives of the same skill type, and complement natives of different skill types. So increasing their supply decreases the marginal productivity of natives of the same skill type and increases the marginal productivity of natives of the different skill. This channel operates only when immigrant inflows alter the relative skill composition of the labor force. A proportional increase in skilled and unskilled due to immigrants will have no impact through this channel. Changes in immigration policy that decrease the relative supply of unskilled labor, such as tighter border control (smaller $x_{I}$ ) or deportations (larger $d_{I}$ ), will put upward pressure on marginal productivity of unskilled workers, and downward pressure on marginal productivity of skilled ones. Effects go in the opposite direction when changes in immigration policies decrease the relative supply of skilled labor.

The overall impact of changes in immigration policies on job creation combines the effects on marginal products and the effects on the expected value of a job (discussed in the previous section) brought by changes in the composition of labor force (due to changes in $\phi_{u}, \phi_{s}, \eta_{I}$ and $\left.\eta_{E}\right) .{ }^{10}$ The impact of these two effects can be in opposite

\footnotetext{
${ }^{10}$ If $d_{L}=d_{I}=0, \pi_{i L}=\pi_{I}=0, \lambda=1$ then immigrants and natives belonging to the same skill group are identical and generate equal profits to firms so that changes in the composition of labor force in terms of nativity and immigrant status no longer affect job creation. All effects, in this case, work through the prices of intermediate inputs, $p_{u}$ and $p_{s}$. If, in addition, skilled and unskilled labor are perfect substitutes in production, i.e. $\sigma=1$, then as can be verified from (2) and (3), prices are constant $\left(p_{s}=\alpha, p_{u}=1-\alpha\right)$ and immigration does not affect prices either. In this case immigration has no
} 
direction, hence the prediction of this model may be opposite from that of the canonical model. Consider for example the enforcement of deportations of illegal immigrants. It will increase marginal productivity of unskilled, $p_{u}$, by reducing their relative supply, but it will also decrease the value of filling an unskilled job for the firm, if illegal immigrants are paid significantly less compared to other unskilled workers. The overall impact on the number of vacancies per unemployed worker, may go either way, and need not be negative, as predicted by the price effect only.

Finally, despite being separated by skill level, job creation in the two labor markets is linked by production complementarity. Immigration-induced changes in one market will carry over to the other through complementarities in production. For instance, any policy hurting the creation of unskilled jobs, will also hurt the creation of skilled jobs, by lowering the marginal productivity of the skilled labor.

\subsection{Immigrant Networks, Incentives and Composition}

The novelty of our model is that it incorporates the important interplay between immigration policies, immigrants' economic incentives and immigrant networks. A change in one policy, targeting entry through one particular channel, will affect the size of immigrant network with consequences on the opportunity for entry through other channels. It will also affect wages and employment opportunities for different skill groups, which will, in turn, influence incentives for entry through each of the three channels. As discussed above these elements are key to our understanding of the labor market effects of immigrants and of immigration policies.

The two legal entry routes of employment and family reunification, depend strongly on networks, which means past immigrants. Inflows through the family unification channel are larger when the stock of legal immigrants (on permanent visas) is larger. Also (19) and (20) show that the stock of employment-based immigrants is proportional to the stock of skilled-family immigrants. This means that inflows of immigrants through the familyand employment-based channels are linked. In the long run equilibrium a policy affecting one entry route will also affect the other entry route. The strong network dependence of the legal entry routes may amplify any impacts of migrations on job creation.

Two interesting facts should be noted about the role of networks. First, employ-

impact on the labor market. In the general case, where different types of immigrants and natives differ, and the two labor inputs are imperfect substitutes $(\sigma<1)$ the effects of immigration work through both of these channels. 
ment immigrants generate entry opportunities for unskilled immigrants through family ties. Likewise, unskilled immigrants generate entry opportunities for skilled immigrants through family ties and on the job referrals. Because of this symmetry either channel will produce similar long run changes in the skill composition of total legal immigrants. Second, and differently, undocumented will not create large network effects, because they can neither sponsor a family member nor create a referral for an employment-entry. ${ }^{11}$

\section{Parameterization of the model}

The model is complex and rich. We devote substantial attention in choosing parameters and performing robustness checks for some of them (see Section 6 and Appendix B). Still, one should think of our simulations as providing a reasonable idea (rather than exact forecast) of the magnitude of labor market effects of different policies. We combine three types of parameters. Some are taken from estimates in the literature. Others are summary statistics taken from the data. A third group is chosen to match some moments of the data through calibration. The parameter choice is summarized in Table 1. Our goal is to match the moments of the data for the 2010-2015 average. Hence we choose the best data available during or as close as possible to this time period. Some variables (such as interest rate and population growth rates) are averaged over a longer time period to ensure a long-run perspective. We describe here the sources and the methods used to calculate these parameters.

We use a Cobb-Douglas matching function, $M_{i}=\xi\left(U_{i}\right)^{\epsilon}\left(V_{i}\right)^{1-\epsilon}, i=[s, u]$. Following common practice in these models, we set the unemployment elasticity of the matching function to $\epsilon=0.5$, which is within the range of estimates reported in Petrongolo and Pissarides (2001). We postulate the worker's bargaining power to be $\beta=0.5$, so that the Hosios condition $(\beta=\epsilon)$ is met (see Hosios, 1990). We use the monthly interest rate $r=0.4 \%$ which implies a yearly real rate of about $5 \% .{ }^{12}$ This is calculated as the 30-year treasury constant maturity bond rate minus the average GDP deflator over the period 1980-2010 for the US. We define as skilled a worker who has at least some college education and unskilled workers are those with no college education. Based on existing

\footnotetext{
${ }^{11} \mathrm{We}$ are not analyzing here long run effects in an overlapping generation framework, but long run effects within the first generation. Considering U.S.-born children of immigrants as immigrants would generate a channel through which undocumented can affect the stock of legal immigrants in the next generation.

${ }^{12}$ We match all the flow rates in the model to monthly rates.
} 
estimates (see Goldin and Katz (2008) and Ottaviano and Peri (2012)) the elasticity of substitution between those two types of workers is around 2. We therefore set $\sigma=0.5$. The migration costs are assumed to be lognormally distributed with $\mu_{z}$ and $\sigma_{z}$ being, respectively, the mean and standard deviation of lognormal values. We standardize the mean to 0 and choose the value of $\sigma_{z}$, which together with the chosen entry approval rates and return probabilities matches the observed numbers of immigrants in the US (see below). We perform sensitivity analysis with respect to the mean of the distribution in Section 6. In order to measure $x_{F}$, the rate at which family reunification visas are issued,we use the fact that the wait time to get a green card for immediate family to a US citizen is 10-17 months. ${ }^{13}$ We set the wait time to the mean of 14 months and set the rate at $x_{F}=0.07$ (i.e. $\frac{1}{x_{F}}=14$ ).

As mentioned above, we consider Mexico as the main country supplying low skilled immigrants and Chinese and Indians as the most relevant foreign group supplying high skilled immigrants. Our measures of $X_{u}$ and $X_{s}$, which represent the population of foreign skilled and unskilled who can migrate to the US include the unskilled Mexican labor force and the skilled Indian and Chinese labor force, respectively. Those values are equal to 0.323 and 0.562 , respectively, when standardized by the US native population between 18 and 65 years, which is set to 1 , and are obtained from Barro and Lee (2010).

The share of native skilled workers in the US is set to $S=0.604$. This is the share of US native workers with some college education or more in the total native population in working age (18-65) from the 2014 US ACS Public Use Microdata Sample (PUMS). ${ }^{14}$ Using Census data over the period 1980 to 2010 we find the annual growth rate of US native labor force to be $0.86 \%$ per year implying a monthly growth rate of $0.072 \%$ and hence we set $\tau=0.00072$. Using matched data from the ORG Current Population Survey (CPS) we estimated the average skilled and unskilled monthly job-separation rates in the US ( $s^{s}$ and $s^{u}$, respectively) to be 0.024 and 0.032 , respectively. ${ }^{15}$ To calculate the unemployment rate of foreign unskilled workers in their country of origin we use estimates of unemployment rates by education in year 2015 for Mexico and find $\tilde{u}_{u}^{2}=0.036$. We set the unemployment rate of skilled foreign workers in their country to $\tilde{u}_{s}^{2}=0.067$. This was calculated using estimates of unemployment rates for highly skilled in India averaged

\footnotetext{
${ }^{13}$ See https://www.boundless.com/immigration-resources/how-long-does-marriage-green-card-take/.

${ }^{14}$ obtained at https://usa.ipums.org/usa/.

${ }^{15}$ These measures calculate the employment to unemployment and employment to inactivity transitions relative to employment and non-employment stocks.
} 
over years 2013-2014 and China for year 2012. ${ }^{16}$

The return probabilities of legal and illegal immigrants in the US, are taken from Chassamboulli and Peri (2015) who calculate these probabilities for Mexican immigrants and find that they are $d_{L}=0.0023, d_{I}=0.0039$. They use estimates for the total number of returnees to Mexico (excluding deportations) and deportations (of non-criminal Mexicans) averaged over the available period 2001-2005 from Masferrer and Roberts (2009). They consider returns other than deportations to be the "basic" returns of legal immigrants and calculate the return migration rate for legal Mexican migrants as the ratio of returnees to Mexican-born unskilled population in the US. In order to compute the yearly return rate of illegal Mexican immigrants they add to the basic rate the deportation rate of non-criminal Mexicans. More specifically, by applying the same basic return rate to the illegal Mexican population in the US (taken from Passel and Capps, 2004), they calculate the number of illegal Mexicans returning to Mexico each year for reasons other than deportations. They then add the number of deportations per year of non-criminal Mexicans to that number (for the period 2001-2005) and divide by the number of illegal Mexicans in the US to get the return+deportation rate of the illegal Mexicans. Given the limited evidence on these parameters we also conduct robustness checks allowing for higher values for the return rates (see section 6).

We jointly calibrate the remaining 17 parameters of the model $\left(c_{s}, c_{u}, b_{s}, b_{u}, \sigma_{z}\right.$, $\left.\xi, \pi_{s L}, \pi_{u L}, \pi_{I}, \alpha, d_{T}, \lambda, U_{s}^{2}, U_{u}^{2}, x_{T}, x_{E}, x_{I}\right)$ to match as many targets. We target the ratio of employment/population in working age (18 to 65$)$ for workers with some

\footnotetext{
${ }^{16}$ Estimates of unemployment rates in Mexico were taken from OECD (2017), Unemployment rates by education level (indicator). doi: 10.1787/6183d527-en (Accessed on 04 May 2017). Estimates are reported for three education groups: below upper secondary, upper secondary non-tertiary and tertiary. To calculate the unemployment rate of workers with no college education, we take the average unemployment rate of the first two education groups. Estimates for India are from the Ministry of Labour and Employment/Labour Bureau, Fourth Annual Employment and Unemployment Survey Report (201314). Chandigarh: Government of India. Estimates for China are from (n.d.). Unemployment rate in China between 2011 and 2012, by education level. In Statista - The Statistics Portal. Retrieved May 4, 2017, from https://www.statista.com/statistics/304678/china-unemployment-rate-trend-by-educationlevel/. We take the average unemployment rate across workers with Diploma, Graduate degree and workers with a post-graduate degree in India in order to get an estimate of the unemployment rate of skilled workers in India. We then multiply with the skilled working age population in India to get an estimate of the number of unemployed-skilled workers in India. To get an estimate of the number of skilled unemployed in China we take the average unemployment rate of workers that have completed Junior college and those that have a Bachelor's degree and above and multiply it with the skilled working age population in China. As mentioned above, the numbers of skilled working age populations in China and India were taken from Barro and Lee (2015) and are relative to year 2010. We then add up the total number of skilled unemployed in the two countries and divide by the total skilled population in working age in the two countries to get an estimate of the average skilled unemployment rate of the two countries.
} 
college education or more (skilled workers) and for high-school graduates or less (unskilled workers) in the US using ACS data in 2014 and we obtain values equal to $84 \%$ and $67 \%$, respectively. ${ }^{17}$ We target the percent wage premium for US-born workers who have at least some college education. Using 2014 ACS PUMS we find it to be equal to $78 \%{ }^{18}$ We use data from the Job Openings and Labor Turnover Survey (JOLTS) to calculate the vacancy to unemployment ratio in the US (averaged over 2014-2016) and set it to 0.62. We then calculate the wage differences between immigrants legal or illegal and natives by education. We use weekly wages for full time (male) workers from the dataset produced by the Center for Migration Studies (CMS) that includes an indicator for "undocumented" to the basic microdata from the American Community Survey, for year 2014. ${ }^{19}$ The ratio of wage of skilled natives relative to skilled legal immigrants in the US was 0.92 and the ratio of wages of unskilled natives relative to unskilled legal immigrants was $1.173 .{ }^{20}$ The ratio of wages of illegal (unskilled) immigrants to the wages of unskilled natives is set at 0.8. ${ }^{21}$ From the New Immigrant Survey (NIS) which is a survey on immigrants who have obtained their permanent resident status, we calculate the wage at first employment of labor immigrants and of those with family reunification permits. We restrict to employed people in prime age (25-50 years old) males. There are 4 categories of immigrants in the NIS: those who have family reunification permits $55 \%$, those who have employment green card $10 \%$, refugees $10 \%$ and others $25 \%$. If we consider those belonging in the last group "others" as labor immigrants we find the ratio of wages of employment to family immigrants to be 1.6, but if we exclude them and take only employment relative to family the ratio is 2.47 , quite larger. In our benchmark calibration we choose the most conservative wage ratio of 1.6 , but we also show results using the alternative estimate

\footnotetext{
${ }^{17}$ As there are very large flows between employment and non-employment for individuals in working age we match the value of $u$ to non-employment rather than to unemployment.

${ }^{18}$ To measure the wage premium we use weekly wages for adults full time employed and US born individuals, ages 16-65.

${ }^{19}$ See http://data.cmsny.org/about.html for a description of data and methodology.

${ }^{20}$ Notice that in line with our assumptions, skilled natives earn on average less than skilled immigrants, since a portion of skilled immigrants are admitted into the US on employment visas and thus are screened for their skills. A recent study of H1B visa workers by Lofstrom and Hayes (2011) calculates that H1B workers, the largest skilled visa program, earn between 8 and $20 \%$ more than natives confirming the high productivity of this group of workers.

${ }^{21}$ Notice that our targeted wage difference between unskilled natives and immigrants is not far from the immigrant-native wage gap of about $20 \%$ estimated in Borjas and Friedberg (2009) for year 2000, after controlling for observed abilities such as education and age. Several other papers (e.g. LaLonde and Topel 1991) show that immigrants are paid less than natives even after controlling for other observable productivity determinants such as education and language. A negative immigrant premium of about $20 \%$ is also within the range found in the survey by Kerr and Kerr (2011).
} 
of 2.47 in Appendix B (see Table 26). We use Hall and Milgrom's (2008) estimate for the ratio of unemployment to employment income of 0.71 to pin down values for the unemployment incomes; we set $b_{s}=0.71 w_{s}, b_{u}=0.71 w_{u}$ where $w_{s}$ and $w_{u}$ are the average wages of skilled and unskilled workers, respectively.

We set the ratio of immigrants on family unification visas, temporary work permits, permanent employment visas and of illegal immigrants to the US native labor force to $L_{s F}+L_{u F}=0.116, L_{T}=0.0092, L_{E}=0.02$ and $I=0.07$, respectively. To get these numbers we first use the CMS database to calculate the number of all immigrants in working age that are illegal and the number that are legal (year 2014). We then use the estimates of the number of temporary visas in 2013 from Costa and Rosenbaum (2017). ${ }^{22}$ We subtract the number of temporary visas from the total number of legal immigrants in working age to get an estimate of the total number of legal immigrants in working age that are on a permanent visa. We then use the NIS to calculate the share of family unification and employment permits among the permanent legal immigrants.

Based on the fact that the average duration of a temporary skilled worker visa (H1B visa) is 3 years we set $\frac{1}{x_{E}+d_{T}}=36$. Finally, we assume that the value of searching for a job in the US to a legal and permanent immigrant is at least four times the value of searching for a job at home. Specifically we set $U_{s F}=4 U_{s}^{2}$ and $U_{u F}=4 U_{u}^{2}$. This value is similar to the ratio of income per person in the US relative to Mexico, which provides an order of magnitude for the real wage gains expected from migrating form that country. ${ }^{23}$

As discussed above, the values of $J_{E}, J_{s F}$, relative to $J_{s N}$ and of $J_{I}, J_{u F}$ relative to $J_{u N}$ are important in determining the impact of changes in immigration policies on the creation of jobs in country 1 . With our targeted wage differences and remaining parameters as described above, we get $J_{E}=2.69 J_{s F}, J_{s F}=0.98 J_{s N}, J_{I}=1.58 J_{u F}, J_{u F}=2.14 J_{u N}$. This implies that employment immigrants generate significantly larger profits to firms than other skilled immigrants or natives because they are significantly more productive. Although skilled family immigrants accept lower wages than skilled natives firms expect to generate slightly lower profits from hiring them than from hiring their native-born counterparts, because firms anticipate that matches with family immigrants will have lower duration, due to the possibility of them returning to their home country. This implies

\footnotetext{
${ }^{22}$ Report form Economic Policy Institute, available at http://www.epi.org/publication/temporaryforeign-workers-by-the-numbers-new-estimates-by-visa-classification/.

${ }^{23}$ Clemens et al (2019) find that the average migrant to the US increases her real wage by a factor of 3 to 4 .
} 
that in the skilled sector, a shift away from family and towards employment immigration generates a significant increase in the expected surplus to the firm and, in turn, a jobcreating effect on the economy of country 1. In the unskilled sector, on the other hand, both types of immigrants (family and illegal), but especially illegal immigrants, generate significantly larger profits to firms than natives because their wages are lower. This means that a higher share of immigrants generates a significant job-creating effect. It also implies that in the unskilled sector, a policy that replaces illegal immigrants with legal ones is less harmful in terms of job creation compared to a purely restrictive immigration policy that reduces the number of undocumented immigrants.

\section{$5 \quad$ Policy Experiments and Structural Changes}

The rich structure of our model allows us to simulate the labor market implications and effects on immigrant inflows of different immigration policies and structural changes in the host country. We consider direct policies, which impose restrictions on specific entry channels and immigrant groups, such as enforcement of deportations or lower visa approval rates, but also "indirect" policies. The latter do not directly impose restrictions on entry channels, but affect, instead, immigrants' conditions of living in the host country and can reduce immigrant entry by decreasing the migration incentive. The outcomes that we consider specifically in evaluating the policies are first the number and composition of immigrants in equilibrium and second the labor market outcomes of natives, skilled and unskilled.

We consider five direct policies: (i) a decrease (slowdown) in the approval rate of petitions for family visas captured by a decrease in $x_{F}$ (ii) a decrease in the approval rate of petitions for temporary work permits captured by a decrease in $x_{T}$, (iii) a decrease in the approval rate of petitions for permanent employment visas captured by a decrease in $x_{E}$, (iv) an increase in border control captured by a decline in $x_{I}$ and (vi) an increase in the intensity of deportations captured by an increase in $d_{I} \cdot{ }^{24}$ By targeting specific entry channels (while keeping the other entry channels unchanged) we are able to illustrate the effects that different types of immigration policies may have on immigrant composition and the labor market.

\footnotetext{
${ }^{24}$ The decrease/increase in approval rates lead to a decrease/increase in the yearly number of entries, which is the usual variable people have in mind in immigration policies, but is an equilibrium outcome in our approach.
} 
The indirect policies that we consider are: (i) an increase in the search cost of legal immigrants, captured by an increase in both $\pi_{s L}$ and $\pi_{u L}$ (ii) an increase in the search cost of illegal immigrants, captured by an increase in $\pi_{I}$ and (iii) a decrease in all immigrants' value of staying in country 1 . The latter is captured by a certain decrease in the flow value of all immigrants of country 1 , irrespective of their visa status or labor market state, employed or unemployed. It can be viewed as an increase in anti-immigration or xenophobic attitudes which makes immigrants feeling less welcome and lowers their flow utility gain from being immigrants of country 1. The increase in search costs reflects policies that reduce immigrants' access to welfare benefits making their cost of being unemployed larger.

Besides the effects of policies, we also simulate the effects of two structural changes in the host country: (i) an increase in the proportion of skilled (native) labor force, captured by an increase in $S$ and (ii) a skill-biased technological change, captured by an increase in $\alpha$, the parameter measuring the relative intensity of skilled labor in production. Such changes can have differential effects on labor market conditions for different immigrant groups and can therefore influence immigrant entry and composition. We can also use them to compare the model's predictions regarding the migration response to wage changes in the host country to the elasticity of immigration to income at destination found in empirical studies.

\subsection{Direct Policies}

The effects of each of the five direct policies listed above are summarized in Table 2. Columns 1-4 show the impact of decreasing, respectively, the approval rate of family permits $x_{F}$, the approval rate of employment-based admissions $x_{T}$, the rate of transition from a temporary to a permanent employment visa $x_{E}$ and the rate of illegal entry $x_{I}$ (border controls), each by $10 \%$. Column 5 shows the impact of increasing the deportation rate $d_{I}$ by $10 \%$. The entries in the Table represent the percentage effect on immigrant stocks and composition (first 10 rows), natives' unemployment rates (next 2 rows) and wages (last 2 rows).

The decrease in the approval rate of family entries delivers, by far, the largest decrease in legal immigration. A $10 \%$ decrease in the approval rate, causes total family immigration to shrink by about $49 \%$. This is due the strong network dependence of the family route. A small decrease in the number of family entries leads to a substantial decrease 
in immigration opportunities in the long-run steady state, though family linkage effects. Decreasing family entries leads also to a substantial decrease in employment-based immigration $(-48 \%)$, since opportunities for job referrals become scarce. The two legal entry routes (employment and family) are linked strongly by networks. Although smaller in magnitude, the effects of decreasing $x_{E}$ or $x_{T}$ resemble those of decreasing $x_{F}$. All three policies reduce the size of the legal immigrant network, and in equilibrium decrease entry of legal immigrants through both the employment and the family channel.

The three policies restricting the legal entry routes, decrease also the ratio of skilled to unskilled immigrant workers. In the working of our model, reducing the approval rate of family unification admissions, leads to a significant decrease in the ratio of skilled to unskilled immigrant workers $(-41 \%)$ for two reasons. First, a large share of family immigrants are skilled, as skilled individuals have larger incentives to migrate. Second, reducing the family entries leads to a significant decrease in referrals for employment entry and, as a result, in the entry of highly skilled individuals. As opportunities for entry through legal channels become more scarce, more unskilled foreigners enter illegally into country 1. In all three cases, however, we see only a small increase in illegal entries. Even when restricting family admissions, which reduces the unskilled legal immigrant population by $50 \%$, the number of illegal immigrants increases by less than $2 \%$. By lowering the ratio of skilled to unskilled immigrant workers, the tightening of legal entry channels, decreases the value of $p_{u}$. At the same time, the proportion of (family) immigrants, who accept lower wages than natives, in the pool of potential hires for unskilled jobs decreases. Both of these changes lower the profits of unskilled jobs, inducing firms to open fewer vacancies for unskilled workers and offer lower wages to them. Consequently, unskilled foreigners have lower incentive to migrate illegally, since they will have to face lower wages and higher unemployment. Despite the large decrease in legal entries, illegal entries increase, but only slightly.

The policies imposing restrictions on illegal immigration, on the other hand, reduce the illegal and the total immigrant population, as expected, but at the same time, they induce more entries through the legal routes. Such policies increase the ratio of skilled to unskilled immigrants and the marginal product of unskilled labor, $p_{u}$, while lowering the marginal product of skilled labor, $p_{s}$. This raises wages for unskilled workers and encourages unskilled foreign workers to enter though the family channel, which in turn, generates opportunities for also skilled immigrants to enter through family linkages and 
job referrals. The decrease in $p_{s}$ implies also lower wages for skilled workers, meaning lower incentive for skilled foreigners to migrate, but the increased entry opportunities through family ties, dominates over the negative incentive effect and the number of skilled immigrants (employment or family) increases.

Turning to the impact of these policies on natives' labor market outcomes, we see that the policies restricting illegal immigration increase the unemployment rates of both skilled and unskilled native workers, because they induce firms to create fewer jobs (per unemployed worker) in both markets. Key to understanding this negative effect on job creation is their impact on the expected values of new jobs, which is negative and dominates over the relative price effects. Decreasing the number of illegal immigrants, through either border enforcement or deportations, reduces the relative supply of unskilled labor and thus increases $p_{u}$, but also increases the expected labor costs of firms seeking to hire unskilled workers, since illegal immigrants accept lower wages. The second effect dominates leading firms in the unskilled market to open fewer vacancies per unemployed. ${ }^{25}$ This negative job creation effect spills over to the skilled marker through complementarities in production. The decrease in the number of illegal immigrants lowers $p_{s}$. This hurts the profit of skilled jobs and lowers job creation for skilled workers as well.

This depressing effect on labor markets produced by a decline of undocumented (via deportation or tightening of the border) was already pointed out in Chassamboulli and Peri (2015). The large surplus that a match with an undocumented provides to employers, drives a strong job creation effect, and their decline reduces labor market tightness. Consistent with this result are also the findings of Lee, Peri and Yasenov (2017), who find negative employment effects on incumbent native workers from an episode of large deportation of Mexicans in the 1929-1934 period. We see here, in addition, that the endogenous responses of immigrant entries through other (legal) channels are not sufficient to overcome this effect. The increased entry of unskilled family immigrants does not offset the negative effect of fewer illegal immigrants on the expected surplus of unskilled jobs. Similarly, the increased entry of employment immigrants is not enough to overturn the negative effect of a lower $p_{s}$ on incentives to create skilled jobs.

Tightening the entry of skilled employment immigrants increases the value of $p_{s}$, on the one hand, because it lowers the relative supply of skilled labor. On the other hand, however, it lowers the expected productivity of skilled jobs, because employment immi-

\footnotetext{
${ }^{25}$ The effects seem to be similar when the decrease in illegal immigration is achieved through increased deportations (increase in $d_{I}$ ) or stronger border enforcement (decrease in $x_{I}$ ).
} 
grants, selected for high skilled jobs, are more productive than native workers. Using the calibrated parameters, the second effect dominates leading to lower job posting by employers and a higher unemployment rate for skilled natives. ${ }^{26}$ The decrease in the number of employment immigrants, lowers job creation (and wages) for unskilled workers as well by lowering $p_{u}$ and reducing incentives for unskilled foreigners to enter. But, as discussed above, network effects are also at work in this case: with fewer employment immigrants there are also fewer entries through family ties. Hence the proportion of immigrants in the pool of potential hires for unskilled jobs decreases, which also hurts the profits from creating unskilled jobs, adding to the decrease in job creation for unskilled workers due to the decrease in $p_{u}$.

As in the case of decreasing employment-based admissions, the decrease in familybased admissions hurts firms in the unskilled sector and induces them to open fewer vacancies for unskilled workers for two reasons. First, with fewer family immigrants, whose wages are lower, firms expect to pay higher wages on average and second, the price of the unskilled labor input, $p_{u}$, decreases as the relative supply of skilled labor decreases. However, compared to the policies targeting employment immigrants, the effects of this policy on job creation in the skilled sector are more positive, because skilled family immigrants and natives generate almost identical surplus to firms. Our calibration gives $J_{s F}=0.98 J_{s N}$, meaning that firms are almost indifferent between the two. Thus, a smaller share of family immigrants in the skilled sector does not hurt incentives to create jobs. Given, in addition, that this policy generates a large decrease in the ratio of skilled to unskilled natives, and thus a large increase in $p_{s}$, one would expect the unemployment rate of skilled natives to fall significantly, as firms react to the increased price by creating more jobs. Nevertheless, the unemployment rate of skilled natives decreases only moderately. This occurs because the decrease in the number of employment immigrants, who are indirectly affected through a lower number of referrals on the job, partially offsets the positive price effect on incentives to create skilled jobs.

The impact of each policy on wages of natives, shown in the last two rows, follows that on prices $\left(p_{s}\right.$ and $\left.p_{u}\right)$. In all cases, one of the two types of workers benefits in terms of wages, while the other is hurt. Decreasing illegal migration increases the wage of

\footnotetext{
${ }^{26}$ In our model having a temporary work permit is the necessary first step to obtaining a permanent employment visa. Hence, a decrease in the number of immigrants on temporary work permits implies, in steady state, an equal percentage decrease in the number of immigrants on permanent employment visas (see equation 20). Thus, the effects of a decreasing $x_{T}$ are similar to those of a decreasing $x_{E}$.
} 
unskilled and reduces that of skilled natives, because the relative supply of skilled labor increases. All other policies, which reduce the size of legal immigrant population, lead to a decrease in the supply of skilled labor. In those cases, the wages of skilled workers increase while those of unskilled workers decrease. In Table 15 in Appendix B, we show that the negative job creation effect dominates and in all of there cases, net native income decreases in response to these direct immigration policies.

Two general features are worth noting in the simulated results. First, the overall takeaway from these policy experiments is that given the productivity of high skilled immigrants, the surplus generated by low skilled immigrants and linkages generated by incentive effects, all types of restrictive policies have a negative job creation effect. Second, looking at the impact of policies across all channels, we see that there is a "complementarity" in legal channels of entry. A restrictive policy in one of them reduces entry in the others. This is mainly due to the linkages generated by networks and magnifies the depressive effect of each restrictive policy. On the other hand there is independence between legal and illegal immigration: affecting one of the two channels changes only moderately, mainly through a labor market feedback, which is rather weak, the inflow of immigrants through the other channels. ${ }^{27}$ These also suggest that combinations of policies that restrict one entry route and relax another thus changing the composition of immigrants but keeping their number constant are more stimulating of the labor market for natives, especially when they increase the component of employment immigrants. In Appendix B (Table 17) we present results for five such policy experiments.

\subsection{Indirect Policies}

Table 3 shows the effects of the three indirect policies listed above and follows the structure of Table 2. Columns 1 and 2 show the effects of increasing the search cost of illegal and legal immigrants, respectively. Higher search costs imply lower value not only while unemployed but also while employed for immigrants, since with higher search cost, their outside option is lower, which forces them to accept lower wages. Thus higher search costs reduce the migration benefit and this is more important for illegal immigrants whose migration benefits are smaller (due to lower wages and the risk of deportation). A $10 \%$

\footnotetext{
${ }^{27}$ As shown in the Appendix B (see Table 16) overlooking network linkages and incentive effects by assuming that changes in the number of one type of immigrants leaves the numbers of other types of immigrants intact, underestimates the negative job creation impact especially of restrictive policies on legal immigration.
} 
increase in the search cost of illegal immigrants decreases their number by about $6 \%$, while a $10 \%$ increase in the search cost of legal immigrants decreases the legal population by only $0.5 \%$. The effects of increasing the search cost of illegal immigrants on immigrant flows is similar those of increasing their deportations or imposing tighter border controls.

One notable difference, however, between this policy and the direct policies considered above, is that with higher search costs firms can pay lower wages to illegal immigrants, with a positive impact on incentives to create unskilled jobs. This positive effect fully offsets the depressing effect of having fewer illegal immigrants in their pool of potential hires. In contrast to increasing deportations or tightening border controls, increasing the search costs of illegal immigrants increases job creation in the unskilled market and decreases the unemployment rate of unskilled native workers. It also implies a smaller negative effects on the price of the skilled labor input, since the two labor inputs are compliments in production, and therefore a smaller increase in the unemployment rate of skilled natives.

Similarly, the job creation effects of reducing legal immigration through higher search costs (shown in column 2) are more positive compared to those of policies that directly restrict legal entries. In this case, the unemployment rates of both types of native workers decrease, as job creation increases in both markets, and this occurs for three reasons. First, as mentioned above, higher search costs induce legal immigrants, skilled or unskilled, to accept lower wages with a positive impact on incentives to create jobs in both markets. Second, relative to policies that restrict entry through the employment channel, this policy, by affecting both types of skilled immigrants (employment and family), implies smaller changes in their composition, and thus smaller negative effects on the profits of skilled jobs. Third, by reducing the benefit of entering legally, it makes an illegal entry opportunity relatively more attractive to unskilled foreigners, and increases illegal immigration be relatively more, which benefits unskilled firms.

In column 3 the effects of reducing immigrants' utility flow value from residing in country 1 are shown. We consider a decrease in the flow value of all immigrants which is equal to $5 \%$ of the wage of an unskilled family immigrant (about $6 \%$ of the wage of an illegal immigrant and $2.5 \%$ of the wage of a skilled family immigrant). Although it targets all types of immigrants, it has a relatively large negative impact on entry incentives of illegal foreigners whose migration benefit is relatively small. In addition, since this policy reduces the flow value of immigrants irrespective of their labor market status (employed 
or unemployed), it does not affect directly an immigrant's bargaining position or wage. Hence, the effects of this policy on natives' labor market outcomes are similar to those of direct policies restricting illegal immigration such as border enforcement. The relative supply of skilled labor increases, unskilled workers benefit in terms of wages while skilled workers are hurt, but the unemployment rates of both types of workers increase.

\subsection{Comparing Effects Across Policies}

The simulations that we perform in this subsection consist in using each of the policy instruments to reduce either legal or illegal immigrants by a certain percentage (we simulate reductions between $2 \%$ and 10\%). In Figure 1 we consider policies that target a certain percentage decrease in the number of legal immigrants. We consider the effects of decreasing approval rates for family visas, temporary employment visas, and permanent employment visas (decreasing $x_{F}, x_{T}$ and $x_{E}$, respectively) and the effects of higher search costs for legal immigrants (increasing $\pi_{s L}$ and $\pi_{u L}$ ). In Figure 2 we consider policies targeting decreases in illegal immigration. We consider the effects of stronger border enforcement and deportations (decreasing $x_{I}$ and increasing $d_{I}$ ) and the impact of imposing higher search costs for illegal immigrants (increasing $\pi_{I}$ ). Each figure is made of twelve panels, each showing the impact of the policies on one endogenous variable at a time. Four of them show the impact on the number of immigrants of each type (skilled-family, employment, unskilled-family and undocumented immigrants). Three panels show that impact of policies on the composition of immigrants: the proportion of skilled immigrants that are on employment visas, the proportion of unskilled immigrants that are undocumented and the proportion of immigrants that are skilled. Four panels show the effects of policies on wage and unemployment rates of skilled and unskilled natives. The last panel shows the impact on net income to natives (our measure of net income is specified in Appendix B.1). In each panel the horizontal axis shows the percentage decrease in the number of immigrants (legal or illegal). The vertical axis shows the effect on the outcome variable as percentage of its initial value. Besides summarizing the key main effects described above, the figures allow us to compare easily the effects of different policies that deliver a certain percentage reduction of legal or illegal immigrants.

One feature that stands out in the figures is that the different policies used to reduce legal immigration by a certain percent have very different labor market effects. Those focused on employment immigration have the largest negative labor market effect, because 
they reduce drastically the proportion of immigrants on employment visas. Given the higher productivity of employment immigrants, this implies strong negative effects on job creation in the skilled market and through complementarities also strong negative job creation effects in the unskilled market. These policies deliver the largest percentage increase in the unemployment rates of both types of native workers. The policy restricting family unification entries comes next. This policy has a smaller negative impact on job creation in the skilled market, because it keeps the proportion of skilled immigrants on employment visas almost intact. It lowers the unemployment rate of skilled natives, and generates a somewhat smaller increase in the unemployment rate of unskilled natives. Lastly, reducing legal immigration through higher search costs has the most positive labor market effect on both types of native workers. This policy decreases the unemployment rate of both types of native workers, not only because it forces legal immigrants to accept lower wages, but also because it keeps the proportion of skilled immigrants on employment visas almost intact. In addition, it increases the entry of undocumented immigrants by more than the other three policies, implying a larger offseting increase in the profits of unskilled jobs.

On the other hand, as shown in Figure 2, the two policies that directly restrict illegal immigration, border controls and deportations, have very similar effects on the composition of immigrants and labor market. Increasing deportations of illegal immigrants hurts unskilled jobs, by decreasing their expected duration, with negative effects on incentives to create such jobs. However, this effect is small, since both policies have almost identical labor market effects. The only policy that lowers the unemployment rate of unskilled natives is the increase in the search costs of illegal immigrants. As discussed above, this policy raises the profits of unskilled jobs by lowering the wages of illegal immigrants, implying also, due to complimentarities in production, smaller negative effects on the creation of jobs for skilled workers.

\subsection{The Effects of Structural Changes}

Finally in Table 4, we show our model prediction on how the two structural changes mentioned above affect immigration. Column 1 summarizes the effects of a $5 \%$ increase in the proportion of skilled native workers $(S)$ and column 2 the effects of a skill-biased technological change captured by a $5 \%$ increase in $\alpha$.

What these changes deliver is effectively a change in the relative productivity of the two 
labor inputs. The increase in $\alpha$ increases $p_{s}$ and decreases $p_{u}$, implying better employment opportunities and wages for skilled workers and worse for unskilled workers. This, in turn, implies more incentive for skilled and less incentive for unskilled foreigners to enter. The increase in $S$ has the opposite effect: it lowers $p_{s} /$ increases $p_{u}$ and decreases incentives for skilled foreigners to enter, while it encourages the migration of unskilled foreigners. But the increased share of natives in the skilled labor force affects also the expected surplus of skilled jobs. It means that firms are less likely to match with an employment immigrant, which reduces incentives to create skilled jobs further, and discourages more the migration of skilled foreigners. The endogenous responses in immigrant flows generate offsetting changes in the skill composition of the labor force that help slow down the relative price effects of these structural changes, but influence also the expected surplus of new jobs.

The structure of the US immigration system is such that most of the offsetting changes in the skill composition of immigrants occur through changes in illegal entries. This is because entries of immigrants through the legal channels depend on network-generated entry opportunities and thus respond less to changes in the migration benefit. The increase in $S$ reduces incentives for skilled immigrants to enter through both the employment and the family channel, but this, in turn, implies also fewer opportunities for unskilled immigrants to enter through family linkages. Despite stronger migration incentives for the latter, their inflow decreases as the legal network shrinks, reinforcing incentives for unskilled workers to enter illegally. Likewise, the increase in $\alpha$ increases the inflow of skilled immigrants, but also generates opportunities for unskilled family immigrants to enter. As a result, the inflow of unskilled family immigrants increases, despite their lower migration incentive, which then implies a larger decrease in the number of illegal immigrants. Larger responses in illegal entry tend to amplify the positive, and negative, respectively, job creation effect of these structural changes on unskilled native workers. As the proportion of illegal immigrants in the unskilled population increases, the profits of unskilled jobs increase, adding to the positive job creation effect of a higher price $p_{u}$ due to the increase in $S$. Similarly, as the entry of illegal immigrants decreases, the effects of the skill biased technological change become more negative on unskilled native workers.

The last two rows of the table show the percentage change in skilled and unskilled immigration relative to the percentage change in the average wage of skilled and unskilled workers, respectively. We can use these elasticities to compare the model predictions regarding the responsiveness of immigrant flows to changes in host-country conditions 
to those found in empirical studies. The most comparable numbers, as estimated on panel and in a log-log specifications are from Ortega and Peri (2012). They find the elasticity of international immigrant flows to changes in per capital income at destination to be between 0.5 and 1 , and of flows between EU countries to be around 2. We find comparable numbers for the elasticities with respect to wages; they are in the range of $0.5-1$, consistent with these estimates.

\section{Robustness Checks}

In spite of our effort locating the most appropriate data for the parameterization, often there is a range of uncertainty about some of the statistics and parameter values. For some important parameters, therefore, we show the simulated effects of policies in a reasonable range, based on the empirical literature. These checks are performed in Tables 5-14 that reproduce the simulations of Tables $2-4$, with each table devoted to one specific policy or structural change. All tables follow the same structure. In the first column we show results in the baseline (benchmark) case. In the rest of the columns we show robustness checks on five parameters. For other parameters that are less relevant we perform robustness checks in the Appendix B (see Tables 18-24, which mirror the structure of Tables 5-14).

A first key parameter is $\lambda$, which measures the productivity gap between employmentbased immigrants, skilled immigrants on family visas and skilled natives. The significant job-creation effect from employment immigrants derives from their higher productivity which is reflected in their higher wages. In order to check the robustness of our main results, in columns (2) and (3) in Tables 5-14 we decrease $\lambda$ so that the productivity of employment immigrants is $10 \%$ and $20 \%$ lower relative to the value we used in our baseline parameterization. The wage ratio between employment and skilled family immigrants drops from 1.55 in our baseline case to 1.41 and 1.26 , respectively.

The return rate of immigrants is an important determinant of their value to a firm and of their job-creating effect. In column (4) we increase the return rate of illegal immigrants, $d_{I}$, while in column (5) we check that our results are robust to a higher exogenous "natural" return rate of legal immigrants, $d_{L}$. In both cases, we re calibrate the model and adjust the values of $\pi_{s L}, \pi_{u L}$ and $\pi_{I}$ so that we keep matching our baseline targeted wage differences (given in Table 1). By increasing $d_{L}$ we essentially decrease the values of $\pi_{s L}$ and $\pi_{u L}$ that match our targeted wage differences, i.e., we decrease the search costs of legal immigrants and make firms' value from hiring them smaller. Likewise, by 
increasing $d_{I}$ we reduce firms' value from hiring illegal immigrants, by increasing their match break up probability and lowering their search cost $\pi_{I}$.

For the results discussed above we standardise the mean of log normal values of the distribution of immigration costs to 0 . This parameter may be important for how immigrant flows respond to changes in the host country conditions. In columns (6) and (7) we increase the mean to 0.5 and 1.

The degree of skilled-unskilled complementarity in production is also important in determining how the immigration-induced changes in the skill-mix of labor force translate into the change in their marginal productivity $p_{u}$ and $p_{s}$. In columns (8)-(10) we change $\sigma$, the parameter that governs the elasticity of substitution between the skilled and unskilled labor inputs. We keep all other targets and parameter vales the same. We consider $\sigma=-0.5$ and $\sigma=0$, which are lower than our benchmark value of $\sigma=0.5$, implying stronger complementarity between the two labor inputs and $\sigma=1$ which means that the two labor inputs are perfect substitutes.

Let us first discuss the effect of a lower productivity for employment immigrants. Confirming our previous conclusion that fewer family admissions benefit incentives to create skilled jobs mainly by decreasing the relative supply of skills and increasing the price of the skilled input we see that decreasing the productivity of employment immigrants (columns 2 and 3) actually strengthens this effect. When employment immigrants are less productive their reduced presence, due to fewer referrals from skilled family immigrants, is less negative on the profits of skilled jobs. We therefore see a larger decrease in the unemployment rate of skilled natives, while the effects on all other market variables and immigrant entry and composition remain almost intact. As expected, the policies restricting employment immigration (Tables 6 and 7), have less negative employment effects, especially on skilled workers, when the productivity of employment immigrants is smaller. The impact of such policies on the unemployment rate of skilled workers turns negative when their productivity of employment immigrants is reduced by $20 \%$. It remains, however, small, while effects on all other market variables and immigrant entry remain robust to this change. The effects of increasing the search costs of legal immigrants (Table 11) are also robust to changes in the productivity of employment immigrants, since this policy affects both types of legal immigrants and keeps their composition almost unchanged. Likewise, the effects of policies reducing illegal immigration (see Tables 8-9 and 10) are not sensitive to changes in the productivity of employment immigrants, since such policies affect little 
the inflow of legal immigrants.

The effects of all policies are also not sensitive to increasing the return rates of either illegal or legal immigrants (column 4 and 5) or to increasing the mean of the distribution of immigration costs. ${ }^{28}$ Moreover, the results for the two structural changes are very similar across the different values of these parameters and the elasticities of immigrant flows with respect to wages remain within the range of available empirical estimates $(0.7-1)$ when the mean of the distribution increases.

Changes in the elasticity of substitution (columns 8-10), on the other hand, alter mainly the distributional effects of policies. ${ }^{29}$ As the degree of skilled-unskilled complementarity decreases ( $\sigma$ increases) the impact of policies that tend to increase (decrease) the relative supply of skilled labor, such as decreasing $x_{I}$ (such as decreasing $x_{F}, x_{T}$ or $\left.x_{E}\right)$ becomes more positive (negative) on skilled workers and more negative (positive) on unskilled workers. This occurs because as the degree of complementarity decreases the effects of changes in relative supply of skills on the marginal products of the two labor types diminish. When $\sigma=1$ and the two labor inputs are perfects substitutes, then their prices are constant and not affected by changes in the relative supply of skills. All effects in this case work through the impact of policies on the composition of immigrants and in turn the expected values of jobs, in line with our previous conclusions that these effects, which are mostly negative, often dominate over the relative price effects.

Finally, it is not surprising that the effects of increasing the proportion of natives that are skilled on immigrant entry and composition fade away as the degree of complementarity decreases. The less compliments the two labor inputs are the smaller the impact of changes in the relative supply of skills on the relative prices of the two inputs. In the extreme case, where the two inputs are perfects substitutes $(\sigma=1)$ prices are constant and all effects on immigrant entry work through the impact of more skilled natives on the expected values of new jobs. But our main conclusion regarding the responses in immigrant flows and the role of network effects remain robust.

\footnotetext{
${ }^{28}$ The return probability of legal immigrants seems to be a bit more important for the effects of indirect policies that work through decreasing the migration incentive, such as anti-immigration attitudes (Table 12). A higher return probability acts as an increase in the rate at which immigrants discount the migration benefit. If the probability of return is large the migration benefit is less sensitive to such policies, meaning that their impact on inflows of legal immigrants reflects more the effect of networks.

${ }^{29}$ Changes in the elasticity of substitution do not alter the impact of policies on net income.
} 


\section{Conclusions}

In this paper we develop a two-country search and matching model that represents the US and the rest of the World, and we model in detail each of the three channels of immigrant entry to the US: Family reunification, Employment and Illegal. Immigration policies together with the effectiveness of their enforcement, the incentives of immigrants and the networks size, determine the observed number of immigrants and their composition in terms of skills and productivity. Most existing models analyzing the impact of immigration have typically treated immigration as an exogenous policy variable, and have neglected the analysis of incentives and network effects. We include these effects in our analysis and we evaluate how immigration policies affect long-run immigration and native labor markets.

We use the model to evaluate the labor market effects of some realistic policy proposals, that mirror existing bills that have been discussed in the Senate and the House in the recent past. For instance the plan to reduce by $50 \%$ the family reunification is similar to the RAISE act which has been proposed in the Senate in 2017. Also a drastic increase in deportation rates, in order to reduce (by 10 or 50\%) the population of undocumented immigrants is an explicit goal of the current presidential administration. We simulate the effects of these policies. The model also allow us to analyze how immigration flows respond to important structural changes taking places in the US such as skill biased technological change and the change in supply of local skills (due to changes in educational attainments). The real novelty of our model is that our simulations account for what happens in equilibrium to the inflow of various groups of immigrants, to incentives to migrate and to native unemployment and wages accounting for all these general equilibrium effects.

Our model allows insights into the effect of different policies that would not be possible in a model based on classical labor demand and supply and on the idea that policy controls the total number of immigrants. First, we show that undocumented and unskilled family immigrants encourage job creation and may have positive employment effects on natives due to their low wages. Highly skilled employment immigrants, on the other hand, receive higher wages, but as their productivity per unit of wage is higher than that of natives they generates a significant job creating effect. Given these effect, we show that a decrease in the inflow of immigrants from any entry route has a depressing effect on the labor market for both skilled and unskilled natives. 
Then we show that the two channels of legal entry, family unification and employment, are connected. Family reunification increases opportunities for equilibrium employment immigration via networks/referrals and vice-versa. The family reunification channels amplifies the negative effects of a decrease in employment immigrants, as fewer employment immigrants generate fewer opportunities for new immigrant entries through family ties. Likewise, to a large extent the negative effects of decreasing family-based admissions come from the consequent decrease in employment immigration. For this reason, a policy combination that reduces entry through one channel but facilitates entry through the other helps attenuate the negative effects and may have positive effects on job creation and net income of natives.

These are only few of the policy experiments that one can perform using the model. We hope that future research will follow, extending and applying the model to evaluate the economic effects of a large array of possible immigration policies. 
Table 1: Parameterization and matched moments

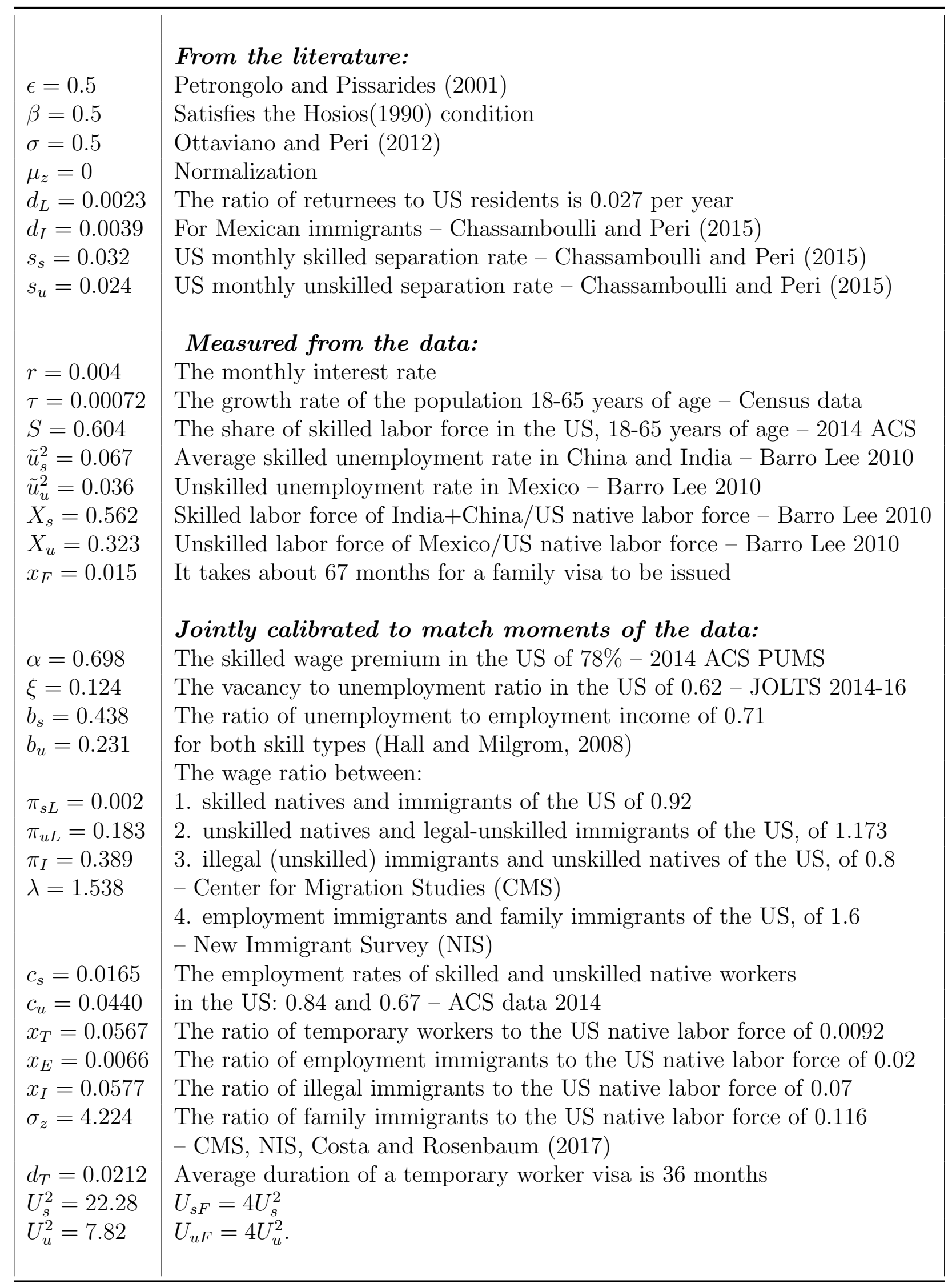


Table 2: Direct Policies

\begin{tabular}{|l|c|c|c|c|c|}
\hline & $\downarrow$ in $x_{F}$ & $\downarrow$ in $x_{T}$ & $\downarrow$ in $x_{E}$ & $\downarrow$ in $x_{I}$ & $\uparrow$ in $d_{I}$ \\
\hline Immigrants: & & & & & \\
$L_{F s}$ & -47.95 & -5.46 & -3.74 & 1.62 & 1.39 \\
$L_{F u}$ & -51.84 & -6.96 & -5.04 & 4.17 & 3.59 \\
$L_{E}$ & -47.88 & -16.87 & -13.19 & 1.54 & 1.32 \\
$L_{T}$ & -47.88 & -16.87 & -3.54 & 1.54 & 1.32 \\
$I$ & 1.97 & 0.16 & 0.16 & -8.10 & -6.98 \\
& & & & & \\
Total family & -48.76 & -5.77 & -4.01 & 2.15 & 1.85 \\
Total employment & -47.88 & -16.87 & -10.15 & 1.54 & 1.32 \\
Total legal & -48.58 & -8.10 & -5.30 & 2.02 & 1.74 \\
Total & -31.66 & -5.34 & -3.47 & -1.37 & -1.18 \\
Skilled/Unskilled & -41.32 & -6.84 & -4.28 & 7.03 & 6.02 \\
& & & & & \\
Unempl. Rates: & & & & & \\
$\tilde{u}_{s N}$ & -0.20 & 0.10 & 0.12 & 0.22 & 0.20 \\
$\tilde{u}_{u N}$ & 2.24 & 0.45 & 0.27 & 0.33 & 0.29 \\
Wages: & & & & & \\
$w_{s N}$ & & & & & \\
$w_{u N}$ & 0.63 & 0.13 & 0.07 & -0.15 & -0.14 \\
\hline
\end{tabular}

The entries in the Table represent the percentage effects of five restrictive immigration policies on immigrant stocks and composition (first 10 rows), natives' unemployment rates (next 2 rows) and natives' wages (last 2 rows). Column 1 shows the effects of a $10 \%$ decrease in the approval rate of petitions for family visas. Column 2 a $10 \%$ decrease in the approval rate of petitions for temporary work permits. Column 3 a $10 \%$ decrease in the approval rate of petitions for permanent employment visas. Column 4 an increase in border control captured by a $10 \%$ decrease in the rate at which illegal immigration opportunities occur, and Column 5 a $10 \%$ increase in the rate of deportations of illegal immigrants. 
Table 3: Indirect Policies

\begin{tabular}{|l|c|c|c|}
\hline & $\uparrow$ in $\pi_{I}$ & $\uparrow$ in $\pi_{L s}, \pi_{L u}$ & $\downarrow$ in flow value \\
\hline Immigrants: & & & \\
$L_{F s}$ & 1.20 & -0.41 & -0.75 \\
$L_{F u}$ & 3.05 & -1.02 & -0.43 \\
$L_{E}$ & 1.18 & -0.40 & -1.10 \\
$L_{T}$ & 1.18 & -0.40 & -1.10 \\
$I$ & -5.70 & 0.12 & -3.83 \\
& & & \\
Total family & 1.59 & -0.53 & -0.69 \\
Total employment & 1.18 & -0.40 & -1.10 \\
Total legal & 1.50 & -0.51 & -0.77 \\
Total & -0.91 & -0.30 & -1.80 \\
Skilled/Unskilled & 4.92 & -0.25 & 2.22 \\
Unempl. Rates: & & & \\
$\tilde{u}_{s N}$ & 0.07 & -0.02 & 0.11 \\
$\tilde{u}_{u N}$ & -0.76 & -0.15 & 0.23 \\
Wages: & & & \\
$w_{s N}$ & -0.05 & 0.01 & -0.06 \\
$w_{u N}$ & 0.21 & -0.02 & 0.13 \\
& & & \\
\hline
\end{tabular}

The entries in the Table represent the percentage effects of three indirect immigration policies on immigrant stocks and composition (first 10 rows), natives' unemployment rates (next 2 rows) and natives' wages (last 2 rows). Column 1 shows a $10 \%$ increase in the search cost of illegal immigrants. Column 2 a $10 \%$ increase in the search cost of legal immigrants and Column 3 a decrease in all immigrants' flow value of staying in the host country (country 1), which is equal to $5 \%$ of the wage of an unskilled family immigrant. 

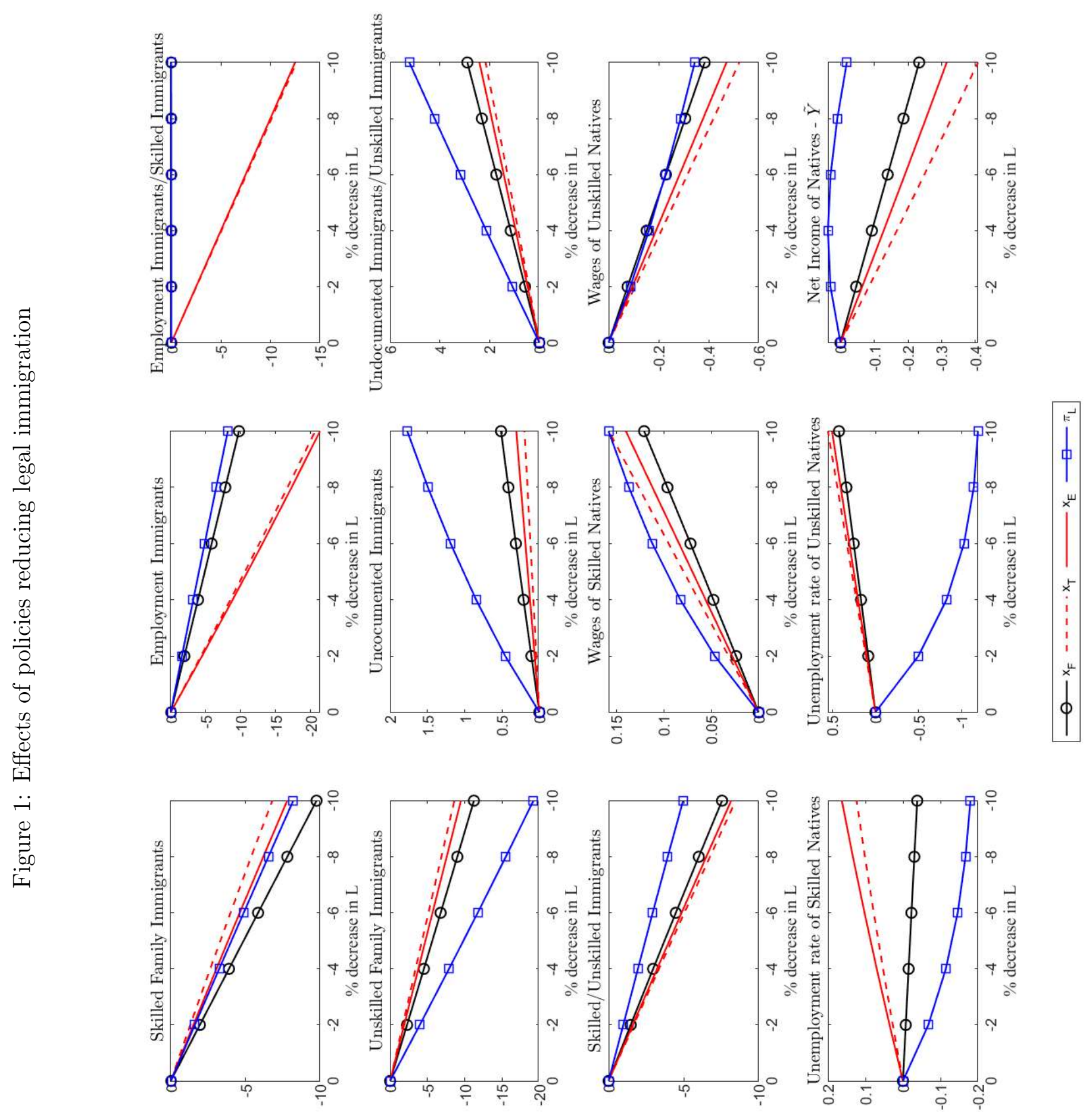

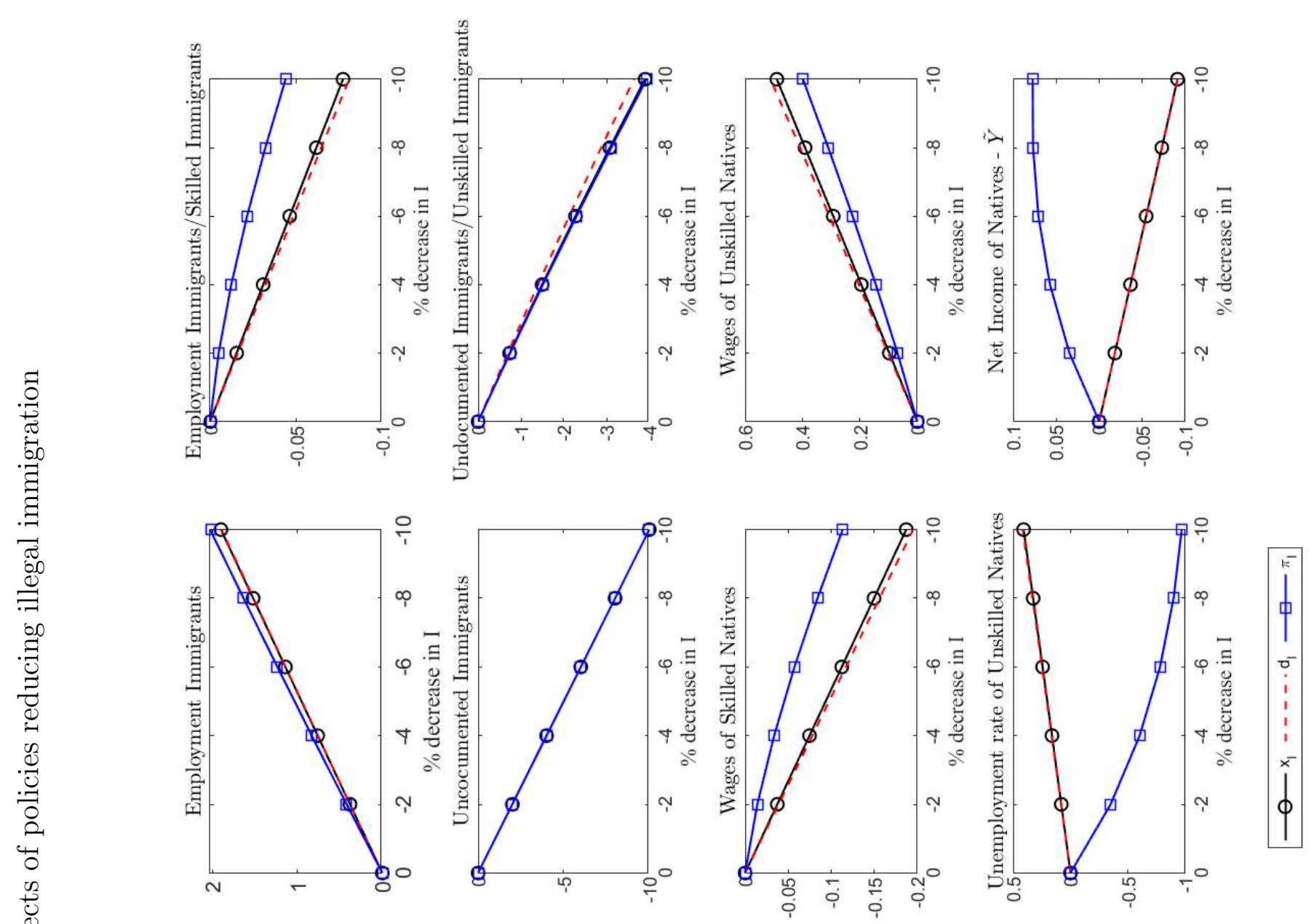

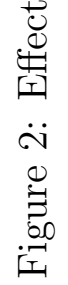
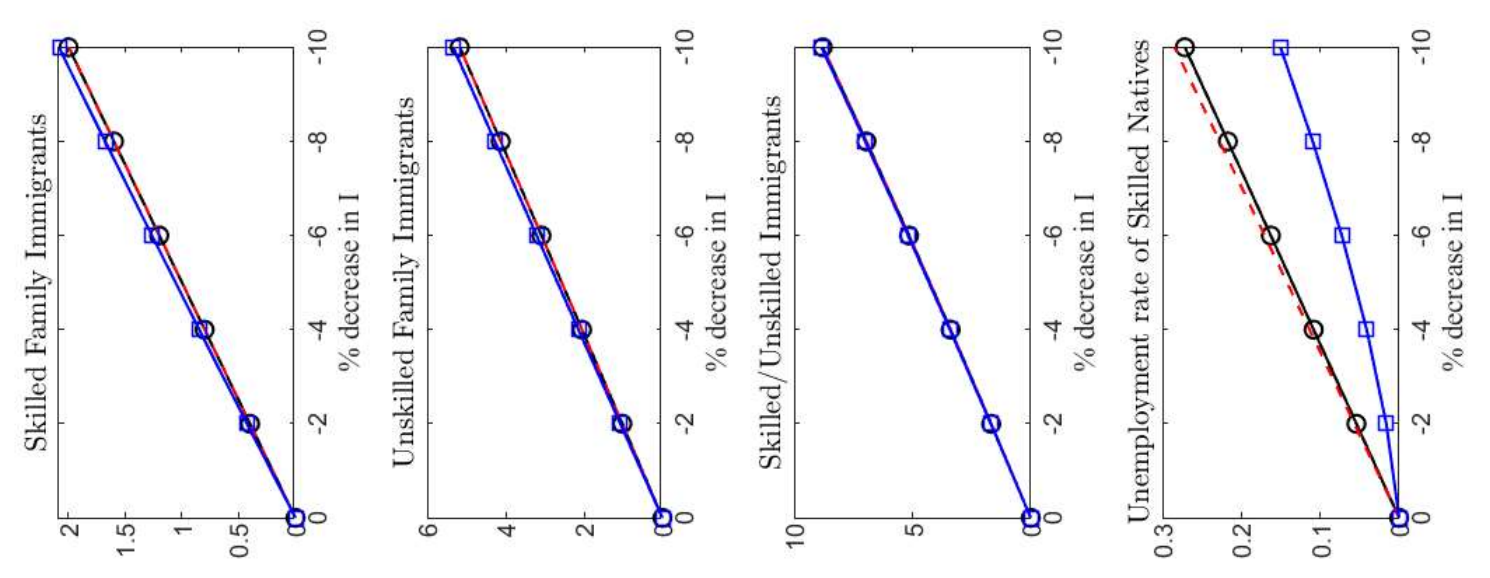
Table 4: Structural Changes

\begin{tabular}{|l|c|c|}
\hline & $\uparrow$ in $S$ & $\uparrow$ in $\alpha$ \\
\hline Immigrants: & & \\
$L_{F s}$ & -0.59 & 3.53 \\
$L_{F u}$ & -0.81 & 5.46 \\
$L_{E}$ & -1.10 & 6.11 \\
$L_{T}$ & -1.10 & 6.11 \\
$I$ & 2.36 & -10.30 \\
& & \\
Total family & -0.64 & 3.93 \\
Total employment & -1.10 & 6.11 \\
Total legal & -0.74 & 4.39 \\
Total & 0.30 & -0.53 \\
Skilled/Unskilled & -2.26 & 11.33 \\
& & \\
Unempl. Rates: & & \\
$\tilde{u}_{s N}$ & 1.56 & -7.30 \\
$\tilde{u}_{u N}$ & -3.44 & 8.28 \\
Wages: & & \\
$w_{s N}$ & & \\
$w_{u N}$ & -0.89 & 5.06 \\
Elasticity of Migrant Flows: & & \\
Skilled & 0.79 & 0.82 \\
Unskilled & 0.59 & 0.88 \\
& & \\
\hline
\end{tabular}

The Table summarizes the simulated effects of two structural changes in the host country (country 1). Column 1 summarizes the effects of a $5 \%$ increase in the proportion of skilled native workers $(S)$ and column 2 the effects of a skill-biased technological change captured by a $5 \%$ increase in $\alpha$. The entries in the Table represent the percentage effects on immigrant stocks and composition (first 10 rows), natives' unemployment rates (next 2 rows) and natives' wages (next 2 rows). The last two rows of the table show the percentage change in the number of skilled and unskilled immigrants relative to the percentage change in the average wage of skilled and unskilled workers, respectively, in the host country. 


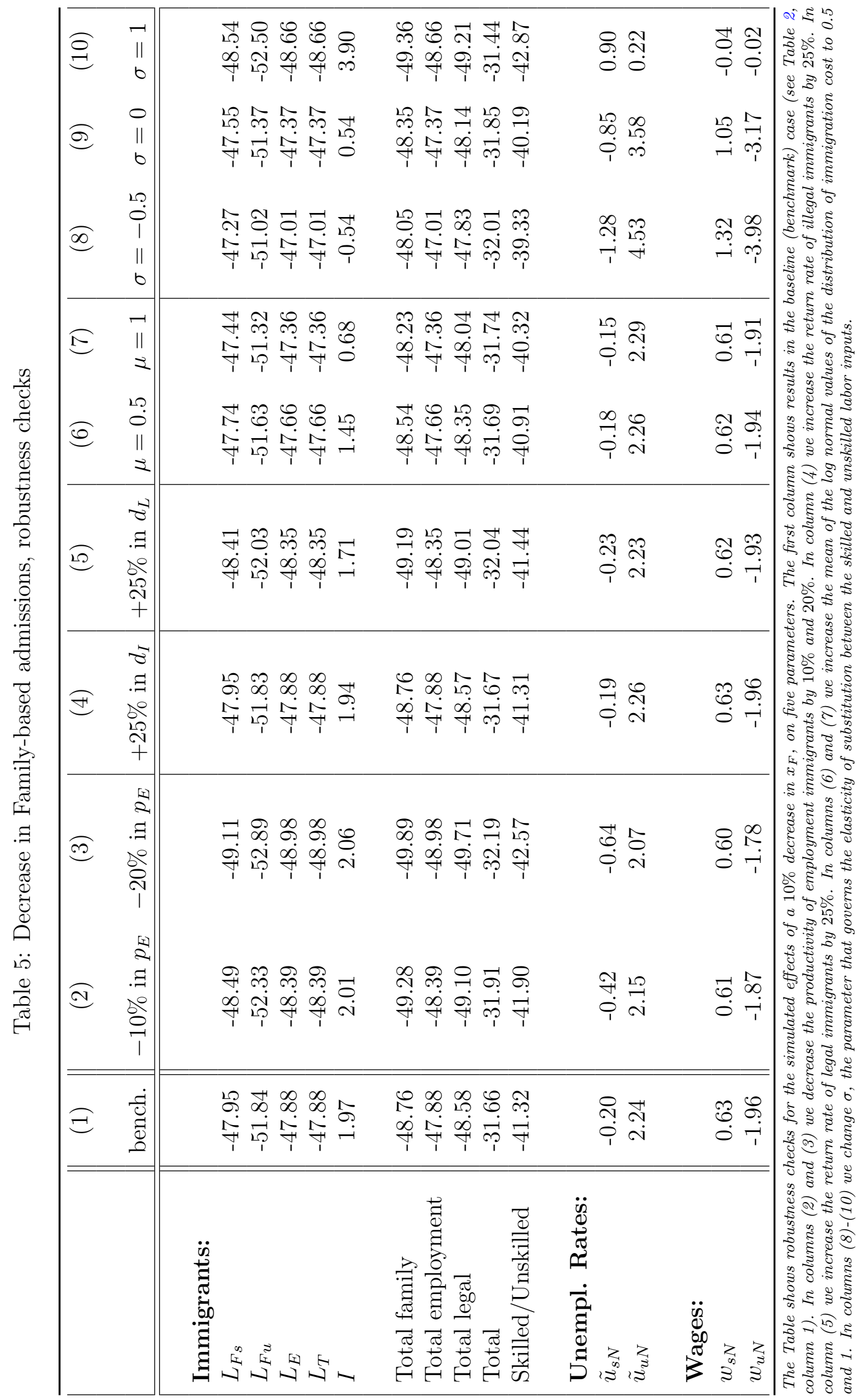




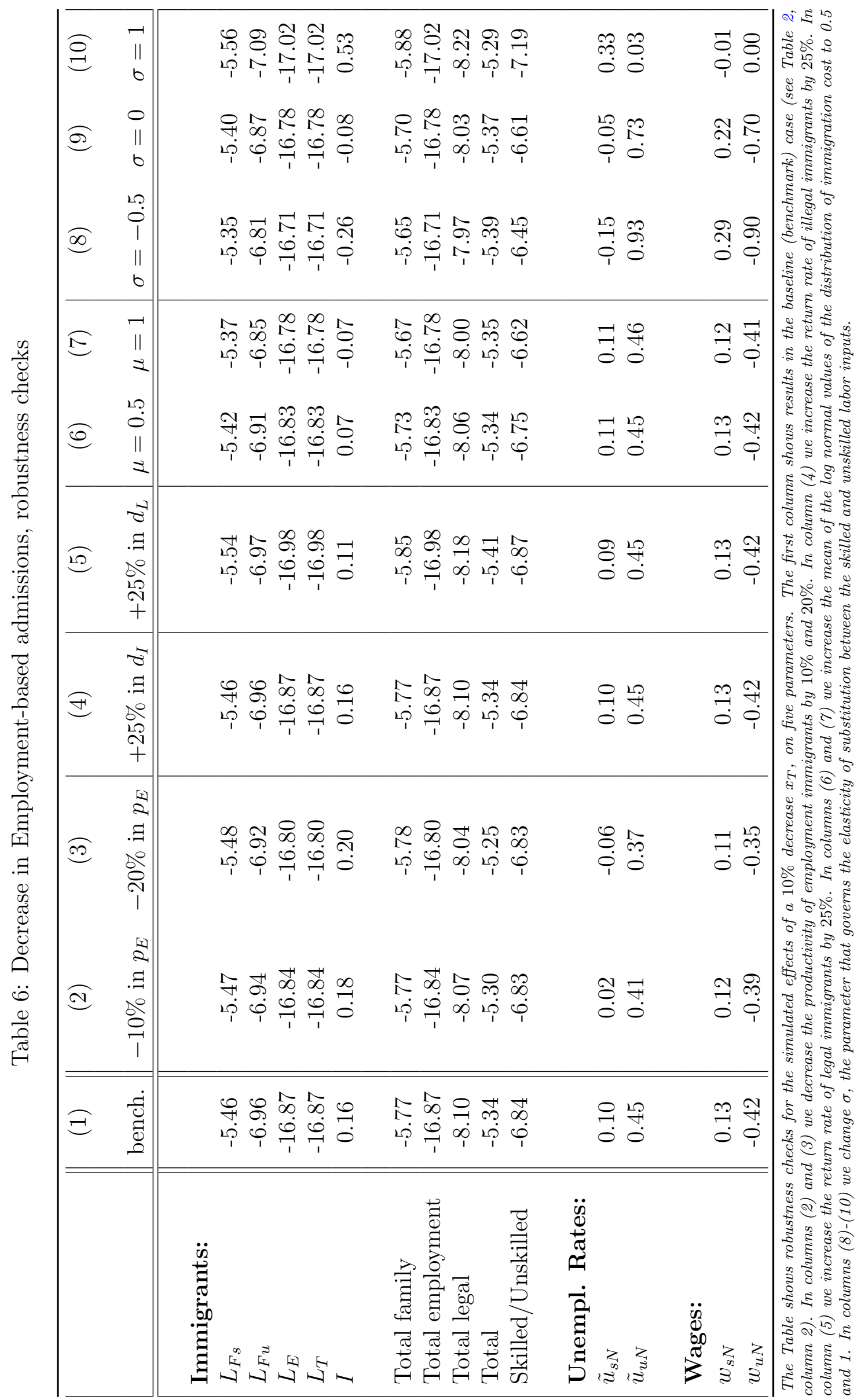




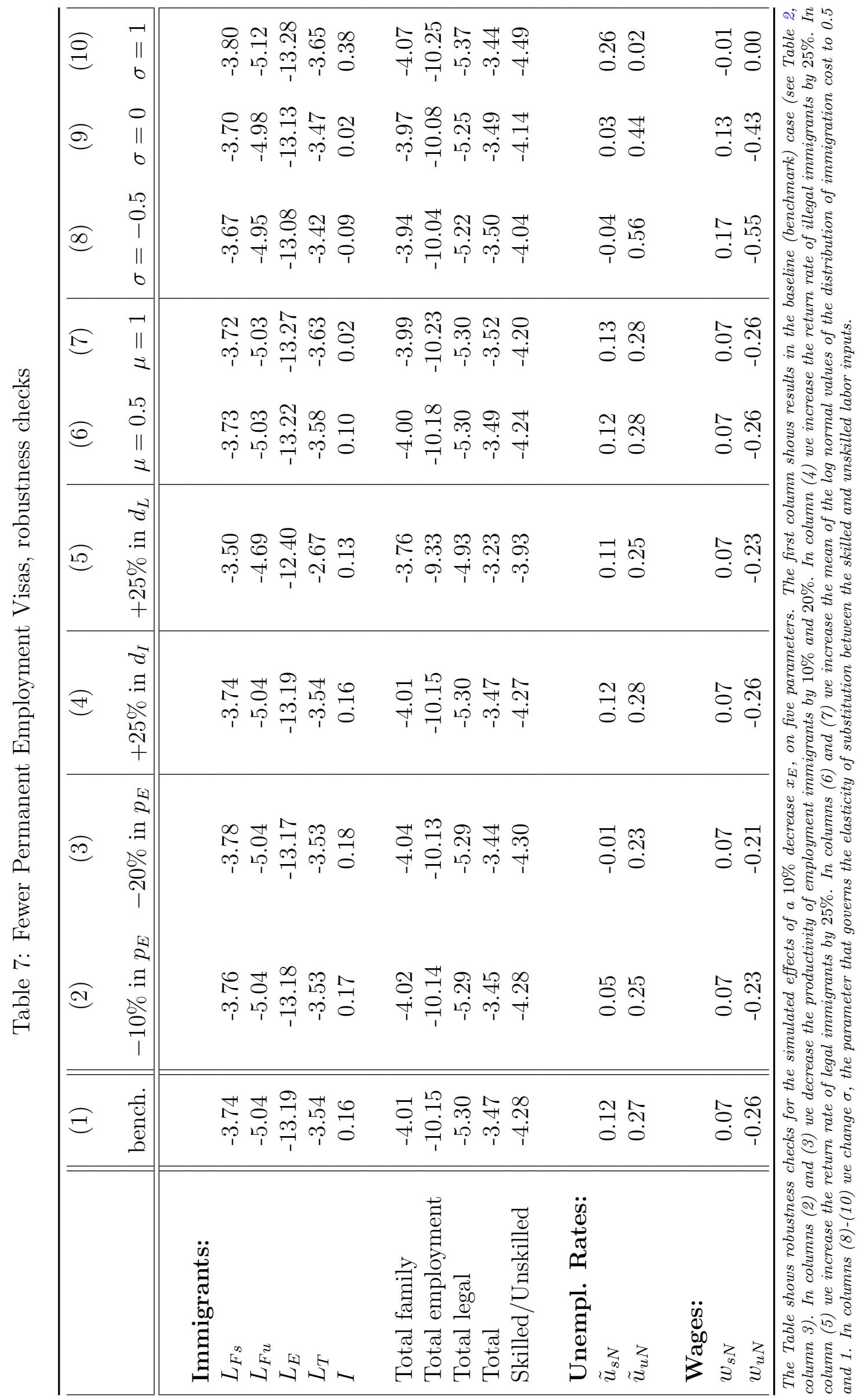




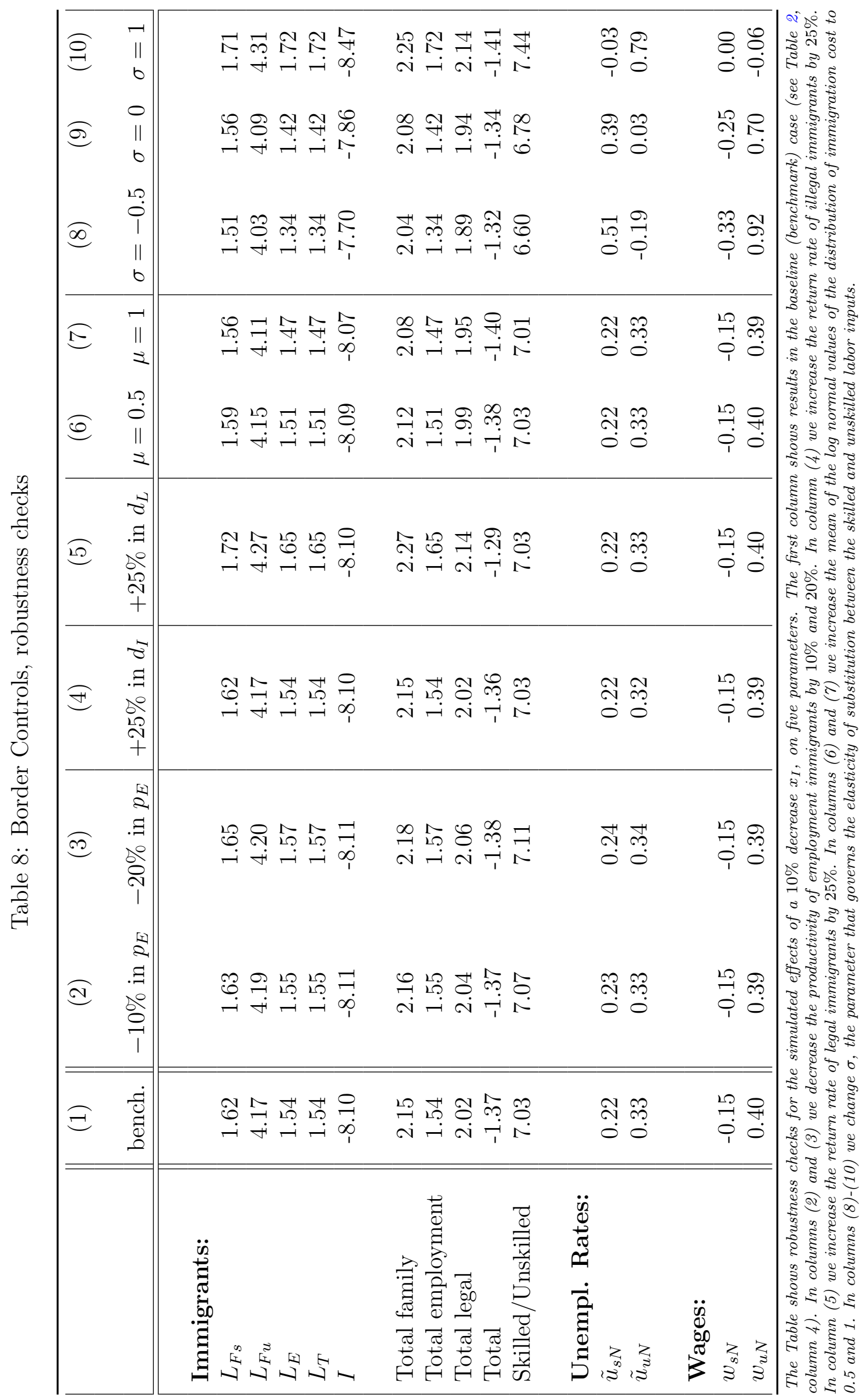




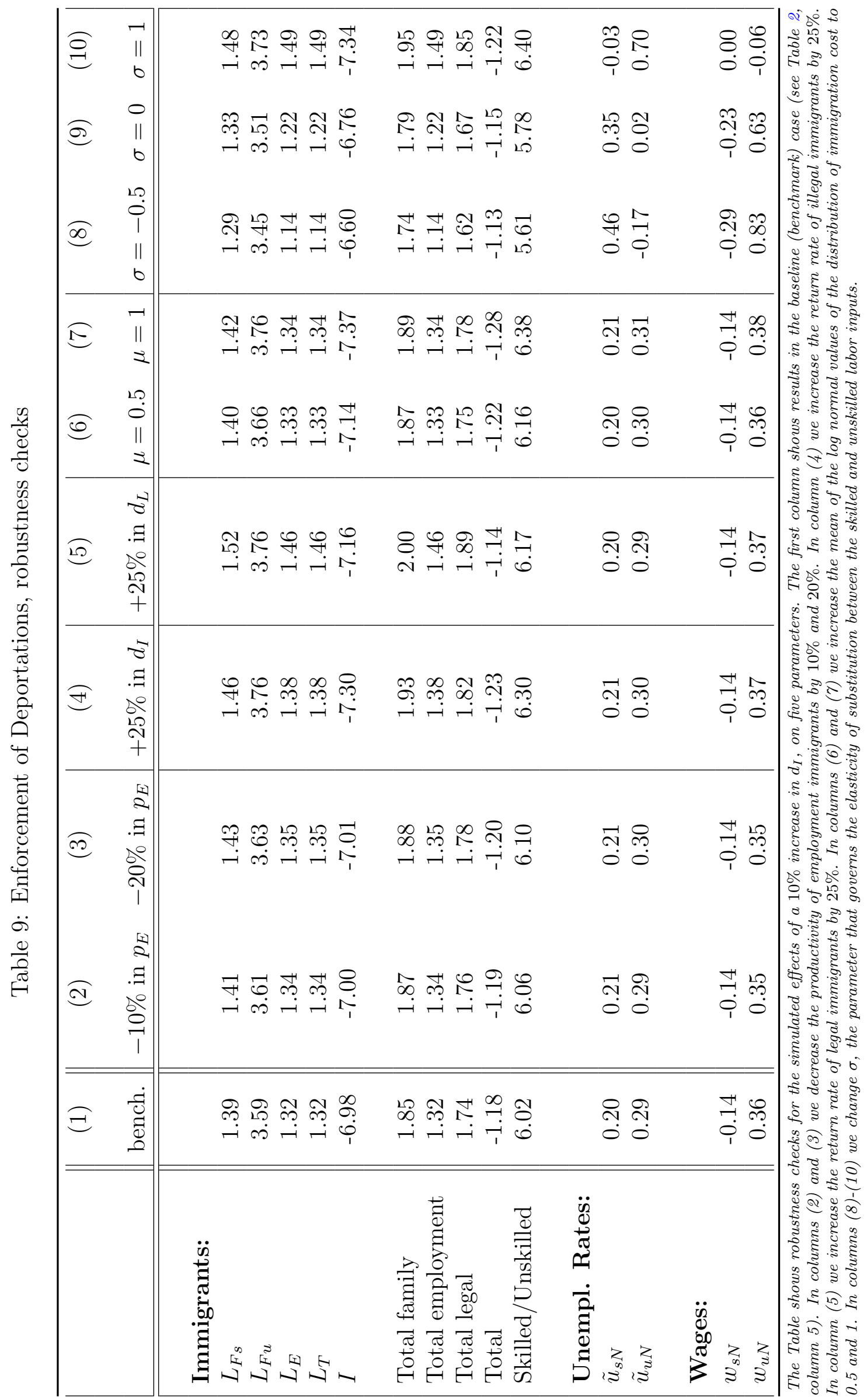




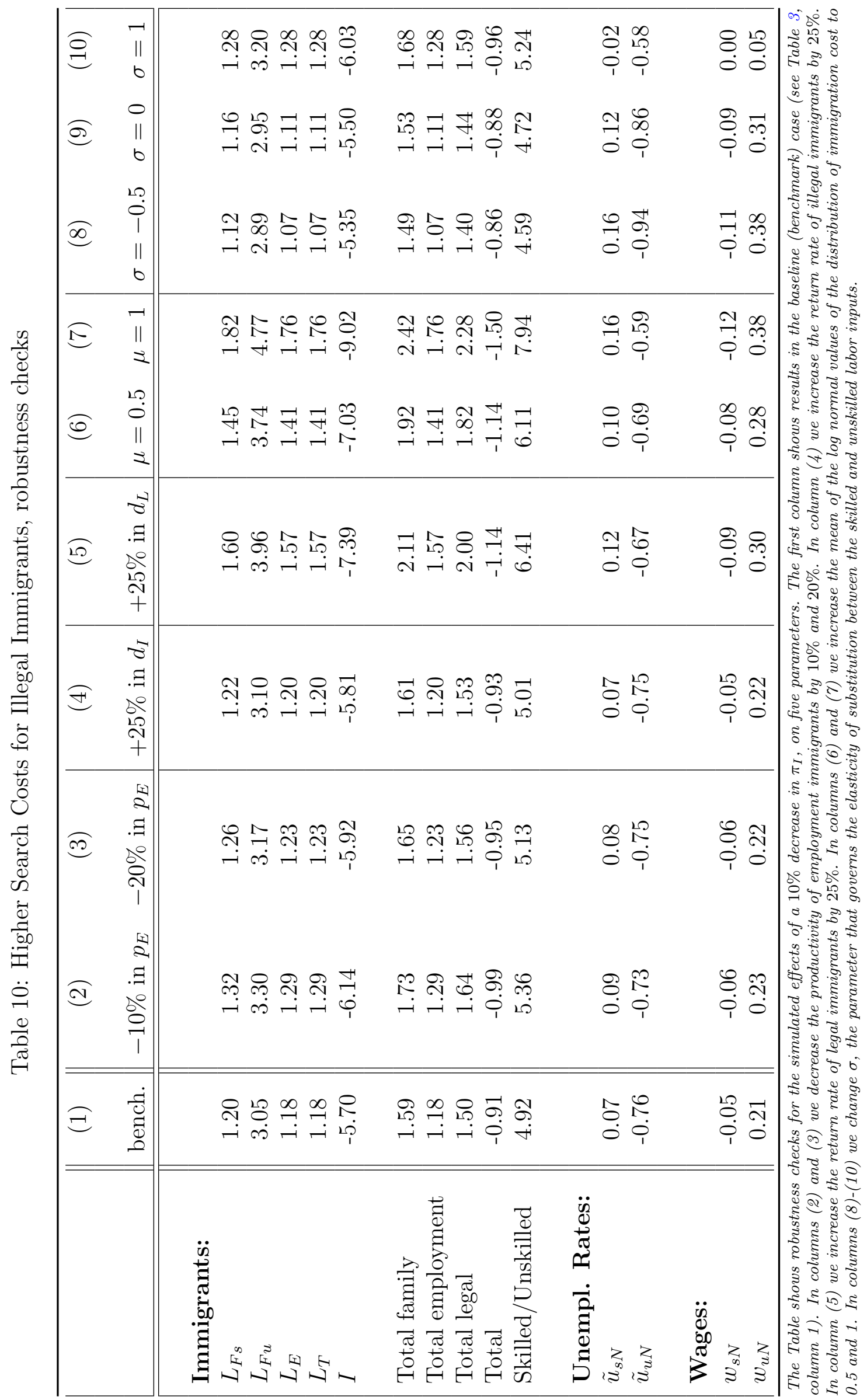




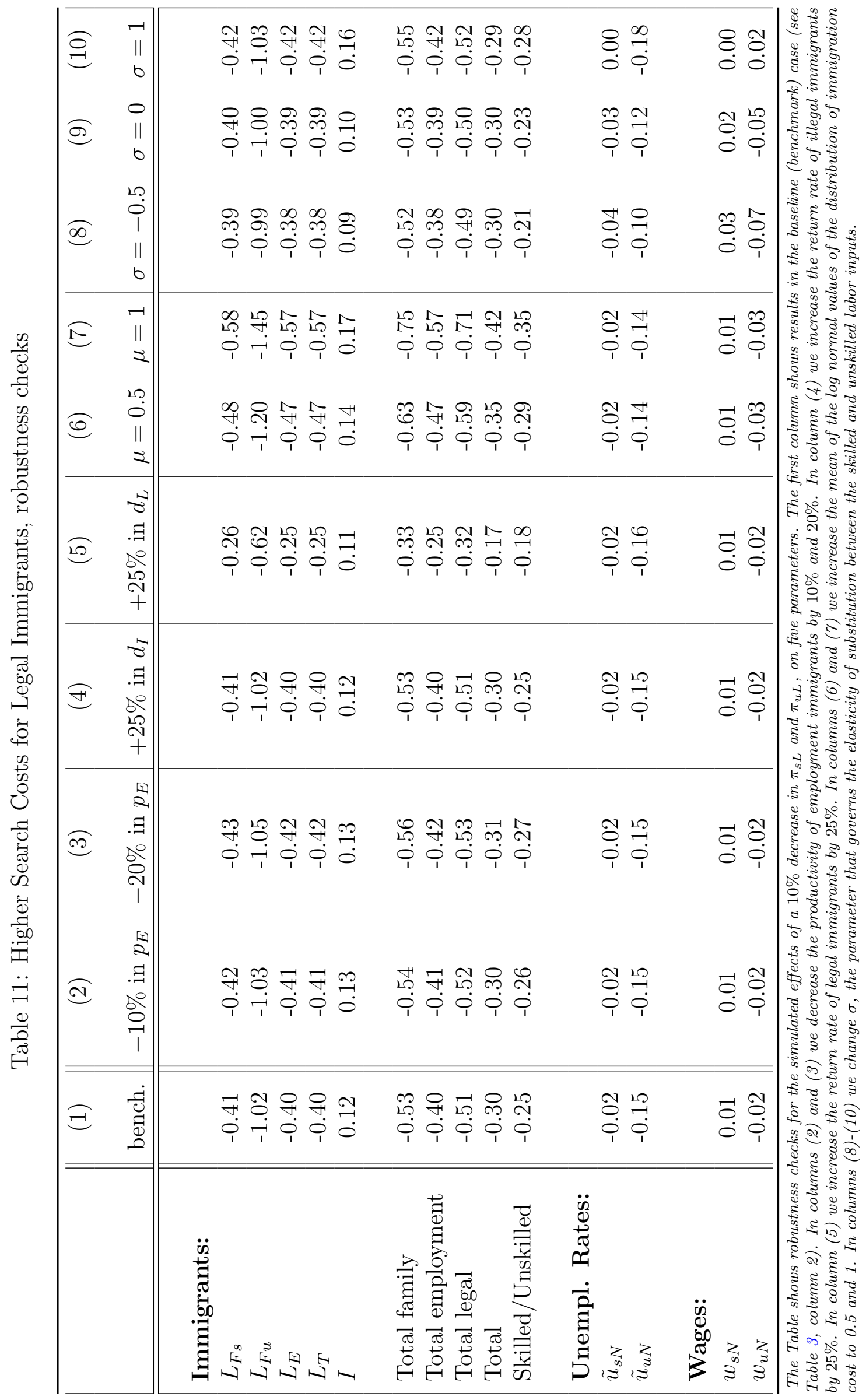




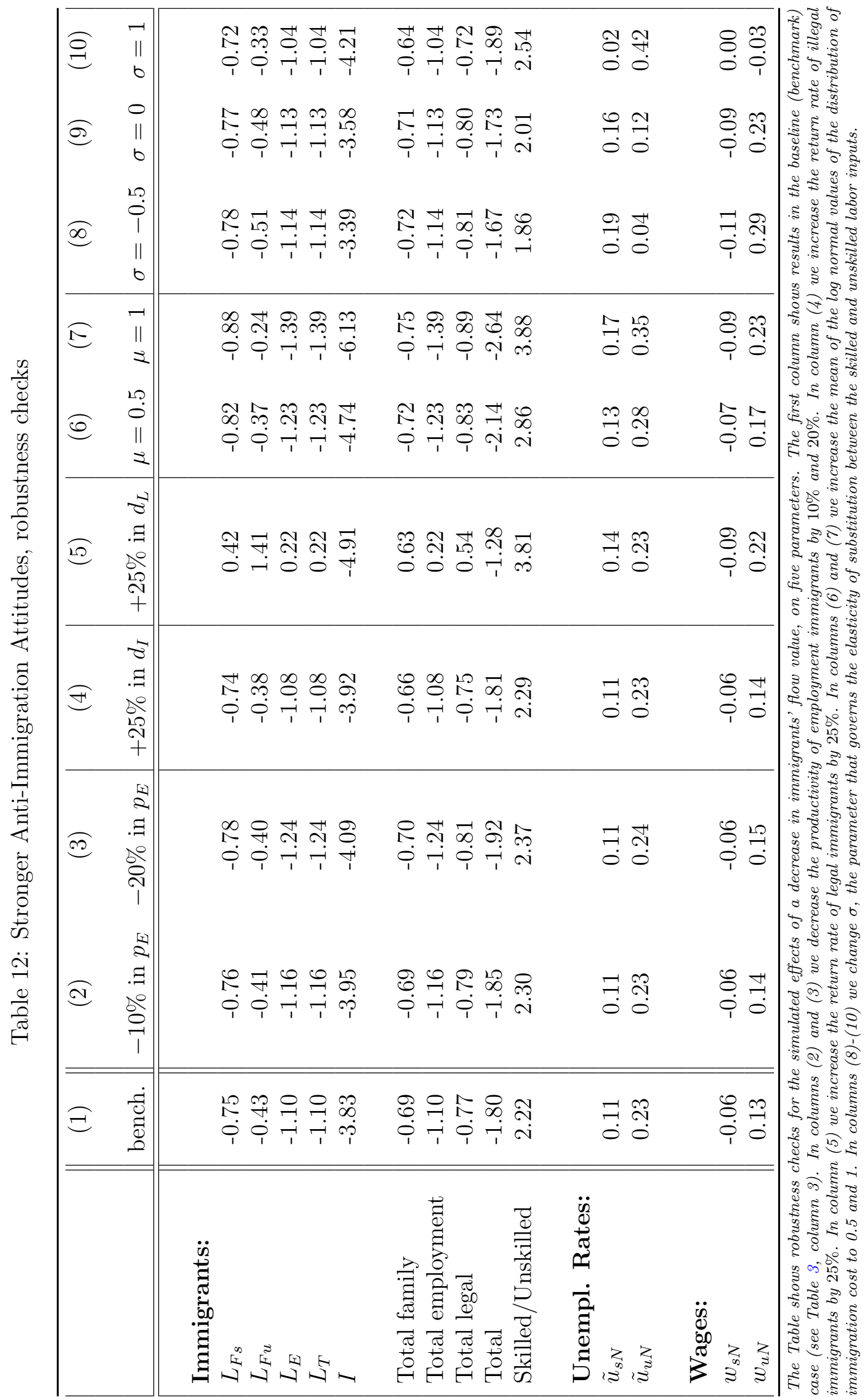




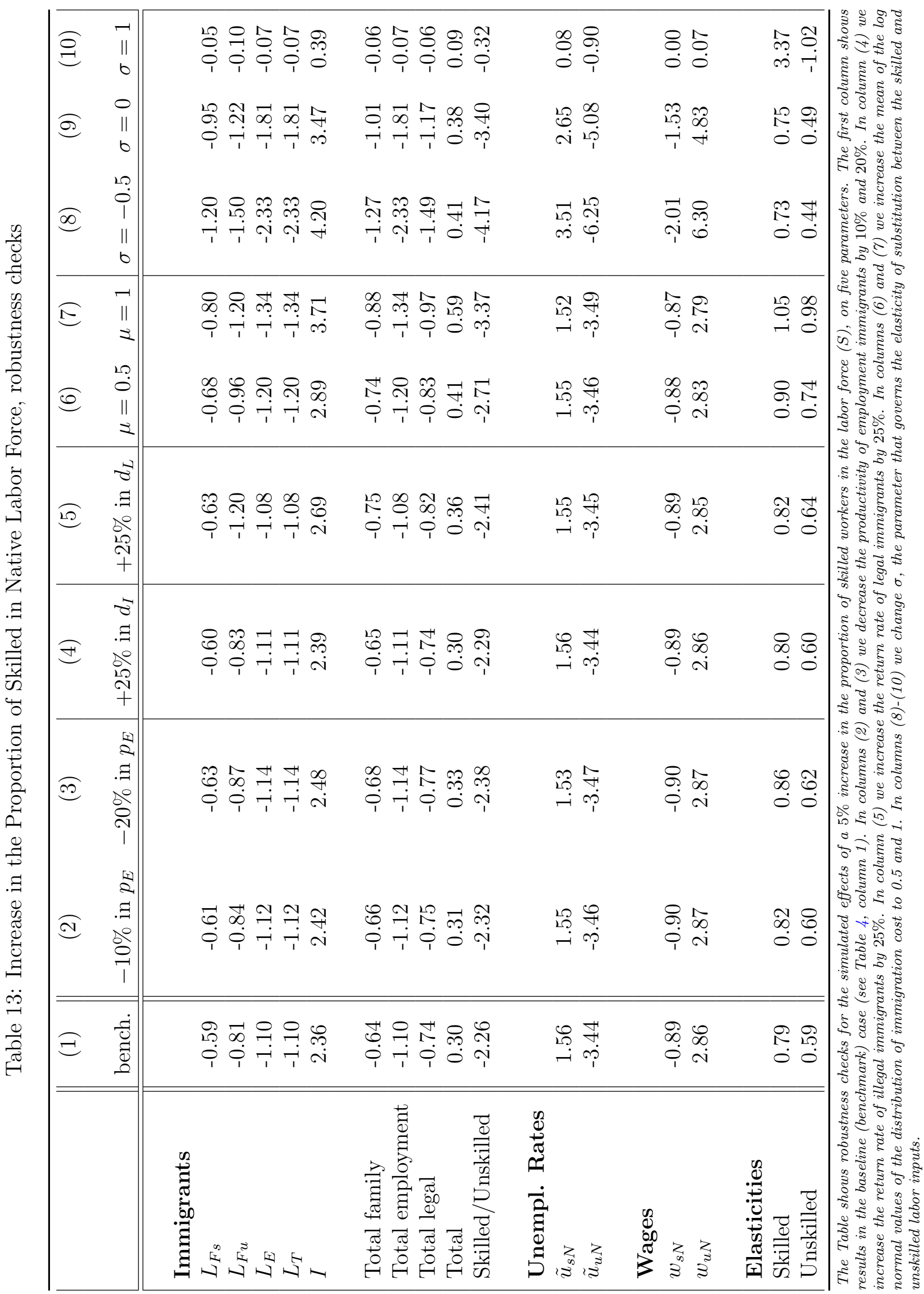




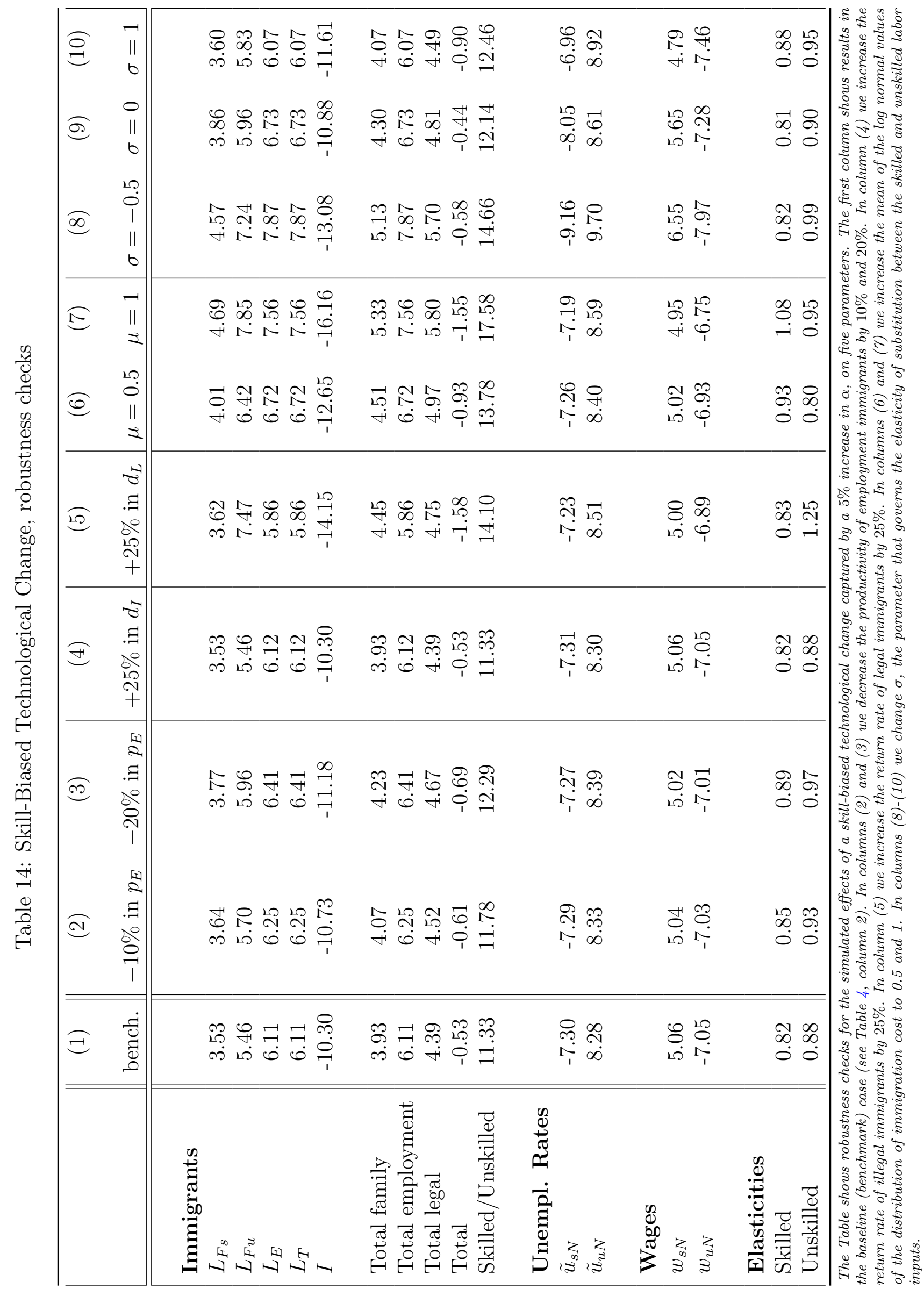




\section{References}

[1] Acemoglu Daron, 2001. "Good Jobs Vs Bad Jobs," Journal of Labor Economics, The University of Chicago Press, vol. 19(1), pages 1-21.

[2] Barro Robert and Jong-wha Lee, 2015. "Data Set on Long-term Educational Attainment by Country" available at http://barrolee.com/data/oupdownloadb.htm.

[3] Basso Gaetano, Giovanni Peri and Ahmed Rahman, 2017. "Computerization and Immigration: Theory and Evidence from the United States," NBER Working Papers 23935, National Bureau of Economic Research, Inc.

[4] Battisti Michele, Gabriel Felbermayr, Giovanni Peri and Panu Poutvaara, (forthcoming) "Immigration, Search, and Redistribution: A Quantitative Assessment of Native Welfare," (forthcoming) Journal of the European Economic Association.

[5] Borjas, George J. (2016) "The Labor Supply of Undocumented Immigrants," NBER Working Papers 22102, National Bureau of Economic Research, Inc.

[6] Bound, J., G. Khanna and N. Morales, 2017. Understanding the Economic Impact of the X-1B Program on the US, " in High-Skilled Migration to the United States and its Economic Consequences, G.X. Hanson, W.R. Kerr and S. Turner (Eds.). University of Chicago Press, forthcoming.

[7] Calvo-Armengol Antoni and Yves Zenou, 2005. "Job matching, social networking and word-of-mouth communication," Journal of Urban Economics, 57, 500-522.

[8] Chassamboulli Andri and Theodore Palivos, (2014) "A Search-Equilibrium Approach To The Effects Of Immigration On Labor Market Outcomes," International Economic Review, vol. 55, 111-129, 02.

[9] Chassambouli Andri and Giovanni Peri, (2015). "The Labor Market Effects of Reducing the Number of I Immigrants," Review of Economic Dynamics, Elsevier for the Society for Economic Dynamics, vol. 18(4), pages 792-821, October.

[10] Clemens Michael, Ethan Lewis, Hannah Postel, 2017. "Immigration Restrictions as Active Labor Market Policy: Evidence from the Mexican Bracero Exclusion - Working Paper 451," Working Papers 451, Center for Global Development. 
[11] Clemens Michael A. Claudio E. Montenegro and Lant Pritchett, (2019). "The Place Premium: Bounding the Price Equivalent of Migration Barriers," The Review of Economics and Statistics, MIT Press, vol. 101(2), pages 201-213, May.

[12] Fernández-Huertas Moraga, Jesús , 2011. "New Evidence on Emigrant Selection," The Review of Economics and Statistics, MIT Press, vol. 93(1), pages 72-96, February.

[13] Francois Fontaine, 2008. "Why are similar workers paid differently? The role of social networks." Journal of Economic Dynamics and Control, 32 3960-3977.

[14] Galenianos M. 2013. "Learning about match quality and the use of referrals." Review of Economic Dynamics, Volume 16, Issue 4, pp. 668-690.

[15] Galenianos M. 2014. "Hiring through Referrals." Journal of Economic Theory, vol. $152,304-323$

[16] Goldin Claudia and Larry Katz (2008) "The Race between education and Technology", Harvard University press, Boston Mass, 2008.

[17] Grogger, Jeffrey and Hanson, Gordon X., 2011. Income maximization and the selection and sorting of international migrants, " Journal of Development Economics, 95(1): $42-57$.

[18] Hanson Gordon \& Chen Liu \& Craig McIntosh, 2017." The Rise and Fall of U.S. Low-Skilled Immigration, “ NBER Working Papers 23753, National Bureau of Economic Research, Inc.

[19] Horvath, G. 2014. "Occupational mismatch and social networks," Journal of Economic Behavior and Organization, 106(C), 442-468.

[20] Hunt, Jennifer 2011. "Which Immigrants Are Most Innovative and Entrepreneurial? Distinctions by Entry Visa," Journal of Labor Economics, University of Chicago Press, vol. 29(3), pages 417-457.

[21] Jaimovich, N. and X.E. Siu. (2017). "High-Skilled Immigration, STEM $L_{E}$, and NonRoutine-Biased Technical Change," in High-Skilled Migration to the United States and its Economic Consequences, G.X. Hanson, W.R. Kerr and S. Turner (Eds.).University of Chicago Press, forthcoming. 
[22] Kaestner Robert and Ofer Malamud (2014) "Self-selection and International migration New Evidence from Mexico" Review of Economics and Statistics Volume 96, Issue 1, March 2014 p.78-91.

[23] Kerr William R. and William F. Lincoln, 2010. "The Supply Side of Innovation: X1B Visa Reforms and U.S. Ethnic Invention," Journal of Labor Economics, University of Chicago Press, vol. 28(3), pages 473-508, July.

[24] Lewis, Ethan \& Peri, Giovanni, (2015). "Immigration and the Economy of Cities and Regions," Handbook of Regional and Urban Economics, Elsevier.

[25] Lofstrom, Magnus and Hayes, Joseph, 2011. "X-1Bs: How Do They Stack Up to US Born Workers?," IZA Discussion Papers 6259, Institute for the Study of Labor (IZA).

[26] Masferrer C. and B. Roberts, (2009). "Going Back Home? The Ambiguities of Contemporary Mexican Return Migration," Conference at UT Austin, 2009.

[27] Mayda Anna Maria, Francesc Ortega, Giovanni Peri, Kevin Shih and Chad Sparber, 2017. "The Effect of the X-1B Quota on Employment and Selection of Foreign-Born Labor," NBER Working Papers 23902, National Bureau of Economic Research, Inc.

[28] Munshi, Kaivan 2003. "Networks in the Modern Economy: Mexican Migrants in the U. S. Labor Market," The Quarterly Journal of Economics, Oxford University Press, vol. 118(2), pages 549-599.

[29] Ottaviano, G. I., and Peri, G. (2012). Rethinking the Effect of Immigration on Wages. Journal of the European Economic Association, 10(1), 152-197.

[30] Ortega Francesc and Giovanni Peri, 2015. "Migration Policies: Recent Advances on Measurement, Determinants and Outcomes," CESifo Economic Studies, CESifo, vol. 61(3-4), pages 521-526.

[31] Peri, Giovanni 2016. "Immigrants, Productivity, and Labor Markets," Journal of Economic Perspectives, American Economic Association, vol. 30(4), pages 3-30, Fall.

[32] Pope, Nolan 2016 "The Effects of DACAmentation: The Impact of Deferred Action for Childhood Arrivals on Unauthorized Immigrants," Journal of Public Economics 143: 98-114, 2016 


\section{A Online Appendix: Model Details}

\section{A.1 Bellman Equations}

The Bellman equations describing the values of job vacancies for unskilled and skilled workers in country 1 are as follows:

$$
\begin{aligned}
r V_{u} & =-c_{u}+q\left(\theta_{u}\right)\left[\phi_{u}\left(\eta_{I} J_{I}+\left(1-\eta_{I}\right) J_{u F}\right)+\left(1-\phi_{u}\right) J_{u N}-V_{u}\right] \\
r V_{s} & =-c_{s}+q\left(\theta_{s}\right)\left[\phi_{s}\left(\eta_{E} J_{E}+\left(1-\eta_{E}\right) J_{s F}\right)+\left(1-\phi_{s}\right) J_{s N}-V_{s}\right]
\end{aligned}
$$

where $\phi_{i}$ is the proportion of unemployed workers of skill type $i$ that are immigrants, $\eta_{I}$ is the proportion of unemployed unskilled immigrants that are illegal and $\eta_{E}$ is the proportion of unemployed skilled immigrants that have (permanent) employment visas.

The value of a job in country 1 depends on the origin and immigrant status of the worker filling the job and is expressed by the following equations:

$$
\begin{aligned}
r J_{T} & =p_{E}-w_{T}+x_{E}\left[J_{E}-J_{T}\right]+\left(d_{T}+\tau\right)\left[V_{s}-J_{T}\right] \\
r J_{i N} & =p_{i}-w_{i N}+\left(s_{i}+\tau\right)\left[V_{i}-J_{i N}\right] \quad i=[s, u] \\
r J_{I} & =p_{u}-w_{I}+\left(s_{u}+d_{I}+\tau\right)\left[V_{u}-J_{I}\right] \\
r J_{u F} & =p_{u}-w_{u F}+\left(s_{u}+d_{L}+\tau\right)\left[V_{u}-J_{u F}\right] \\
r J_{s F} & =p_{s}+\delta x_{T} \tilde{u}_{s}^{2} \Phi\left(\tilde{z}_{T}\right) J_{T}-w_{s F}+\left(s_{s}+d_{L}+\tau\right)\left[V_{s}-J_{s F}\right] \\
r J_{E} & =p_{E}+\delta x_{T} \tilde{u}_{s}^{2} \Phi\left(\tilde{z}_{T}\right) J_{T}-w_{E}+\left(s_{s}+d_{L}+\tau\right)\left[V_{s}-J_{E}\right]
\end{aligned}
$$

When a job is filled by a native worker its value $\left(J_{i N}\right)$ takes the standard form: it is equal to the flow surplus that the job generates (productivity minus the wage) plus the expected capital loss in case the job is destroyed (match breaks up), which occurs at rate $s_{i}+\tau$. Because immigrants may also return home, the effective rate of destruction of jobs filled by immigrants is larger; it is given by $s_{s}+d_{L}+\tau$ if the immigrant is legal and $s_{u}+d_{I}+\tau$ if illegal. If the immigrant is on a temporary work permit, then the rate of job destruction is $d_{T}+\tau$. Notice that matches with immigrants on temporary work permits break up only due to labor force exits or returns. There are no separations to unemployment in this case, since stay in country 1 on a temporary work permit is conditional on having a job. As can be see in (26) immigrants on temporary employment visas (work permits) may transfer to a permanent status with probability $x_{E}$ and thereby generate a flow surplus equal to $J_{E}-J_{T}$.

The use of referrals to hire skilled workers from country 2 can generate an expected flow of surplus equal to $x_{T} \tilde{u}_{s}^{2} \Phi\left(\tilde{z}_{T}\right) J_{T}$ : the probability that an employment visa is approved (given that the employer is willing to sponsor a skilled worker's migration), $x_{T}$, times the probability that a match with a foreign skilled worker is created, $\tilde{u}_{s}^{2} \Phi\left(\tilde{z}_{T}\right)$, times the firm's value of such a match, $J_{T}$. A match with a foreign worker will be created if the contacted worker is unemployed, the probability of which is $\tilde{u}_{s}^{2}$ and willing to immigrate (i.e. his immigration cost is sufficiently low) the probability of which is $\Phi\left(\tilde{z}_{T}\right)$. In general, the use of referrals can increase the value of a job filled by a skilled immigrant by a fraction $\delta \in[0,1]$ of this expected surplus. If $\delta=1$ the employer fully internalizes that flow surplus, while in the other extreme, where $\delta=0$ the employer does not internalize it and 
the flow value of a match with a skilled immigrant worker is only his/her productivity $\left(p_{s}\right.$ or $\left.p_{E}\right) .{ }^{30}$ In our benchmark model, analyzed in the main text, we set $\delta=0$ so that the use of referrals to hire skilled foreigners does not generate any rents to the firm and does not affect job creation incentives. In Appendix B, in Table 25, we show results for $\delta>0$.

The value of being unemployed is described in the following equations, relative to each worker type:

$$
\begin{aligned}
(r+\tau) U_{i N} & =b_{i}+m\left(\theta_{s}\right)\left[E_{i N}-U_{i N}\right] \\
(r+\tau) U_{i F} & =b_{i}-\pi_{i L}+m\left(\theta_{s}\right)\left[E_{i F}-U_{i F}\right]+d_{L}\left[U_{i}^{2}-U_{i F}\right] \\
(r+\tau) U_{I} & =b_{u}-\pi_{I}+m\left(\theta_{u}\right)\left[E_{I}-U_{I}\right]+d_{I}\left[U_{u}^{2}-U_{I}\right] \\
(r+\tau) U_{E} & =b_{s}-\pi_{s L}+m\left(\theta_{s}\right)\left[E_{E}-U_{E}\right]+d_{L}\left[U_{s}^{2}-U_{E}\right]
\end{aligned}
$$

There is no value of being unemployed in country 1 for an immigrant on temporary work permit, since, as already mentioned, stay in country 1 , in this case, is conditional on having a job. All immigrants on temporary work permits are employed, otherwise they must return home.

Finally the value of being employed in steady state is given by the following five conditions relative to each country and worker type:

$$
\begin{aligned}
(r+\tau) E_{i N} & =w_{i N}+s_{i}\left[U_{i N}-E_{i N}\right] \\
(r+\tau) E_{i F} & =w_{i F}+s_{i}\left[U_{i F}-E_{i F}\right]+d_{L}\left[U_{i}^{2}-E_{i F}\right] \\
(r+\tau) E_{I} & =w_{I}+s_{u}\left[U_{I}-E_{I}\right]+d_{I}\left[U_{u}^{2}-E_{I}\right] \\
(r+\tau) E_{E} & =w_{E}+s_{s}\left[U_{E}-E_{E}\right]+d_{L}\left[U_{s}^{2}-E_{E}\right] \\
(r+\tau) E_{T} & =w_{T}+x_{E}\left[E_{E}-E_{T}\right]+d_{T}\left[U_{s}^{2}-E_{T}\right]
\end{aligned}
$$

\section{A.2 Steady-State Conditions}

By equating the outflow of immigrants of each type, which includes returns to the home country and labor force exits, to the inflow of new immigrants into each group we obtain the steady-state conditions for the number of immigrants that hold permanent family or employment visas, $L_{i F}$ and $L_{E}$, respectively, the number of immigrants on temporary work permits, $L_{T}$ and the number of illegal immigrants, $I$ :

$$
\begin{aligned}
\left(d_{L}+\tau\right) L_{i F} & =x_{F} \frac{L_{P}}{X} u_{i}^{2} \Phi\left(\tilde{z}_{i F}\right) \\
\left(d_{L}+\tau\right) L_{E} & =x_{E} L_{T} \\
\left(d_{T}+x_{E}+\tau\right) L_{T} & =x_{T}\left(\frac{L_{s}-u_{s L}}{X_{s}-L_{s}}\right) u_{s}^{2} \Phi\left(\tilde{z}_{T}\right) \\
\left(d_{I}+\tau\right) I & =x_{I} u_{u}^{2} \Phi\left(\tilde{z}_{I}\right)
\end{aligned}
$$

where $L_{s}-u_{s L}=e_{s L}$ and $u_{s L}=u_{s F}+u_{E}$ gives the total number of skilled immigrants on permanent visas that are unemployed. It includes both those holding employment visas

\footnotetext{
${ }^{30}$ Galenianos (2014) adopts an alternative assumption; that new jobs created through the use of referrals are immediately sold off to keep a firm's employment at one. The firm receives a share $\delta \in[0,1]$ of the surplus of the job from selling it and the remaining goes to the buyer.
} 
$\left(u_{E}\right)$ and those holding family visas $\left(u_{s F}\right)$. Notice that besides repatriations and labor force exits, outflows from the group of temporary employment immigrants $\left(L_{T}\right)$ include also transitions to permanent residency (at rate $x_{E}$ ). Notice also that flows into the pool of illegal, family, and temporary (employment) immigrants all come directly from country 2 , whereas, flows into the pool of permanent employment immigrants come only from those on temporary work permits.

The conditions for steady-state unemployment of natives $\left(u_{s N}\right.$ and $\left.u_{u N}\right)$, immigrants on family visas $\left(u_{s F}\right.$ and $\left.u_{u F}\right)$, immigrants on employment visas $\left(u_{E}\right)$ and illegal immigrants $\left(u_{I}\right)$ are as follows

$$
\begin{aligned}
\tau S+s_{s}\left(S-u_{s N}\right) & =\left(m\left(\theta_{s}\right)+\tau\right) u_{s N} \\
\tau(1-S)+s_{u}\left(1-S-u_{u N}\right) & =\left(m\left(\theta_{u}\right)+\tau\right) u_{u N} \\
s_{i}\left(L_{i F}-u_{i F}\right)+x_{F} \frac{L_{P}}{X} \Phi\left(\tilde{z}_{i F}\right) u_{i}^{2} & =\left(m\left(\theta_{i}\right)+d_{L}+\tau\right) u_{i F} \\
s_{s}\left(L_{E}-u_{E}\right) & =\left(m\left(\theta_{s}\right)+d_{L}+\tau\right) u_{E} \\
s_{u}\left(I-u_{I}\right)+x_{I} \Phi\left(\tilde{z}_{I}\right) u_{u}^{2} & =\left(m\left(\theta_{u}\right)+d_{I}+\tau\right) u_{I}
\end{aligned}
$$

Equations (45) and (46) show that flows into the pools of unemployed skilled and unskilled natives of country 1 include new labor force entrants and those who separate from their jobs (at the exogenous rate $s_{s}$ and $s_{u}$, respectively), while flows out of these pools consist of those who find jobs (at the job finding rate $m\left(\theta_{s}\right)$ and $m\left(\theta_{u}\right)$, respectively) and those who exit the labor force. The rates at which workers find skilled and unskilled jobs depend on the labor market tightness that prevails in the skilled and unskilled labor market $\left(\theta_{s}\right.$ and $\theta_{u}$, respectively). Since new family-based and illegal immigrants arrive in country 1 without a job, flows into these two pools (left-hand-sides of 47 and 49) come partly from the inflow of new immigrants $\left(x_{F} \frac{L_{P}}{X} \Phi\left(\tilde{z}_{i F}\right) u_{i}^{2}\right.$ and $x_{I} \Phi\left(\tilde{z}_{I}\right) u_{u}^{2}$, respectively) and partly from the job separations of incumbent immigrants. Flows out of these pools (right-hand-sides of 47 and 49) can be either due to job finding, exogenous returns to country 2 and labor-force exits. Similarly, flows of employment immigrants out of unemployment (right-hand-side of 48) come from job finding, returns and labor-force exits. However, inflows of (permanent) employment-based immigrants into unemployment (lefthand-side of 48) come only from job separations and do not include new immigrants, since new employment-based immigrants, i.e. those who switch from temporary to permanent employment visas, already have jobs.

\section{A.3 Wages}

Using the Bellman equations (24) to (40), the free-entry conditions (4) the Nash bargaining conditions (5) to (8) and the immigration conditions in (9) to (11), we can solve for 
the equilibrium wage rates. Their expressions are as follows:

$$
\begin{aligned}
w_{i N} & =\beta p_{i}+(1-\beta)\left[b_{i}+\beta m\left(\theta_{i}\right) S_{i N}\right], \quad i=[s, u] \\
w_{u F} & =\beta p_{u}+(1-\beta)\left[b_{u}-\pi_{u L}+\beta m\left(\theta_{u}\right) S_{u F}\right] \\
w_{I} & =\beta p_{u}+(1-\beta)\left[b_{u}-\pi_{I}+\beta m\left(\theta_{u}\right) S_{I}\right] \\
w_{s F} & =\beta\left[p_{s}+\delta x_{T} \tilde{u}_{s}^{2} \Phi\left(\tilde{z}_{T}\right) J_{T}\right]+(1-\beta)\left[b_{s}-\pi_{s L}+\beta m\left(\theta_{s}\right) S_{s F}\right] \\
w_{E} & =\beta\left[p_{E}+\delta x_{T} \tilde{u}_{s}^{2} \Phi\left(\tilde{z}_{T}\right) J_{T}\right]+(1-\beta)\left[b_{s}-\pi_{s L}+\beta m\left(\theta_{s}\right) S_{E}\right] \\
w_{T} & =\beta p_{E}+(1-\beta)\left[(r+\tau) U_{s}^{2}-x_{E}\left(U_{E}-U_{s}^{2}\right)\right]
\end{aligned}
$$

A worker's wage is a weighted average of the flow value that he generates to the firm and the outside option available to him. The weight put on the flow value by the Nashbargaining formula is the parameter expressing the workers' bargaining power $(\beta)$. The outside options depend on not only the workers' skill type but also on their nativity and immigration status and they are equal to the unemployment flow income (net of search cost) plus the expected gain from search. Notice that the outside option of those working in country 1 on temporary employment visas is not the value of searching for a job in country 1 , but instead, the value of searching for a job in country $2\left((r+\tau) U_{s}^{2}\right)$, since as explained above, these workers' stay (or entry) in country 1 is conditional on them having a job in country 1. Finally, notice that workers on temporary visas are willing to accept a wage cut in exchange of the possibility of switching from a temporary to a permanent employment visa. This is captured by the last term in (55): the wage of temporary visa holders $\left(w_{T}\right)$ is smaller the higher the probability that they will transition from temporary to permanent residency, $x_{E}$, and the larger the expected gain from this transition. The expected gain from this transition is the difference between the value of searching for a job in country 1 as a permanent employment-based immigrant and the value of searching for a job in country 2 as a native.

\section{A.4 Value of a Filled Vacancy}

Setting $V_{i}=0$ in (26) to (31) we get:

$$
\begin{aligned}
J_{i N} & =\frac{p_{i}-w_{i N}}{r+s_{i}+\tau}, \quad t=[s, u] \\
J_{u F} & =\frac{p_{u}-w_{u F}}{r+s_{u}+d_{L}+\tau} \\
J_{s F} & =\frac{p_{s}-w_{s F}+\delta x_{T} \tilde{u}_{s}^{2} \Phi\left(\tilde{z}_{T}\right) J_{T}}{r+s_{s}+d_{L}+\tau} \\
J_{E} & =\frac{p_{E}-w_{E}+\delta x_{T} \tilde{u}_{s}^{2} \Phi\left(\tilde{z}_{T}\right) J_{T}}{r+s_{s}+d_{L}+\tau} \\
J_{I} & =\frac{p_{u}-w_{I}}{r+s_{u}+d_{I}+\tau} \\
J_{T} & =\frac{p_{E}-w_{T}+x_{E} J_{E}}{r+d_{T}+\tau+x_{E}}
\end{aligned}
$$


Apparently the values of jobs to the firms increase with the worker's productivity and decease with the worker's break up probability and wage, while the use of referrals to hire workers on temporary visas may also increase the value of jobs filled by skilled immigrants given $\delta \geq 0$. Notice also that the value to the firm from employing a temporary worker $J_{T}$ increases with $J_{E}$, since with probability $x_{E}$ the worker may become a permanent immigrant.

Substituting the equilibrium wages (given in equations 50 to 55 ) into the equations above and using the Nash bargaining conditions in (5) to (8) we can write:

$$
\begin{aligned}
J_{i N} & =(1-\beta) S_{i N}=\frac{(1-\beta)\left(p_{i}-b_{i}\right)}{r+s_{i}+\tau+\beta m\left(\theta_{i}\right)}, \quad i=[s, u] \\
J_{u F} & =(1-\beta) S_{u F}=\frac{(1-\beta)\left(p_{u}-b_{u}+\pi_{u L}\right)}{r+s_{u}+d_{L}+\tau+\beta m\left(\theta_{u}\right)} \\
J_{s F} & =(1-\beta) S_{s F}=\frac{(1-\beta)\left(p_{s}-b_{s}+\pi_{s L}+\delta x_{T} \tilde{u}_{s}^{2} \Phi\left(\tilde{z}_{T}\right) S_{T}\right)}{r+s_{s}+d_{L}+\tau+\beta m\left(\theta_{s}\right)} \\
J_{E} & =(1-\beta) S_{E}=\frac{(1-\beta)\left(p_{E}-b_{s}+\pi_{s L}+\delta x_{T} \tilde{u}_{s}^{2} \Phi\left(\tilde{z}_{T}\right) S_{T}\right)}{r+s_{s}+d_{L}+\tau+\beta m\left(\theta_{s}\right)} \\
J_{I} & =(1-\beta) S_{I}=\frac{(1-\beta)\left(p_{u}-b_{u}+\pi_{I}\right)}{r+s_{u}+d_{I}+\tau+\beta m\left(\theta_{u}\right)} \\
J_{T} & =(1-\beta) S_{T}=\frac{(1-\beta)\left(p_{E}+x_{E} S_{E}-(r+\tau) U_{s}^{2}+x_{E}\left(U_{E}-U_{s}^{2}\right)\right)}{r+d_{T}+\tau+x_{E}}
\end{aligned}
$$

where

$$
U_{E}-U_{s}^{2}=\frac{b_{s}-\pi_{s L}+\beta m\left(\theta_{s}\right) S_{E}-(r+\tau) U_{s}^{2}}{r+\tau+d_{L}}
$$

The marginal products $p_{s}, p_{u}$ and $p_{E}=\lambda p_{s}$, can be expressed using (2) and (3) and the steady-state conditions in (12)-(21) and (43) in terms of market tightness and the thresholds immigration costs. The above equations therefore give the values of the surpluses $S_{i N}, S_{i F}, S_{E}$ and $S_{T}, i=[s, u]$, in terms of the endogenous variables: $\theta_{u}, \theta_{s}, \tilde{z}_{I}, \tilde{z}_{s F}, \tilde{z}_{u F}, \tilde{z}_{T}$.

\section{A.5 Differences in Job Surplus}

Manipulating the Bellman equations for jobs filled by employment- and skilled-familybased immigrants (equations 64 and 65) we get:

$$
J_{E}-J_{s F}=\frac{(1-\beta)\left(p_{E}-p_{s}\right)}{r+s_{s}+\tau+d_{L}+\beta m\left(\theta_{s}\right)}
$$


Clearly, if $p_{E}>p_{s}$, then $J_{E}>J_{s F}$. Using (62)-(64) and (66) we can write:

$$
\begin{aligned}
J_{s F}-J_{s N} & =(1-\beta)\left[\frac{\pi_{s L}+\delta x_{T} \tilde{u}_{s}^{2} \Phi\left(\tilde{z}_{T}\right) S_{T}-d_{L} S_{s N}}{r+s_{s}+\tau+d_{L}+\beta m\left(\theta_{s}\right)}\right] \\
J_{u F}-J_{u N} & =(1-\beta)\left[\frac{\pi_{u L}-d_{L} S_{u N}}{r+s_{u}+\tau+d_{L}+\beta m\left(\theta_{u}\right)}\right] \\
J_{I}-J_{u F} & =(1-\beta)\left[\frac{\left(\pi_{I}-\pi_{u L}\right)-\left(d_{I}-d_{L}\right) S_{u F}}{r+s_{u}+\tau+d_{I}+\beta m\left(\theta_{u}\right)}\right]
\end{aligned}
$$

Expression (70) reveals skilled family immigrants can generate larger surplus to firms than skilled natives for two reasons. First, because they face higher search costs, which forces to accept lower wages, and second, because firms can use referrals from them to hire highly skilled foreigners from abroad. As mentioned above, in our benchmark model we choose the most conservative case for the firms' surplus from employing skilled immigrants and set $\delta=0$. That is, we assume that the firm does not internalize the surplus generated from the use of referrals (we consider the case where $\delta>0$ in Appendix B.4, Table 25). Therefore, in our benchmark case if family immigrants have higher search cost than natives, that is, if $\pi_{i L}>0$, then $J_{i F}-J_{i N}>0$ as long as $d_{L}$ is small. Similarly, if the search cost of illegal immigrants is higher than that of unskilled family immigrants, that is, if $\pi_{I}>\pi_{u L}$, then $J_{I}-J_{u F}>0$ as long as $d_{I}-d_{L}$ is small.

\section{A.6 The Threshold Immigration Costs}

Applying the Nash bargaining conditions in (5) to (8) to equations (33), (34) and (40) and using the threshold conditions in (9)-(11) we get:

$$
\begin{aligned}
\tilde{z}_{I} & =\frac{b_{u}-\pi_{I}+\beta m\left(\theta_{u}\right) S_{I}-(r+\tau) U_{u}^{2}}{r+\tau+d_{I}} \\
\tilde{z}_{i F} & =\frac{b_{i}-\pi_{u L}+\beta m\left(\theta_{i}\right) S_{i F}-(r+\tau) U_{i}^{2}}{r+\tau+d_{L}}, \quad i=[s, u] \\
\tilde{z}_{T} & =\frac{\beta\left(p_{E}-(r+\tau) U_{s}^{2}\right)+x_{E}\left(U_{E}-U_{s}^{2}+S_{E}\right)}{r+\tau+d_{T}+x_{E}}
\end{aligned}
$$

where $U_{E}-U_{s}^{2}$ is given by expression (68). Inspecting the above equations shows that all threshold immigration costs increase when the relevant job finding rate is higher, the corresponding job surplus larger, and the return probability smaller. In other words, a worker incentive to migrate through any of the three channels is larger the faster she expects to find a job, the larger the wage she expects to earn and the longer she expects to stay at destination. This can be seen more clearly when we use (51)-(55) to express 
the thresholds in terms of wages:

$$
\begin{aligned}
\tilde{z}_{I} & =\frac{\frac{w_{I}-\beta p_{u}}{1-\beta}-(r+\tau) U_{u}^{2}}{r+\tau+d_{L}} \\
\tilde{z}_{i F} & =\frac{\frac{w_{i F}-\beta p_{i}}{1-\beta}-(r+\tau) U_{i}^{2}}{r+\tau+d_{L}}, \quad i=[s, u] \\
\tilde{z}_{T} & =\frac{C w_{T}+(1-C) W_{P}-(r+\tau) U_{s}^{2}}{r+\tau+d_{L}}
\end{aligned}
$$

where

$$
\begin{aligned}
W_{P} & \equiv\left[D w_{E}+(1-D)\left(\frac{\left.w_{E}-\beta\left(p_{i}+\delta x_{T} \tilde{u}_{s}^{2} \Phi\left(\tilde{z}_{T}\right) S_{T}\right)\right)}{1-\beta}\right)\right] \\
C & \equiv \frac{r+\tau+d_{L}}{r+\tau+d_{L}+x_{E}} \\
D & \equiv \frac{r+\tau+d_{L}}{r+\tau+d_{L}+s_{s}}
\end{aligned}
$$

The first terms in (76) and (77) represent the values of searching for jobs in country 1 for an illegal immigrant and a family immigrant, respectively. These values are higher the higher the corresponding wage $\left(w_{I}\right.$ and $\left.w_{i F}\right)$. In the case of a temporary work permit, where entry is with a job, the first term (in 78), represents the value of being employed on a temporary work permit given that there is a possibility of transition to permanent residency. It is the weighted average of the wage he can earn as temporary immigrant $\left(w_{T}\right)$ and the value of switching to permanent residency $\left(W_{P}\right)$. The latter is the weighted average of the wage he can earn as a permanent employment immigrant $\left(w_{E}\right)$ and the value of searching for a new job in country 1 , in the event of separation with he current employer. Because of the possibility of transferring to a permanent visa, the benefit of entry on a temporary work permit increases with both $w_{T}$ and $w_{E}$.

\section{A.7 Solving the Model}

By substituting the equations (62) to (68) into the two job creation conditions (22)-(23) and the four threshold conditions in (73)-(75) we get six equations in six unknowns which can be used to solve for the two market tightnesses, $\theta_{u}$ and $\theta_{s}$, and the four thresholds, $\tilde{z}_{I}, \tilde{z}_{s F}, \tilde{z}_{u F}, \tilde{z}_{T}$, in terms of model parameters. The equilibrium values of tightnesses and thresholds can then be substituted in (2) and (3) to determine the equilibrium productivities, and then in (50)-(55) to determine wages, and in the steady-state conditions in (12)-(21) to determine immigrant stocks and unemployment rates. 


\section{B Online Appendix: Additional Robustness Checks and Extensions}

\section{B.1 Effects on Natives' Net Income}

In Table 15, we summarize net income changes generated by the policy and structural changes we considered in the text. The net income of natives, $\tilde{Y}$, is given by the following expression:

$$
\tilde{Y}=Y+b_{s} u_{s N}+b_{u} u_{u N}-c_{s} v_{s}-c_{u} v_{u}-w_{s F} e_{s F}-w_{u F} e_{u F}-w_{E} e_{E}-w_{I} e_{I}-w_{T} L_{T}
$$

where $e_{i F}=L_{i F}-u_{i F}, i=[s, u], e_{E}=L_{E}-u_{E}$, and $e_{I}=I-u_{I}$. The expression above assumes that employers are natives and it shows that net income to natives includes total wage income to natives plus unemployment income to natives minus the cost of vacancy posting and the wages paid to immigrants. An alternative definition can be obtained by omitting the natives' unemployment income (if one thinks that such income is generated by transfers rather than by additional home production).

$$
\tilde{Y}_{1}=\tilde{Y}-b_{s} u_{s N}-b_{u} u_{u N}
$$

\section{B.2 Exogenous Changes in the Number of Immigrants}

In Table 16, we examine how results change when network and incentive effects are eliminated so that policies can completely control all types of immigration, i.e. when immigration is exogenous. We implement the percentage changes in the relevant immigrant group generated by the $10 \%$ decreases in approval rates $\left(x_{F}, x_{T}, x_{E}\right.$ and $x_{I}$ - see Table 2) we considered in the text, but we keep the numbers of all other types of immigrants constant. E.g, we decrease the number of family immigrants by the same percentage as in our baseline model when the approval rate of family visas decreases by $10 \%$, but we keep all other types of immigrants constant. We do this for all four cases and compare the resulting effects to those obtained in our model where immigration is an equilibrium outcome.

\section{B.3 Policy Combinations}

We compare here the effects of purely restrictive policies, which reduce the total immigrant population, to those of policy combinations that restrict one entry channel but relax another so that total immigrant population remains constant. Table 17 summarizes the effects of two purely restrictive policies and of five policy combinations. The first two columns show the effects of a 10\% decrease the number of illegal immigrants, achieved trough border enforcement (decreasing $x_{I}$ ). The second column shows the effects of decreasing the approval rate of family visas (decreasing $x_{F}$ ) to achieve a $10 \%$ decrease the number of family immigrants. The next five columns show the policy combinations. In the first three policy combinations we lower $x_{I}$ to achieve a $10 \%$ decrease in illegal immigration, but increase the approval rate of temporary employment visas $x_{T}$, permanent employment visas $x_{E}$ and family visas $x_{F}$, respectively, so that the total number of im- 
migrants remains constant. What these three policy combinations deliver effectively is a replacement of illegal immigrants with legal immigrants (both family and employment, since increasing the network implies more entries through both channels). In the fourth and fifth combinations, we replace family immigrants with employment immigrants. That is, we lower the visa approval rate for family entries so as to decrease the number of family immigrants by $10 \%$ and increase the approval rate of temporary and permanent employment visas, respectively, so as to keep total immigration constant. The entries in the Table represent the percentage effects of these policies on natives' unemployment rates, wages, and total net income.

\section{B.4 Additional Robustness Checks}

The structure of Tables 18-24 that follow mirrors that of Tables 5-12 in the text. Each table is devoted to one policy or structural change. It shows results in the baseline case in the first column while the rest of the columns are devoted to robustness checks on seven parameters. In columns (2) and (3) we change the bargaining power parameter. In particular we set $\beta=0.4$ and $\beta=0.3$. In columns (4) and (5) we set $\epsilon=0.6$ and $\epsilon=0.4$; a higher and lower value for the matching function elasticity. In column (6) we lower the targeted replacement ratio to 0.5 implying a lower value for the flow unemployment income $b_{i}$. In columns (7) and (8) we increase the value of searching for a job as an immigrant in the US relative to the value of searching for a job at home and set $U_{i F}=5 U_{i}^{2}$ and $U_{i F}=6 U_{i}^{2}$, respectively. In columns (9) and (10) we decrease and increase, respectively, the time it takes for a family visa to be approved to 12 and 16 months. And finally, in columns (11) and (12) we double the separation rates $\left(s_{s}\right.$ and $\left.s_{u}\right)$ for skilled and unskilled workers, respectively. The tables show is that our main results are not sensitive to these changes.

Next we analyze the case where firms internalize the surplus that the use of referrals generates. In Table 25 we examine how the effects of the policies and structural changes considered in the text change when the use of referrals to hire skilled workers from abroad increases the employers' surplus (i.e. $\delta>0$ ). While in the benchmark calibration we set $\delta=0$ in the table we also show results for $\delta=0.5$. When employers internalize the benefit from the use of referrals, employing skilled (employment or family) immigrants becomes more valuable to them. As a result, the impact of policies that restrict entries of skilled immigrants, either directly, or through network effects, such as decreasing familyor employment-based admissions, becomes more negative on skilled job creation. On the other hand, the negative impact of policies restricting/discouraging illegal entries on job creation in the skilled sector, becomes smaller (and may turn positive), since such policies increase entries of skilled immigrants (mainly through network effects).

Finally, in Table 26 we show results when the wage ratio of employment to family immigrants is set to 2.47. As mentioned in Section 4 this is the ratio obtained from NIS when we consider as employment immigrants those belonging to the group "others". By increasing the wage ratio of employment to family immigrants to 2.47 we essentially make employment immigrants much more productive and therefore much more valuable to employers. Thus, the effects of increasing the wage ratio of employment to family immigrants are similar to those of increasing $\delta$ (in Table 25). The job creation effect of policies restricting illegal entries on skilled natives turns positive, since such policies 
induce more employment-based entries of skilled immigrants, but remains, however small, while the negative job creation effect of policies restricting legal entries on skilled natives becomes larger, since such policies decrease the entry of employment immigrants. We see here that the endogenous responses in legal entries to the policies imposing restrictions on illegal entries, can overturn the negative job creation effect of such policies only if employment immigrants are significantly more productive than natives. Moreover, in line with our previous conclusion that reduced entry of employment immigrants (due to network effects) magnifies the job depressive effect of policies imposing restrictions on family entries, we see here that the effects of these policies are much more negative when employment immigrants are significantly more productive.

Table 15: Effects on Natives' Net Income

\begin{tabular}{|lcc|}
\hline & $\tilde{Y}$ & $\tilde{Y}_{1}$ \\
Direct Policies & & \\
$10 \%$ decrease in $x_{F}$ & -1.14 & -1.46 \\
$10 \%$ decrease in $x_{T}$ & -0.33 & -0.43 \\
$10 \%$ decrease in $x_{E}$ & -0.18 & -0.24 \\
$10 \%$ decrease in $x_{I}$ & -0.07 & -0.13 \\
$10 \%$ increase in $d_{I}$ & -0.06 & -0.11 \\
& & \\
Indirect Policies & & \\
$10 \%$ increase in $\pi_{I}$ & 0.07 & 0.13 \\
$10 \%$ increase in $\pi_{s L}$ and $\pi_{u L}$ & 0.01 & 0.02 \\
decrease in flow value & -0.09 & -0.13 \\
& & \\
Structural Changes & & \\
$5 \%$ increase in $S$ & 1.64 & 2.01 \\
$5 \%$ increase in $\alpha$ & 1.94 & 2.40 \\
\hline
\end{tabular}

The Table shows the percentage changes in natives' net income generated by the policies and structural changes considered in the text. The two measures of net income $\tilde{Y}$ and $\tilde{Y}_{1}$ are as described in Section B.1. 
Table 16: Effects of Policies when Immigration is Exogenous

\begin{tabular}{|l|cc|cc|cc|cc|}
\hline & \multicolumn{2}{|c}{$10 \% \downarrow$ in $x_{F}$} & \multicolumn{2}{c}{$10 \% \downarrow$ in $x_{T}$} & \multicolumn{2}{c}{$10 \% \downarrow$ in $x_{E}$} & \multicolumn{2}{c}{$10 \% \downarrow$ in $x_{I}$} \\
Unempl. Rates: & bench & exog & bench & exog & bench & exog & bench & exog \\
$\tilde{u}_{s N}$ & -0.20 & -0.64 & 0.10 & -0.06 & 0.12 & 0.18 & 0.22 & 0.23 \\
$\tilde{u}_{u N}$ & 2.24 & 1.40 & 0.45 & 0.10 & 0.27 & 0.16 & 0.33 & 0.40 \\
& & & & & & & & \\
Wages: & & & & & & & & \\
$w_{s N}$ & 0.63 & 0.30 & 0.13 & 0.04 & 0.07 & 0.05 & -0.15 & -0.15 \\
$w_{u N}$ & -1.96 & -0.89 & -0.42 & -0.11 & -0.26 & -0.17 & 0.40 & 0.37 \\
Net Income & & & & & & & & \\
$\tilde{Y}_{\tilde{Y}}$ & & & & & & & & \\
$\tilde{Y}_{1}$ & -1.14 & -0.34 & -0.33 & -0.23 & -0.18 & -0.05 & -0.07 & -0.12 \\
\hline
\end{tabular}

Each of the four panels of the Table summarizes the effects of a restrictive immigration policy on natives' unemployment rates (first 2 rows), wages (next 2 rows) and net income (last 2 rows). The first panel shows the effects of decreasing family immigrants (through a $10 \%$ decrease in $x_{F}$ ). The second panel the effects of decreasing employment immigrants on temporary work permits (through a $10 \%$ decrease in $x_{T}$ ). The third panel the effects of decreasing employment immigrants on permanent visas (through a $10 \%$ decrease in $x_{E}$ ), and the fourth panel the effects of decreasing illegal immigrants (through a $10 \%$ decrease in $x_{I}$ ). In each of the four panels the first column (bench) shows the effects in our benchmark model, where the number of immigrants of each type is an equilibrium outcome (see Table 2, columns 1-4). The second column (exog) shows the effects of a decrease in the relevant immigrant group equal to that generated in the benchmark model, when immigration is exogenous - that is, when the numbers of other types of immigrants remain the same. 


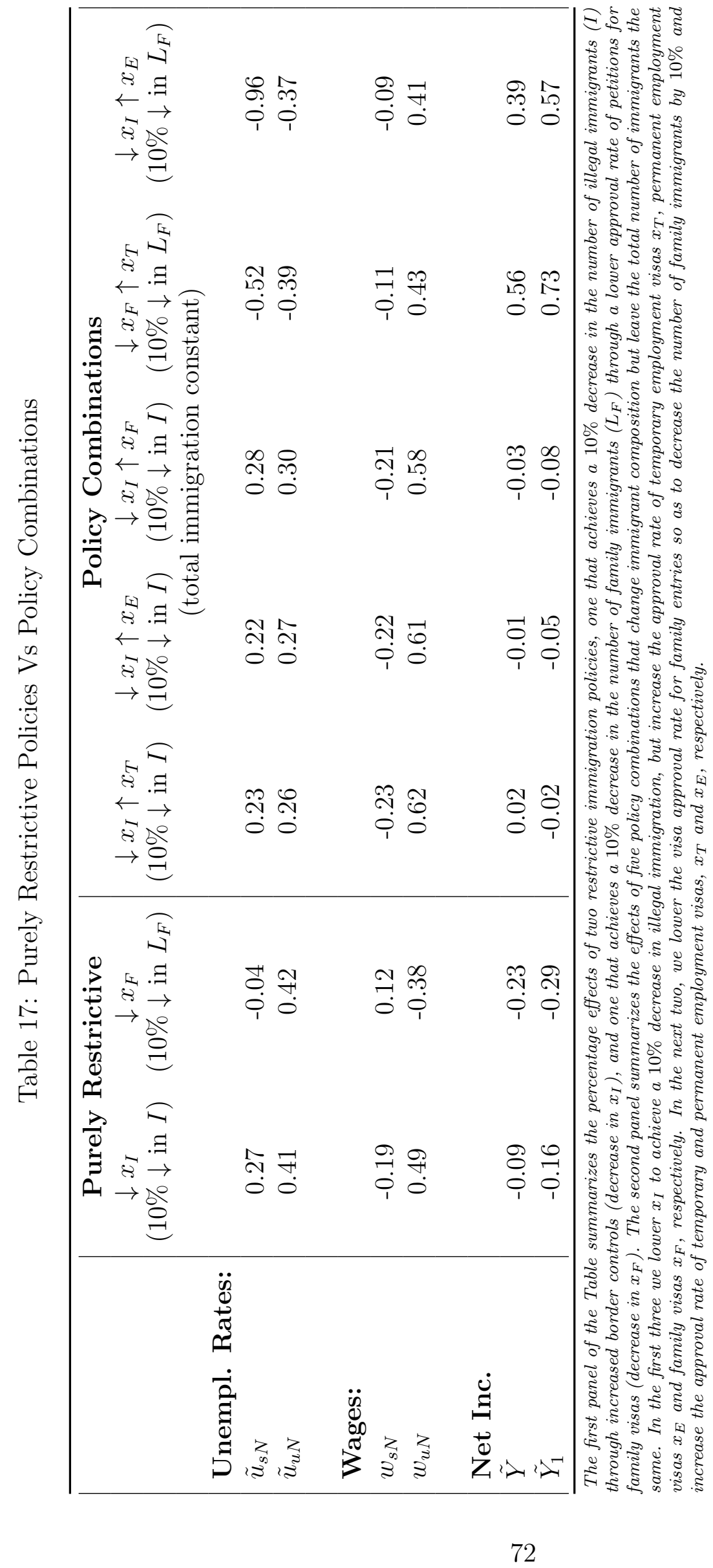




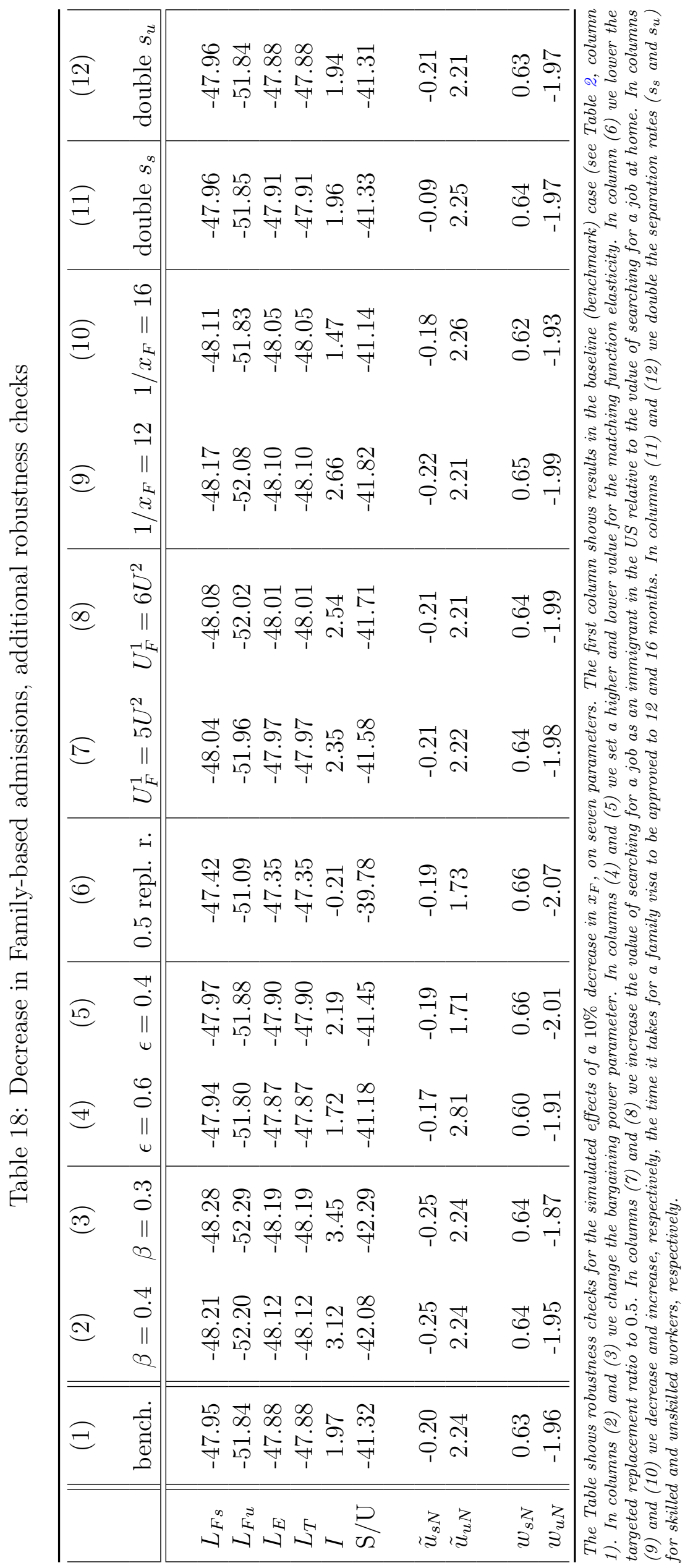




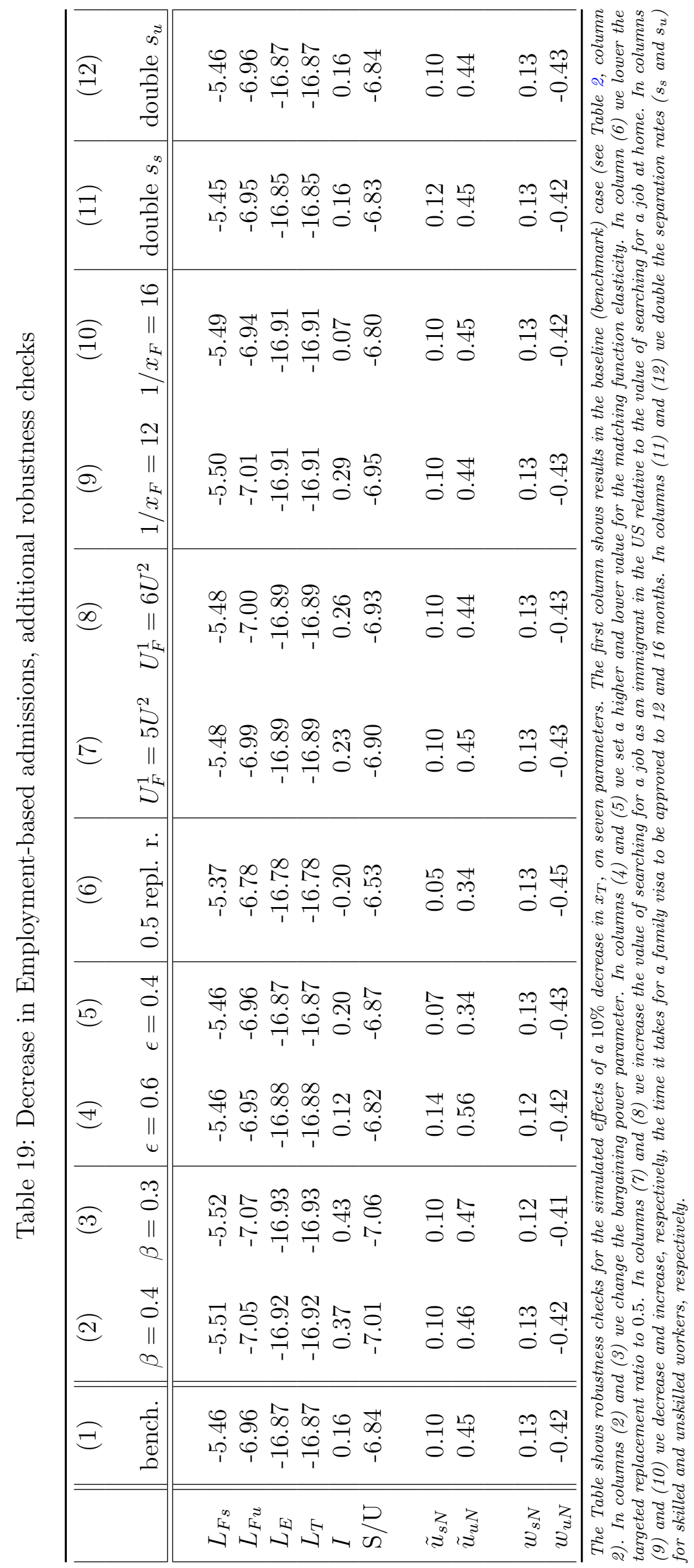




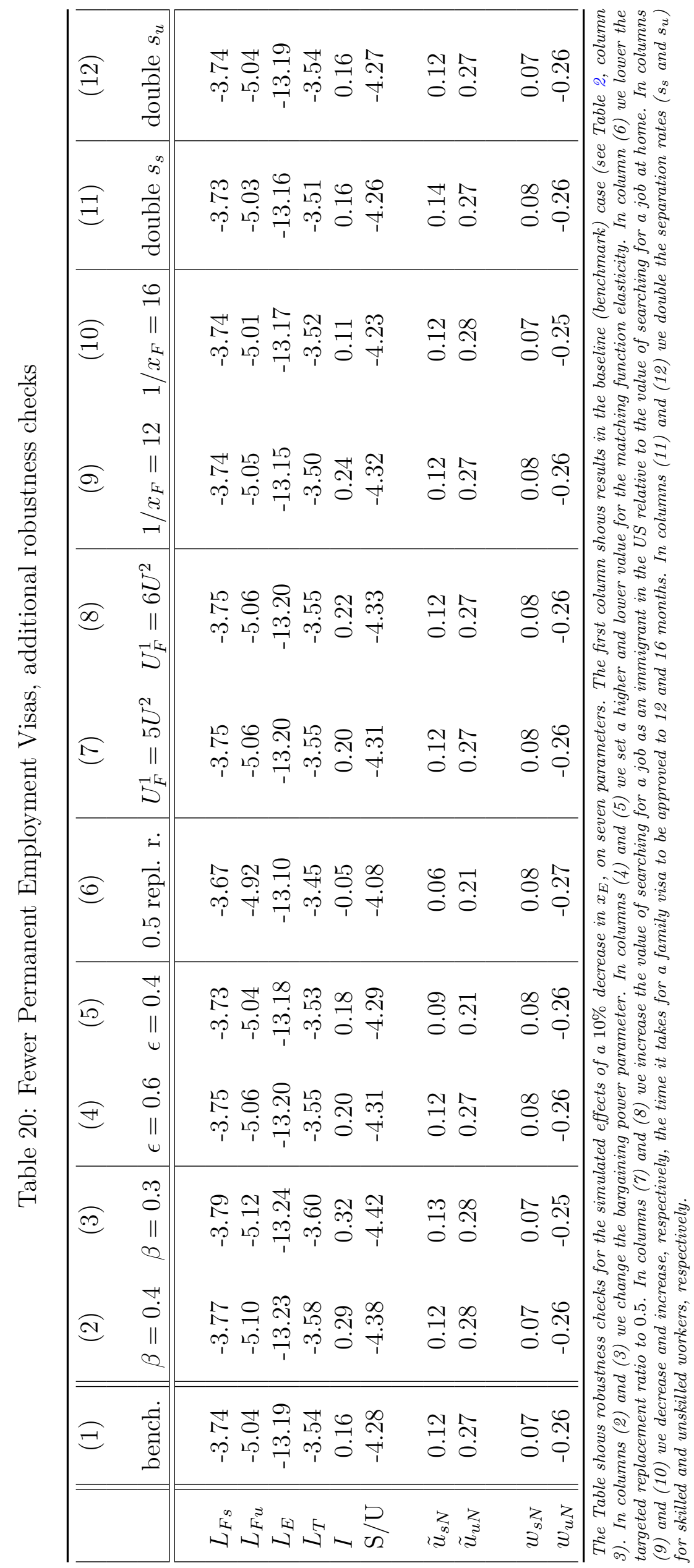




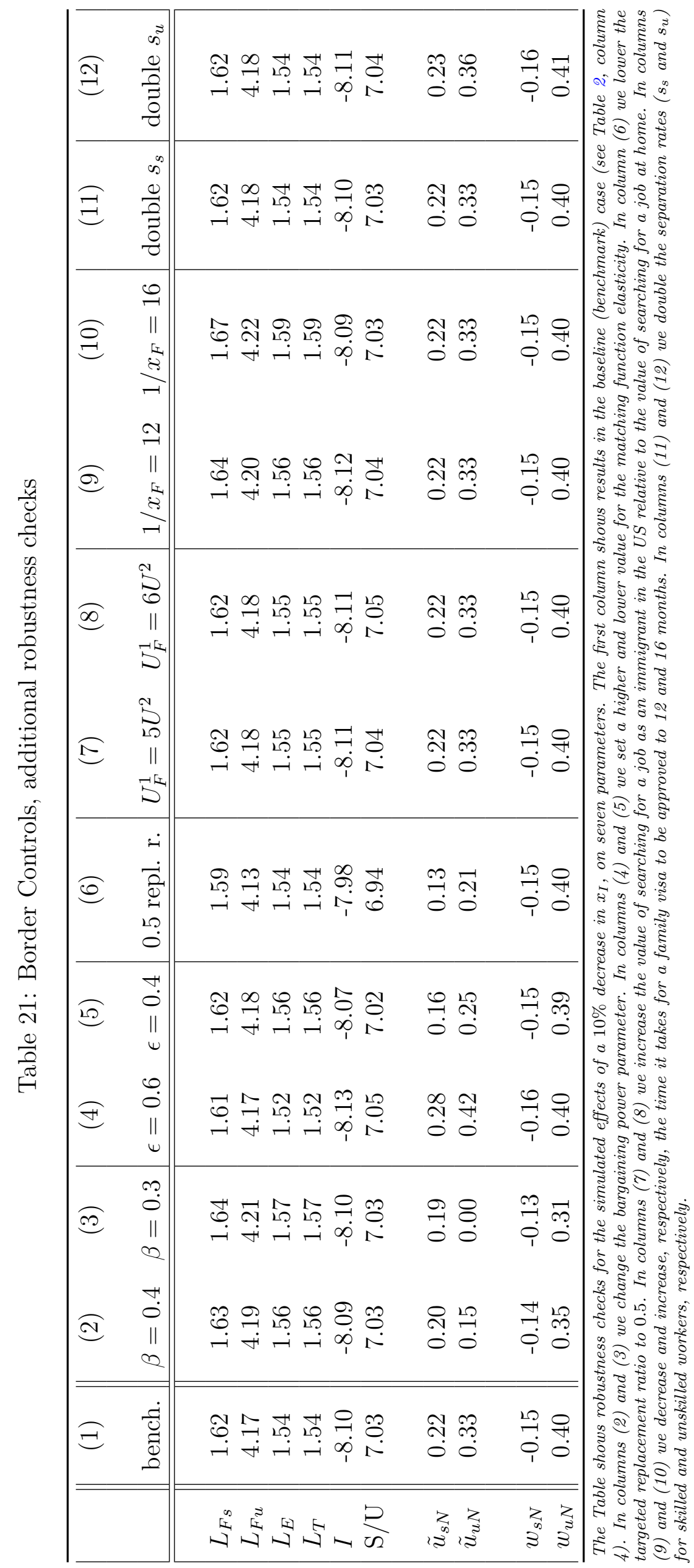









\begin{tabular}{|c|c|c|c|c|c|}
\hline$\stackrel{\overbrace =}{\beth}$ & $\begin{array}{l}w^{2} \\
0 \\
\frac{0}{0} \\
\overrightarrow{0} \\
0\end{array}$ & 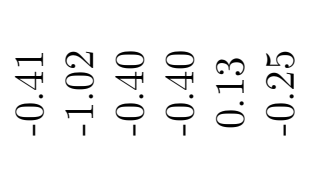 & $\underset{0}{0} \underset{0}{\stackrel{10}{\longrightarrow}}$ & 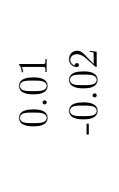 & \\
\hline$\stackrel{\overbrace =}{\beth}$ & $\begin{array}{l}\infty^{\infty} \\
\frac{0}{0} \\
\frac{0}{0} \\
0\end{array}$ & 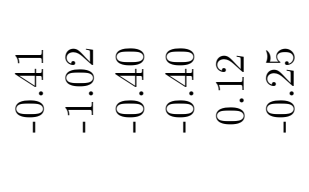 & 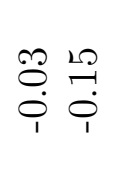 & $\begin{array}{l}-1 \\
0 \\
0 \\
0\end{array}$ & \\
\hline 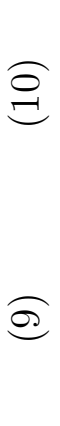 & 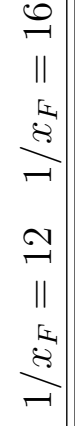 & 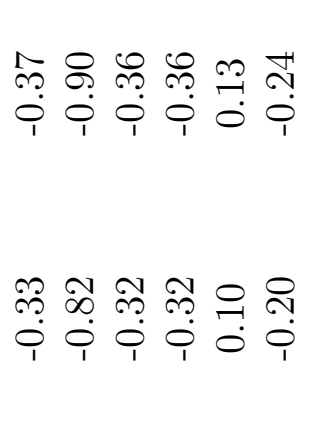 & 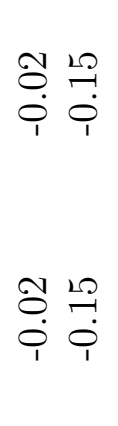 & $\begin{array}{l}\overrightarrow{0} \\
0 \\
0\end{array}$ & \\
\hline E & 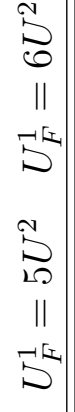 & 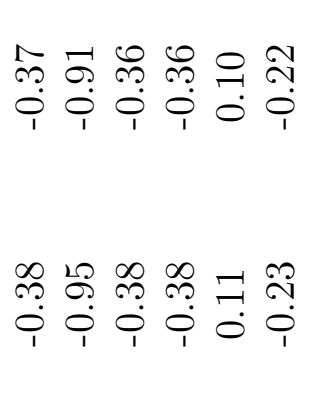 & $\underset{0}{\stackrel{2}{0}} \stackrel{20}{0}$ & $\begin{array}{ll}\overrightarrow{0} & \stackrel{0}{0} \\
0 & 0 \\
0 & 1\end{array}$ & \\
\hline (6) & $\begin{array}{c}\dot{i} \\
\dot{0} \\
\dot{0} \\
0 \\
\dot{0} \\
\dot{2} \\
\dot{0}\end{array}$ & 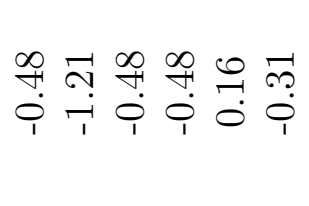 & $\begin{array}{ll}\overrightarrow{0} & 0 \\
0 & \stackrel{1}{0} \\
& 1\end{array}$ & 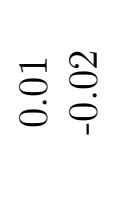 & \\
\hline$\overparen{E}$ & 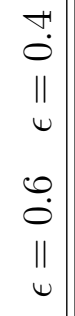 & 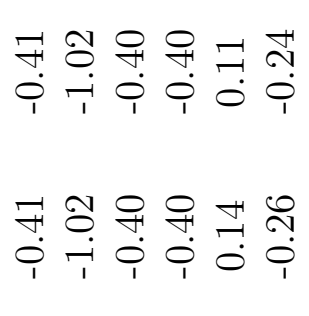 & 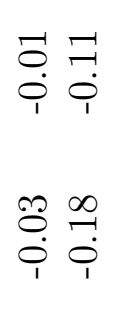 & 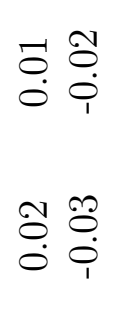 & \\
\hline$\overparen{\mathcal{V}}$ & $\begin{array}{l}m \\
0 \\
11 \\
0 \\
\ddot{1} \\
\dot{0} \\
11 \\
0\end{array}$ & 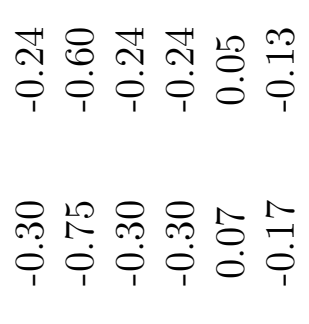 & 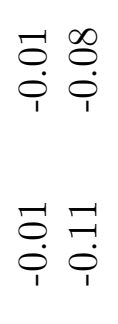 & 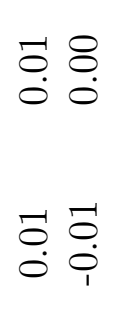 & \\
\hline 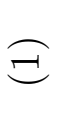 & $\begin{array}{l}\dot{j} \\
\dot{0} \\
0 \\
0\end{array}$ & 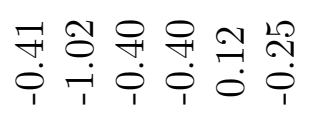 & $\begin{array}{l}\stackrel{2}{0} \\
\stackrel{20}{\longrightarrow} \\
0 \\
0\end{array}$ & $\begin{array}{ll}-j & 0 \\
0 \\
0 & 0 \\
0 & 1\end{array}$ & \\
\hline & & 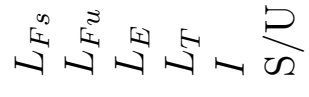 & 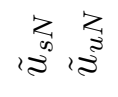 & $\begin{array}{ll}3 & \vdots \\
\vdots & \vdots \\
\vdots & \vdots\end{array}$ & \\
\hline
\end{tabular}




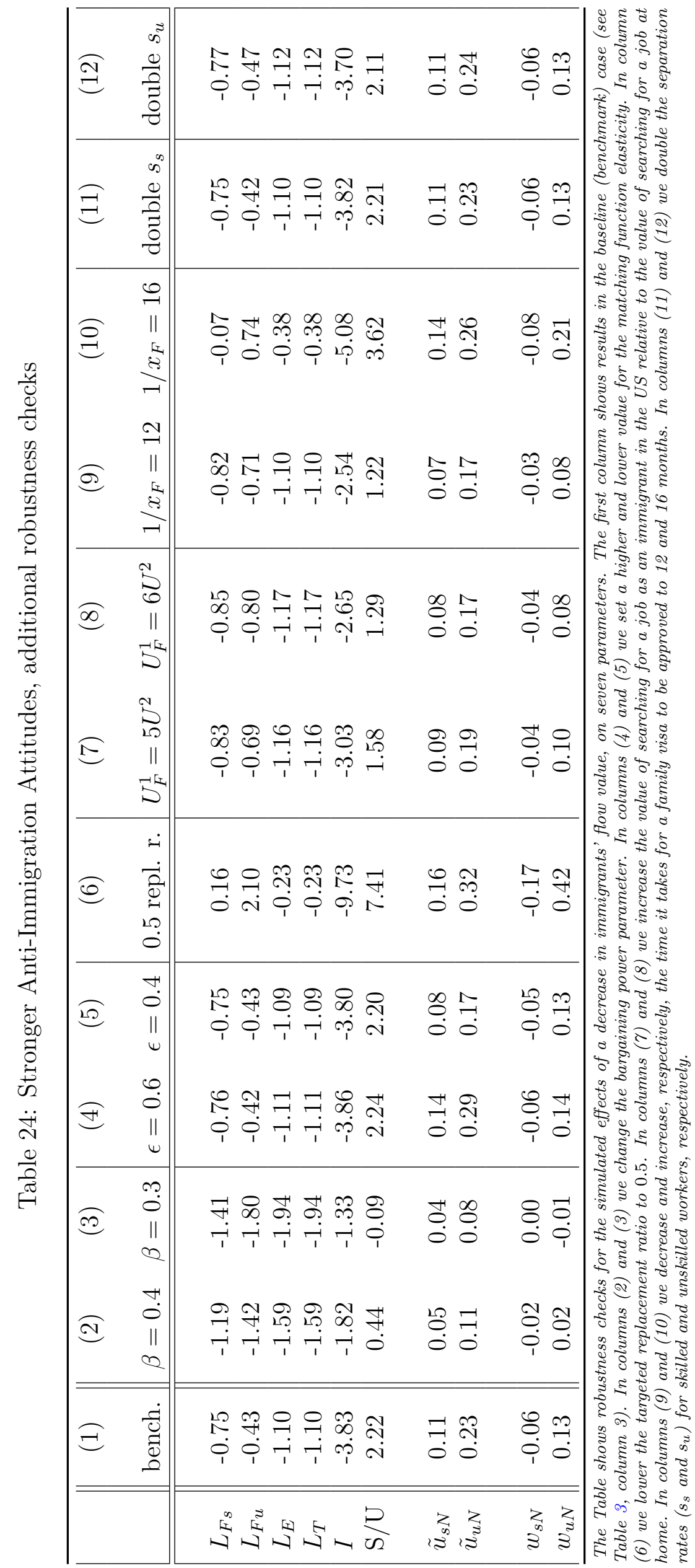




\begin{tabular}{|c|c|c|c|c|}
\hline 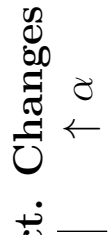 & 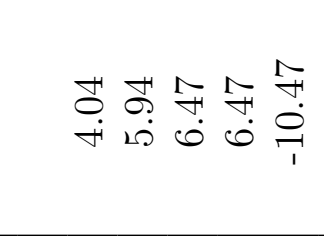 & 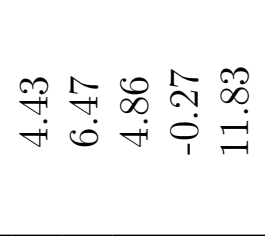 & 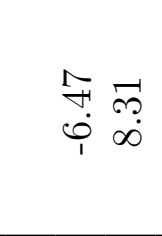 & 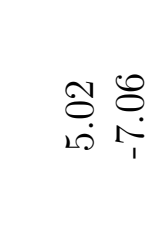 \\
\hline 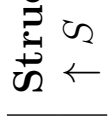 & 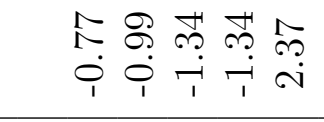 & 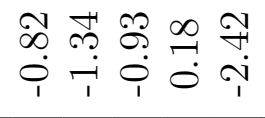 & $\underset{1}{\stackrel{0}{*}}$ & 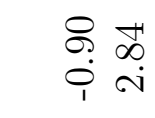 \\
\hline 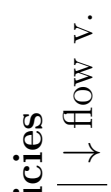 & 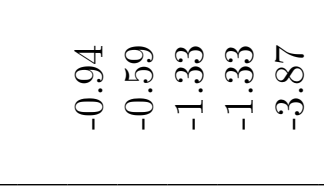 & 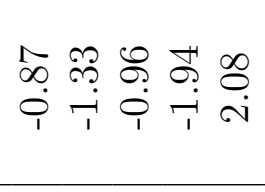 & $\stackrel{\dddot{2}}{\dddot{n}}$ & 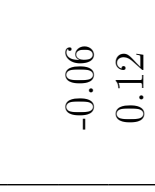 \\
\hline 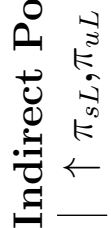 & 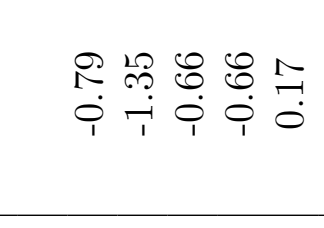 & 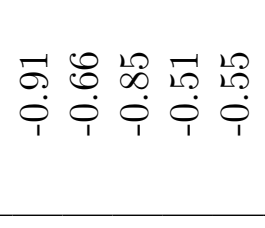 & 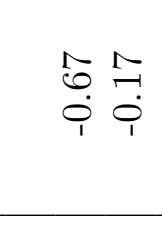 & $\begin{array}{ll}3 & 8 \\
0 & 0\end{array}$ \\
\hline $\begin{array}{l}\vec{E} \\
\leftarrow\end{array}$ & 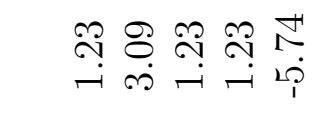 & 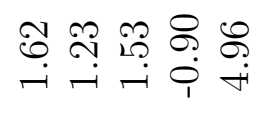 & $\begin{array}{ll}\dot{0} & 0 \\
0 & 0 \\
0 & 0 \\
1 & 1\end{array}$ & 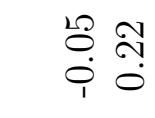 \\
\hline$\vec{\sigma}$ & 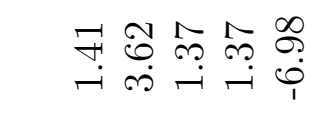 & 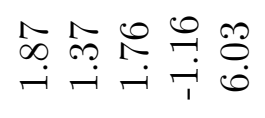 & $\stackrel{\mathscr{0}}{0} \stackrel{\infty}{\sim}$ & $\stackrel{m}{\dddot{n}}$ \\
\hline 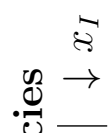 & 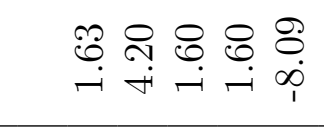 & 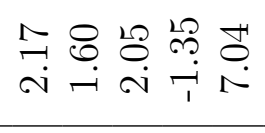 & 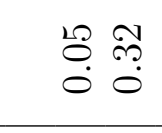 & 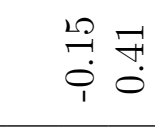 \\
\hline $\begin{array}{l}.=1 \\
0 \\
0 \\
0\end{array}$ & 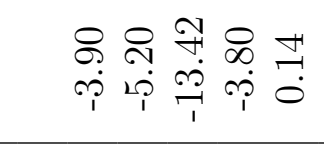 & 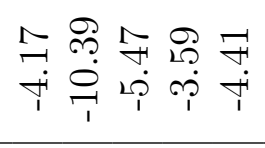 & कृ & $\begin{array}{l}1 \\
0 \\
0 \\
0\end{array}$ \\
\hline 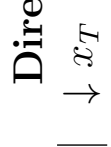 & 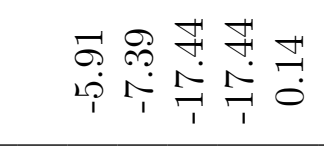 & 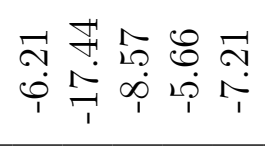 & बें & $\vec{F} \stackrel{9}{7}$ \\
\hline$\stackrel{\substack{x \\
\rightarrow}}{\rightarrow}$ & 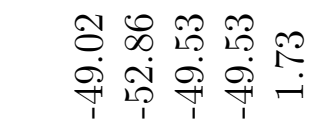 & 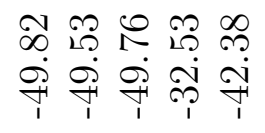 & 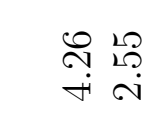 & 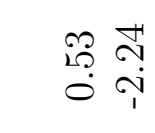 \\
\hline & 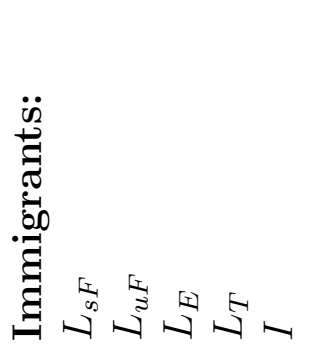 & 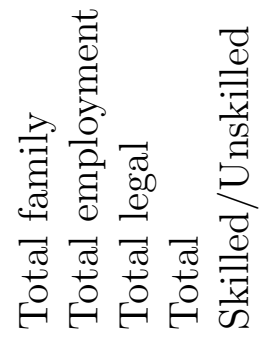 & 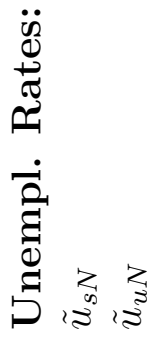 & 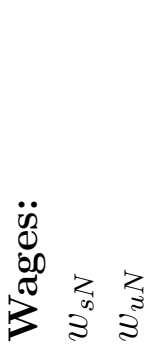 \\
\hline
\end{tabular}




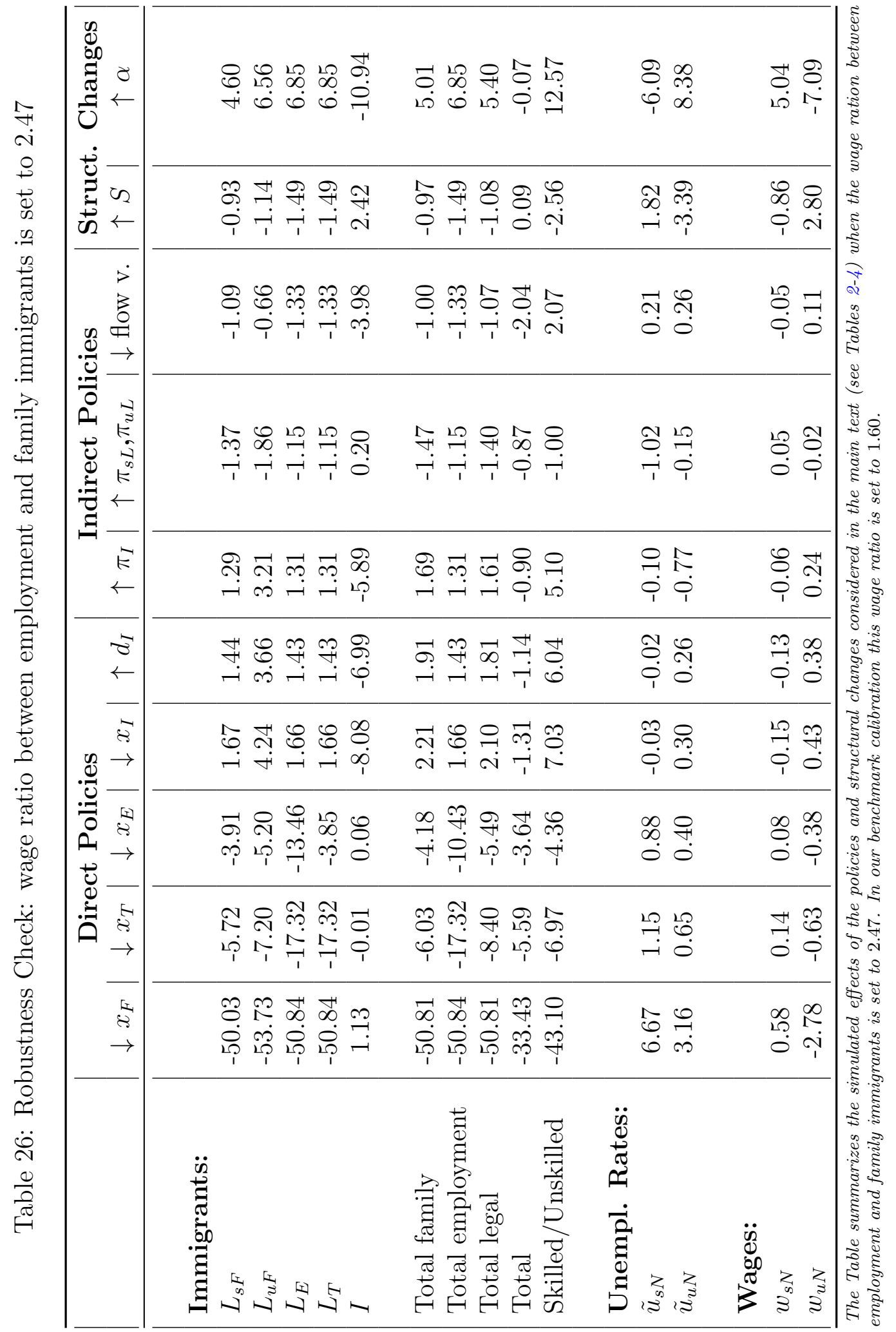

